LBNL-47911

\title{
Scoping Study on Trends in the Economic Value of Electricity Reliability to the U.S. Economy
}

\author{
Prepared for \\ Revis James \\ EPRI \\ Palo Alto, CA \\ Prepared by \\ Joseph Eto, Jonathan Koomey, Bryan Lehman, Nathan Martin, \\ Evan Mills, Carrie Webber and Ernst Worrell \\ Energy Analysis Department \\ Environmental Energy Technologies Division \\ E. O. Lawrence Berkeley National Laboratory \\ Berkeley, CA
}

June, 2001

The work described in this report was funded by EPRI under Work for Others Agreement No. BG00-503(00) and by the U.S. Department of Energy under Contract No.DE-AC0376SF00098. The work described in this report was coordinated by the Consortium for Electric Reliability Technology Solutions. 


\begin{abstract}
During the past three years, working with more than 150 organizations representing public and private stakeholders, EPRI has developed the Electricity Technology Roadmap. The Roadmap identifies several major strategic challenges that must be successfully addressed to ensure a sustainable future in which electricity continues to play an important role in economic growth. Articulation of these anticipated trends and challenges requires a detailed understanding of the role and importance of reliable electricity in different sectors of the economy. This report is intended to contribute to that understanding by analyzing key aspects of trends in the economic value of electricity reliability in the U.S. economy.
\end{abstract}

We first present a review of recent literature on electricity reliability costs. Next, we describe three distinct end-use approaches for tracking trends in reliability needs: 1) an analysis of the electricity-use requirements of office equipment in different commercial sectors; 2) an examination of the use of aggregate statistical indicators of industrial electricity use and economic activity to identify high reliability-requirement customer market segments; and 3) a case study of cleanrooms, which is a cross-cutting market segment known to have high reliability requirements. Finally, we present insurance industry perspectives on electricity reliability as an example of a financial tool for addressing customers' reliability needs. 


\section{Acknowledgement}

The project team members express appreciation to Revis James for his consistent and conscientious guidance and support for this scoping study. The team also acknowledges Karl Stahlkopf and Clark Gellings of EPRI's Consortium for Electric Infrastructure to Support a Digital Society for their efforts to initiate and provide on-going direction to the effort. Finally, the team acknowledges Marek Somotyj and Don Von Dollen, EPRI, and Jane Thornton (formerly, Clemmensen), IBM Net Gen Market Intelligence, for their reviews and helpful comments on early drafts of the study. 


\section{Table of Contents}

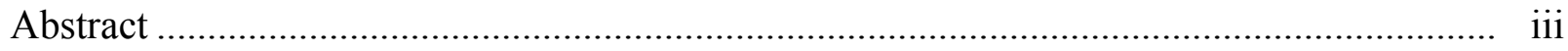

Acknowledgment ................................................................................................... iv

List of Figures and Tables ................................................................................................ v

Executive Summary …………………………………............................................ ix

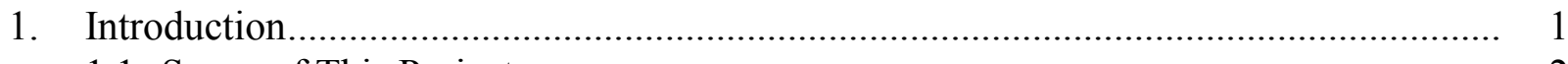

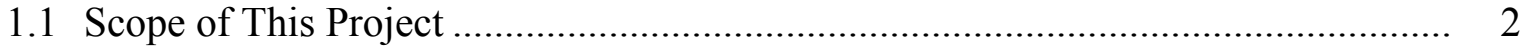

1.2 Overview and Organization of this Report............................................................ 2

2. Review of Recent Literature on the Cost of Reliable Electricity..................................... 5

2.1 Background and Typology ................................................................................ 5

2.1.1 A Customer's Perspective on Electricity Reliability .................................... 5

2.1.2 The Cost of Unreliable Electricity to Customers …………………………..... 7

2.1.3 Electricity Reliability Cost Estimation........................................................... 9

2.2 Database on Electricity Reliability Cost Literature .................................................. 11

2.3 Summary of Literature ................................................................................ 12

2.3.1 The Aggregate Cost of Electricity Reliability Problems ................................ 13

2.3.2 The Cost of Specific Power System Events .................................................... 14

2.3.3 Customer Surveys of Outage Costs ............................................................ 16

2.3.4 Non-Survey-Based Estimates of Outage Costs ............................................. 18

2.3.5 Applications of Outage Cost Estimates...................................................... 18

2.3.6 Power Quality........................................................................................... 18

2.3.7 Summary of Outage and Power Quality Event Costs..................................... 19

2.4 Key Findings and Recommendations for Next Steps............................................... 29

3. Office Equipment Electricity Use in the Commercial Sector ......................................... 31

3.1 Assessing High Reliability Requirements Within the Commercial Sector ............... 31

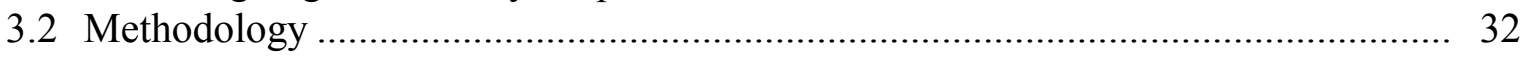

3.3 Office Equipment Electricity Use in the Commercial Sector .................................. 32

3.4 Key Findings and Recommendations for Next Steps............................................. 37

4. Statistical Indicators of Manufacturing Subsectors with High Reliability

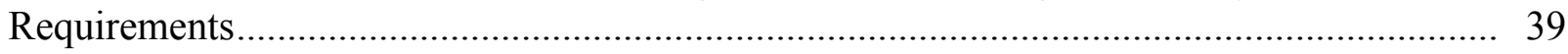

4.1 Census Data and the Development of Statistical Indicators.................................... 39

4.2 Manufacturing Sub-Sectors with High Reliability Requirements............................. 41

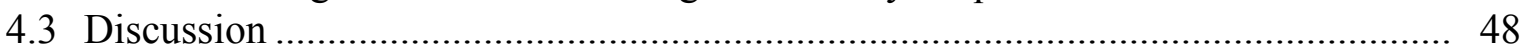

4.4 Key Findings and Recommendations for Next Steps............................................ 49

5. High Reliability Requirements Case Study - Cleanrooms .......................................... 51

5.1 Overview of Cleanrooms ............................................................................ 51

5.2 Cleanroom Energy Use................................................................................... 55

5.3 Cleanrooms in Manufacturing Settings ............................................................. 56 
5.4 The Semiconductor Industry. .......................................................................... 57

5.5 Electricity Reliability and Semiconductor Manufacturing ...................................... 57

5.6 Current Strategies for Electricity Reliability Risk Management .............................. 58

5.7 Key Findings and Recommendations for Next Steps.............................................. 59

6. An Insurance Industry Perspective on Electric Power Reliability Issues .................. 61

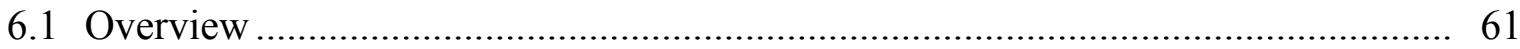

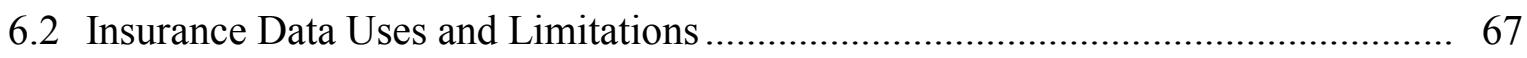

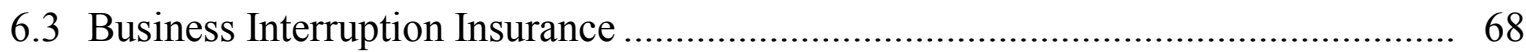

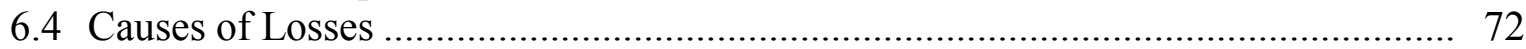

6.4.1 Internal vs. External Events/Direct Damage vs. Consequential Loss ............. 72

6.4.2 External Events: Lightning..................................................................... 72

6.4.3 External Events: Other Natural Disasters.................................................... 75

6.4.4 External Events: "Space Weather"............................................................... 76

6.4.5 Trends Toward Greater Incidence of Extreme Weather Events ...................... 76

6.5 Risk Management Strategies .................................................................................. 77

6.5.1 Financial Risk Management..................................................................... 77

6.5.2 Engineered Risk Management.................................................................. 79

6.5.3 Business Continuity Planning …………………….................................. 80

6.6 Innovative Partnerships between Insurers and the Energy Sector............................ 81

6.7 Key Findings and Recommendations for Next Steps............................................. 82

7. Next Steps Toward a National Estimate of the Value of Reliability to the U.S.

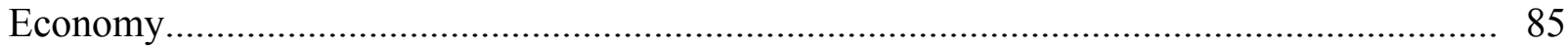

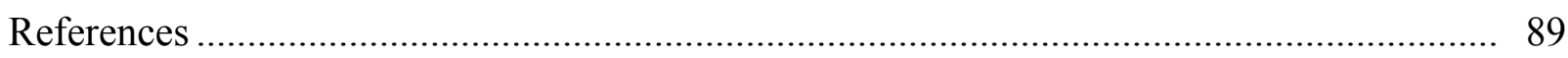

Appendix A: Electricity Reliability Cost Literature Review - References and Abstracts ....... 99

Appendix B: Insurance Implications for Electric Utility Operations .................................... 125 


\section{List of Figures and Tables}

Figure 2-1. Definitions of Voltage Events in IEEE Std. 1159-1995 ..................................... 6

Figure 2-2. Voltage Tolerance Curves for Personal Computers .......................................... 7

Figure 3-1. Commercial Sector U.S. Office Equipment Electricity Use by Building Type

and Equipment Type .............................................................................................. 34

Figure 3-2. Commercial Sector U.S. Office Equipment Electricty Use by Equipment

Type and Building Type ………………………………............................................ 35

Figure 4-1. Economic Intensity ('000 US\$ Value Added/Employee) vs. Electricity

Intensity (kWh/'000 US\$ Value Added) in 1995. ................................................................ 46

Figure 4-2. Economic Intensity ('000 US\$ Value Added/Employee) vs. Electricity

Intensity (kWH/'000 US\$ Value Added) for Selected Industries in 1995. .......................... 46

Figure 5-1. U.S. Cleanroom Type by Industry Segment. ..................................................... 54

Figure 5-2. Share of HVAC Electricity Consumption for Cleanrooms ................................. 55

Figure 6-1. Sensitivity of U.S. Property/Casualty Insurance Sector Net Financial Results to Investment Income and Underwriting Gain/Loss........................................................... 63

Figure 6-2. Electrical Claims (Filtered) vs. Cooling Degree Days North East ...................... 66

Figure 6-3. Claims Involving Electrical Equipment by Time of Year .................................... 66

Figure 6-4. Causes of Business Disruptions....................................................................... 69

Figure 6-5. Lightning-related Insurance Losses ................................................................... 73

Figure 6-6. Restoration Curves for Lifeline Services Following Hypothetical

Magnitude 7.5 Earthquake in Memphis/Shelby County …………………………................ 78

Table 2-1. Attributes of Electricity Reliability Problems..................................................... 8

Table 2-2. Commercial and Industrial Electricity Reliability Cost Categories ....................... 9

Table 2-3. Summary of Literature Reviewed by Source ....................................................... 11

Table 2-4. Literature Review Database Fields .................................................................... 12

Table 2-5. Summary of Literature Reviewed ................................................................. 13

Table 2-6. Customer Surveys of Outage Costs ............................................................... 17

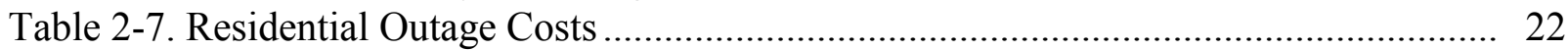

Table 2-8. Commercial and Industrial Outage Costs ........................................................ 24

Table 2-9. Power Quality Event Costs ............................................................................... 28

Table 3-1. Electricity Used by Equipment Type and Building Type in the U.S.

Commercial Sector in 2000 (TWh) ............................................................................... 33

Table 3-2. Top Ten List of Commercial Sector Office Equipment End Uses in 2000 ........... 33

Table 4-1. Electricity Intensity of Economic Output (kWh/'000US\$ Value of Shipments)

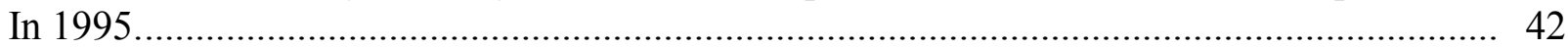

Table 4-2. Electricity Intensity of Economic Output (KWh/'000 US\$ Value Added) in

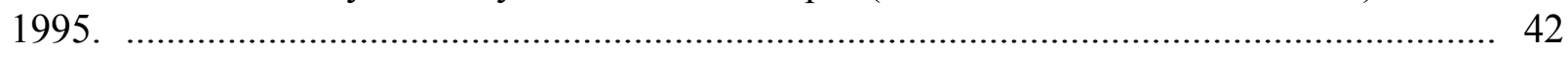

Table 4-3. Economic Intensity of Employment ('000 US\$ Value of

Shipments/Employee) in 1995.

Table 4-4. Economic Intensity of Employment ('000 US\$ Value Added/Employee) in 1995. 
Table 4-5. Electricity Spending as a Proportion of Total Energy Expenditures in Industries with Total Energy Expenditures Greater than \$10M per Year (\%) in 1995

Table 4-6. Electricity Spending as a Proportion of Total Energy Expenditures (\%) in 1995

Table 4-7. Purchased Electricity (TWh), Electricity Intensity (kWh/'000 US\$ Value

Added), Economic Intensity ('000 US\$ Value Added/Employee) in 1995. 47

Table 5-1. Hospital Cleanroom Standards

Table 5-2. Cleanroom Classes and Typical Applications

Table 5-3. Standard Industrial Classification (SIC) for Industries that Use Cleanrooms 53

Table 6-1. Mapping of Types of Damages Caused by Power Disruptions onto the Applicable Form of Insurance..... 64

Table 6-2. Size and Profitability of Several Insurance Lines Under Which Electricity

Outage Losses Would be Tabulated.... 65

Table B-1. Costs of Power Outages at Duke Power. 127 


\section{Executive Summary}

During the past three years, working with more than 150 organizations representing public and private stakeholders, EPRI has developed the Electricity Technology Roadmap (EPRI 2000). The Roadmap is a dynamic "living" document that provides context for EPRI's R\&D planning and a resource for energy policy makers in the U.S. and abroad.

The roadmap identifies several major strategic challenges that must be successfully addressed to ensure a sustainable future in which electricity continues to play an important role in economic growth. A significant element of these challenges is the anticipation of increasingly "digitized" economies in which, in addition to the increased direct use of computers, distributed microprocessor based measurement and control is a critical infrastructure element for a wide range of applications in the residential, commercial, and industrial sectors.

Articulation of these anticipated trends and challenges requires a detailed understanding of the role and importance of reliable electricity in different sectors of the economy. Electric power availability, reliability, and quality are anticipated to have somewhat independently varying economic importance in different applications and industries.

In order to frame the issue of reliability comprehensively, the following key questions must be addressed:

1. What is the cost to the U.S. economy of unreliable electricity?

2. How is the value of reliable electricity to the U.S. economy likely to change in the future?

3. How are customers addressing their reliability needs and risk management preferences?

This scoping study offers partial, not final, answers to each of the three key questions. It is a first step toward defining a future program of investigation to address the many unanswered aspects of these questions. Accordingly, an integral element of the project has been to develop recommendations for high-priority next steps.

\section{The Cost of Unreliable Electricity to the U.S. Economy}

As a first step toward assessing the cost of unreliable electricity to the U.S. economy, we reviewed recent literature on electricity reliability costs. The objectives of the literature review are to: 1) supplement older literature reviews with information on more recent events and studies, and 2) integrate the literature on utility system outage costs with that on customer power quality costs.

\footnotetext{
${ }^{1}$ Though not pursued in the present study, this question also could be framed with utilities as "customers" for many of the same risk management approaches being undertaken by electricity consumers.
} 
We developed a database reporting on 117 documents. We grouped the findings from these documents in six categories: the aggregate cost of reliability problems; the cost of specific power system events; customer surveys of outage costs; other estimates of outage costs; applications of outage cost estimates (which cite additional estimates of outage costs); and site-specific power quality studies.

Key Findings:

1. There are few estimates of the aggregate cost of unreliable power to the U.S. economy. Documentation for existing estimates is either absent or based on assumptions that need additional review.

2. Reports on the costs of large outage events are not well documented; they are often developed based on applying rules of thumb derived from existing studies extrapolated to a current situation. There have been few systematic studies of the costs of actual large-scale outages. In reviewing costs reported for some events, we encountered complications in tying reported costs uniquely to electricity (e.g., much of the literature includes other costs from the natural disasters that precipitate outages). Insurance claims as a measure of cost are reported on in separate section of this report.

3. Studies of hypothetical outages are typically organized in ways that appear to support extrapolation of outage costs to the preparation of aggregate estimates of these costs. However, differences in methodology and data limitations prevent rigorous metaanalysis. Caution must be used in extrapolating results from existing studies to larger populations.

4. Studies of power quality generally involve case studies of specific sites and do not focus on cost issues.

\section{The Changing Reliability Needs of the U.S. Economy}

We adopted an end-use perspective for tracking changing reliability needs in the U.S. economy and prepared three examples of analysis from this perspective. In the commercial sector, we examined the electricity use requirements of office equipment. In the industrial sector, we assessed the viability of using aggregate statistics on industrial electricity use and economic activity to identify high-reliability-requirement customer market segments. A final approach was a case study of cleanrooms, which is a crosscutting market segment known to have high reliability requirements.

\section{Office Equipment Electricity Use}

We developed estimates of electricity use by office equipment according to commercial building type. We accomplished this by combining information developed previously on total U.S. electricity use by office equipment with information on commercial building office equipment stocks. The framework developed for assembling this information can be used to evaluate scenarios for future office equipment load growth.

Key Findings: 
1. Total U.S. office equipment electricity use in the commercial sector is about 58 $\mathrm{TWh} / \mathrm{yr}$., which is less than 2 percent of total U.S. electricity use.

2. Personal Computers (PCs), Monitors, and Minicomputers together account for more than half of all commercial sector office equipment electricity use.

3. Offices account for almost half of all commercial sector office equipment electricity use.

4. PCs and Monitors in offices account for almost one-quarter of all commercial sector office equipment electricity use.

5. Because electronic technologies change quickly, there are significant uncertainties in these calculations.

Statistical Indicators of High Reliability Requirements in the Industrial Sector

We next implemented a direct approach to better understand the variations in sensitivity to power-quality and reliability issues among industrial subsectors. Specifically, we developed and evaluated statistical indicators for high-reliability-requirement customer market segments based on aggregate data on industrial sector electricity use and economic activity.

Key Findings:

1. We identify 43 industries likely to be most susceptible to economic harm from disruptions in electricity supply. Together these industries consume almost 370 $\mathrm{TWh} / \mathrm{yr}$.

2. The method provides a direct approach for identifying high-reliability-requirement market segments in the U.S. economy. Nevertheless, it should be recognized that these data by themselves cannot be used to formulate mitigation strategies to address these requirements or to find the particular electricity uses in those sectors that have high reliability demands.

3. The method is not sufficient to provide information on the need for high quality power needs, aside from the likelihood of economic damage resulting from delivery disruptions.

4. To identify specific electricity applications with high reliability requirements a bottom-up analysis is needed. A bottom-up analysis would start by identifying the electricity end uses that are most sensitive to changes in power quality, e.g. adjustable-speed drives (ASDs).

\section{High Reliability Requirements Case Study - Cleanrooms}

We then reviewed the importance of electricity reliability for cleanrooms, which typically combine production of highly valuable products (e.g., computer chips fabrication) with $24 / 7$ operation. We described the diversity of cleanroom types and applications (by industry), the costs of power disruptions to cleanrooms, and risk-management strategies currently in use. We propose this case study as a model for future case studies of other high-reliability-requirement processes or industries. 
Key Findings:

1. Cleanrooms are a fast-growing part of the industrial sector; floorspace growth rates are forecasted at greater than $10 \%$ annually.

2. While cleanrooms are typically associated with high-tech manufacturing (production of semiconductor-based integrated circuits and other electronic components, and with the pharmaceutical and biotechnology industries), they are found throughout many other sectors, ranging from optics, to food, to medical settings. Cleanrooms can be found in at least 37 SIC categories

3. Primary energy consumption for cleanrooms is estimated at 230-260 TBTU/yr.

4. Semiconductor manufacturing and related industries account for two-thirds of cleanroom heating, ventilation, and air conditioning (HVAC) electricity use.

5. Class 1-10 cleanrooms, which include those used for semiconductor manufacturing, tend to have high reliability demands and can experience significant losses from disruptions in electricity service.

6. While some cleanroom fabrication facilities do spend money to support backup power for improved power quality and reliability, there is anecdotal evidence that over the past decade the willingness of industry to invest in reliability, even with two-year paybacks, may be limited.

\section{Customer Options for and Trends in Addressing Reliability Needs - Insurance Industry Perspectives}

EPRI has already conducted a number of studies on specific technological options for addressing customer's reliability needs, such as back-up generation, uninterruptible power supply (UPS) systems, and other power-quality-enhancing technologies and approaches. We have complemented this work with new information on insurance as an indicator of the costs of electricity outages and reliability problems, and as a strategy for managing risk.

Key Findings:

1. Power outages are a material issue for insurers. Insured loss data are, in turn, a valuable source of information on electricity reliability costs for the power sector and are more rigorous than many estimates promulgated by others.

2. Because of limited penetration of the relevant forms of insurance and role of deductibles, insurance loss data represent only part of the total cost. Some costs are covered by self-insurance, governments, and utilities who pay claims made by customers or municipalities.

3. Reliability-related insurance risks are perceived by insurers as being on the rise as customers become increasingly vulnerable to power outages. These losses can be triggered by natural or manmade catastrophes or localized interruptions in the utility system.

4. Power outages can precipitate various types of insurance claims from residential, commercial, or industrial customers (e.g., business interruption, property loss, machinery breakdown, additional living expense, and claims as well as claims by utilities for unserved energy). Insurance claims for "data losses" are a growing issue. 
5. Risk management options for insurance companies fall into two broad categories. Financial techniques include limiting insurance exposure e.g., by means of deductibles or loss limits (for insurance providers). Engineering risk management techniques include a host of technology responses that may be promoted by insurers, ranging from specific technologies such as back-up generation to management strategies such as early warning systems and post-event business continuity planning.

6. Insurers are likely to increase their participation in risk management in the future (both to reduce their exposure and the loss potential on the customer side) and have begun to explore collaborations with electricity and equipment providers. Some innovative examples are already visible. In some instances, energy-efficient technologies offer ancillary loss-control benefits by making systems more resilient following power disruptions.

\section{Next Steps}

In the final section of the report, we integrated recommendations for next steps developed separately for each section of the report and prioritized them into a single list.

Our primary recommendation is to initiate development of a comprehensive framework and then estimate a range for the cost of unreliable electricity to the U.S. economy. We recommend a "bottom-up" approach in order to support sub-analyses for specific events, regions, or market sectors. First and most importantly, while an aggregate estimate is valuable for strategic reasons, estimates for specific events, regions, or market sectors are more useful for planning specific R\&D initiatives. Second, a bottom-up approach is well-suited to future integration of information from different sources and perspectives. The organizing principle for future efforts should be triangulation. Third, a bottom-up approach will permit a more structured approach to assessing uncertainty and prioritizing incremental data collection and analysis. Credibility will be enhanced by clear statements regarding the limitations of future analyses.

In view of these considerations, we developed a consolidated short-list of recommended priorities:

1. Collect, consolidate, and improve the quality of information on customer reliability costs.

- Extend the database on outage and power quality event costs to include older assessments, including work summarized in earlier surveys of the literature, and to include studies in the "gray" literature.

- Conduct meta-analysis to synthesize and better understand the limits of extrapolation of the database toward supporting development of a comprehensive national estimate and related sub analyses. For any given event, location, or customer type, we are limited by available data. Meta-analysis can help to improve confidence in extrapolating from existing data.

- Integrate information on costs of outages and power quality events with information on frequency of occurrence. 
- Collect additional information on customer power quality costs.

2. Systematically approach developing information on customer spending on capital and operations to address electricity reliability.

- Work with vendors, manufacturers, trade associations (back-up generation, UPS, etc.) to gather aggregate information on spending and mitigation approaches. This is a "supply-side" approach to this issue.

- Continue case studies to track high-reliability requirements customer market segments (cleanrooms, data centers, etc.) and/or equipment (PCs, ASDs, process controls). This is a complementary, "demand-side" approach to this issue.

3. Develop relationships with the insurance industry to develop information on customer spending on insurance. This scoping study has indentified the insurance industry as key source of information on the cost of electricity reliability and as a potential partner for promoting technology solutions.

- Use insurance techniques to provide a new proxy for the value of electricity reliability nationally in order to seek additional insight on how insurers "Value" electricity reliability.

- Obtain quantitative information from self insurers on reliability related losses, as well as on risk-management strategies.

- Conduct analysis for and pursue coordination among insurers and energy-focused firms to identify and value the risk-management characteristics of electricity reliability enhancing and energy efficiency technologies in the context of the insurance marketplace, both from technical and market standpoints. 


\section{Introduction}

During the past three years, working with more than 150 organizations representing public and private stakeholders, EPRI has developed the Electricity Technology Roadmap (EPRI 2000). The roadmap is a dynamic "living" document that provides context for EPRI's R\&D planning and a resource for energy policy makers in the U.S. and around the world.

The roadmap identifies several major strategic challenges that must be successfully addressed to ensure a sustainable future in which electricity continues to play an important role in economic growth. A significant element of these challenges is the anticipation of increasingly "digitized" economies in which, in addition to the increased direct use of computers, distributed microprocessor based measurement and control is a critical infrastructure element for a wide range of applications in the residential, commercial, and industrial sectors.

Articulation of these anticipated trends and challenges requires a detailed understanding of the role and importance of reliable electricity in different sectors of the economy. Electric power availability, reliability, and quality are anticipated to have somewhat independently varying economic importance in different applications and industries.

In order to frame this issue comprehensively, the following key questions must be addressed:

1. What is the cost to the U.S. economy of unreliable electricity?

a) What is reliability from a customer's perspective (typology of outages and power quality events)?

b) What kinds of costs are incurred (cost categories, valuation methods)?

c) Who incurs them (residential, non-residential, by sector)?

d) What are recent trends (during the past 5, 10, 20 years)?

e) What are the costs, and can they be compared/extrapolated?

2. How will the value of reliable electricity to the U.S. economy change in the future?

a) To what extent can customers with high reliability requirements be identified (e.g., not just customers associated with the "digital" economy, but also other customers with different types of high reliability requirements, such as those utilizing cleanrooms)?

b) How can their requirements be categorized and tracked over time?

c) Are there offsetting considerations, which affect the trend toward the need for high reliability, that must also be considered (e.g., in the form of structural changes in the economy, substitution effects, etc.)? 
3. How do customers address their reliability needs?

a) What risk management approaches are available, and how extensively are they being utilized?

b) What are the trade-off among different risk management approaches such as financial instruments (e.g., types of business interruption insurance), capital investments (e.g., in back-up generation, UPS, power-conditioning equipment), and operational strategies (e.g., load management and perhaps energy efficiency).

c) Can these approaches be differentiated by type of customer or market segment?

d) To what extent are customers satisfied with current approaches (including cost effectiveness as but one measure of satisfaction)?

\subsection{Scope of this Project}

In preparing this scoping study, we have begun to address each of the above key research questions based on available information. Specifically, we have:

1. Articulated the issues underlying these questions

2. Assembled readily available existing information building on both prior research at Lawrence Berkeley National Laboratory (LBNL) and information from other sources;

3. Assessed this information in light of the research questions;

4. Drawn preliminary conclusions on what is currently known; and

5. Identified priorities for future research to address gaps in current knowledge.

\subsection{Overview and Organization of this Report}

The activities undertaken to address the three key research questions are organized as separate tasks. (The second task contains three sub-tasks.) Our investigation of each task or sub-task is reported on in a separate section of the report. A final section of the report integrates recommendations for next steps, which are first identified at the end of each section, into a single, prioritized list.

\section{Task 1. The Cost of Unreliable Electricity to the U.S. Economy (Section 2)}

As a first step toward assessing the cost of unreliable electricity to the U.S. economy, we review readily available literature on outage cost estimates, focusing initially on the most recent estimates. We develop a typology of reliability events, costs, and estimation methods to categorize the literature and the cost estimates they report. To the extent supportable by the literature, we assess information that allows for differentiation of costs by customer types and reliability-related attributes (e.g., types of interruptions/power quality issues) for the purpose of tracking trends in these costs over time. In addition, we review and discuss the context for the development of the estimates and the comparability of the estimates. Appendix A presents complete citations for all references used in the literature review along with abstracts.

\footnotetext{
${ }^{2}$ Though not pursued in the present study, this question also could be framed with utilities as "customers" for many of the same risk management approaches being undertaken by electricity consumers.
} 


\section{Task 2. The Changing Reliability Needs of the U.S. Economy}

In view of the variation in reliability costs among different customers, we next consider three end-use approaches for tracking changing reliability needs in the U.S. economy. In the commercial sector, we examine the electricity use requirements of office equipment by commercial building type. In the industrial sector, we assess the viability of using aggregate statistics on industrial electricity use and economic activity to identify highreliability-requirement customer market segments. A final approach reviews cleanrooms, which represent a cross-cutting market segment known to have high reliability requirements.

\section{Subtask 2.1 Office Equipment Electricity Use (Section 3)}

Electricity use in the commercial sector is traditionally examined by considering variations in use by building type and end use. From the perspective of electricity reliability, office equipment is both a key enabling technology for the economic productivity of commercial firms and at the same time one that is known to be especially vulnerable to electricity interruptions and power quality problems. There are also differences of opinion regarding the total U.S. electricity use by office equipment.

We develop estimates of electricity use by office equipment according to commercial building type. This is accomplished by combining recently developed information on total U.S. electricity use by office equipment with survey information on commercial building office equipment stocks by building type. The framework developed for assembling this information can be used to evaluate scenarios for future office equipment load growth.

\section{Subtask 2.2 Statistical Indicators of High Reliability Requirements in the Industrial Sector (Section 4)}

One can also postulate a relationship between overall measures of economic productivity and electricity use as an approach for identifying and tracking customers with highreliability requirements. Examining this relationship is especially appropriate for the industrial sector because the end uses relevant for studying commercial building electricity use are typically a small portion of electricity use compared to that use in the production processes of firms. These processes, themselves, are either somewhat idiosyncratic (i.e., not common to all industries) or highly variable in their relationship to the value of goods produced.

We present initial results from a direct approach to better understand the variations in sensitivity to power-quality and reliability issues among industrial subsectors. Specifically, we develop and evaluate statistical indicators for high-reliabilityrequirement customer market segments based on aggregate data on industrial sector electricity use and economic activity. 


\section{Subtask 2.3 High Reliability Requirements Case Study-Cleanrooms (Section 5)}

A final approach to studying customers with high reliability requirements involves identification of particular end-use functions, which are both vulnerable to electricity interruptions and power quality problems and common to more than one industry. This is an intermediate approach between the highly dis-aggregate examination of office equipment (Section 3) and the highly aggregate review of industrial subsectors (Section 4).

As an example of this approach, we review the importance of electricity reliability to cleanrooms, which typically combine production of highly valuable products (e.g., computer chips) with $24 / 7$ operation. We describe the diversity of cleanroom types and applications (by industry), the costs of power disruptions, and risk-management strategies currently in use. We propose this case study as a model for future case studies of other high-reliability-requirement processes or industries.

\section{Task 3. Customer Options for and Trends in Addressing Reliability Needs - Insurance Industry Perspectives (Section 6)}

Broadly, this task involves developing a comprehensive inventory of the range of options (technological, operational, and financial) currently available to customers and information on their current satisfaction with these options. EPRI has already conducted a number of studies on specific technological and operational options for addressing customer's reliability needs, such as back-up generation, uninterruptible power supply (UPS) systems, and other power-quality-enhancing technologies and approaches.

We complement EPRI's existing work with new information on insurance as an indicator of the costs of electricity outages and reliability problems and as a strategy for managing risk. We: 1) review the relevance of electric power reliability for North American insurers and look at how the issue is regarded today within the industry; 2) describe the specific types of insurance that address reliability-related incidents (e.g., property, business interruption, machinery breakdown); 3 ) describe the nature of events triggering power reliability losses; and 4) provide selected examples of reliability risk management tools used by insurers.

Next Steps Toward a National Estimate of the Value of Reliable Electricity to the U.S. Economy (Section 7)

Each of the main sections of this scoping study identifies a series of next steps that emerges from the information considered and findings developed for each task or subtask. In this final section of the report, we integrate these recommendations and prioritize them into a single list. 


\section{Review of Recent Literature on the Cost of Reliable Electricity}

As a first step toward assessing the cost of unreliable electricity to the U.S. economy, we review recent literature on electricity reliability costs. The objectives of the literature review are to:

1. Supplement older literature reviews with information on more recent events and studies; and

2. Integrate the literature on utility system outage costs with that on customer power quality costs.

We address these objectives in four steps. First, we present a typology of reliability events, costs, and estimation methods (Subsection 2.1). Second, we categorize the literature (Subsection 2.2). The information has been organized in a flexible database to facilitate subsequent analyses. Third, we summarize our findings on six topics (Subsection 2.3): a) the aggregate cost of reliability problems; b) the cost of specific power system events; c) customer surveys of outage costs; d) other estimates of outage costs; e) applications of outage cost estimates (which contain additional estimates of outage costs); and f) site-specific power quality studies. As part of this effort, we also report on the availability of information for differentiating costs by customer types and reliability-related attributes (e.g. types of interruptions/power quality issues) for use in tracking trends in these costs over time. Our findings and recommendations for next steps are summarized in Subsection 2.4. Appendix A presents complete citations for all references used in the literature review along with abstracts.

\subsection{Background and Typology}

\subsubsection{A Customer's Perspective on Electricity Reliability}

From a customer's perspective, electricity reliability problems come in a variety of forms. Sustained interruptions (voltage drops to near zero), more commonly referred to as "outages" or "interruptions," are the most visible problems and affect the widest range of electricity-consuming equipment. Less apparent are smaller voltage deviations, either above or below nominal voltage, which influence the operation of only some types of equipment depending on the magnitude and duration of the variations. These smaller deviations are aspects of power quality. It is important to consider both outages and power quality problems because from a customer's perspective both can affect the cost of unreliable electricity.

Power quality refers to the degree to which power characteristics align with the ideal: $120-\mathrm{V}$ (in the U.S.), 60-Hz., sinusoidal voltage and current waveform, with current and voltage in phase. Power quality therefore encompasses not only variations in voltage magnitude but also a host of other, more subtle deviations from the ideal. Harmonics are one example. Harmonics are integer multiples of the fundamental frequency that are imposed on the fundamental frequency and can affect certain types of equipment, such as adjustable-speed drives. 
Voltage events may be classified by magnitude and duration. A variety of terms exist to describe voltage events; we use the taxonomy from Institute for Electrical and Electronic Engineers (IEEE) standard 1159-1995. Normal voltage is considered to be $\forall 10$ percent of nominal voltage. Very short voltage events, under 0.5 cycles, are classified as voltage notches (undervoltage) or transient overvoltages. Voltages below 10 percent of nominal are considered to be interruptions (or outages). Outages can be classified as momentary ( 0.5 cycles to three seconds), temporary (three seconds to one minute), or sustained (more than one minute). Voltage sag describes voltage events between 10 and 90 percent of nominal lasting up to a minute. Sustained voltage events of 10 to 90 percent of nominal are referred to as undervoltage. Similarly, overvoltages greater 110 percent of nominal lasting less than one minute are referred to as voltage swells; sustained voltage in this range is overvoltage. Figure 2-1 illustrates these definitions. Other terms appearing in the literature are voltage surge, impulse, and voltage dip.

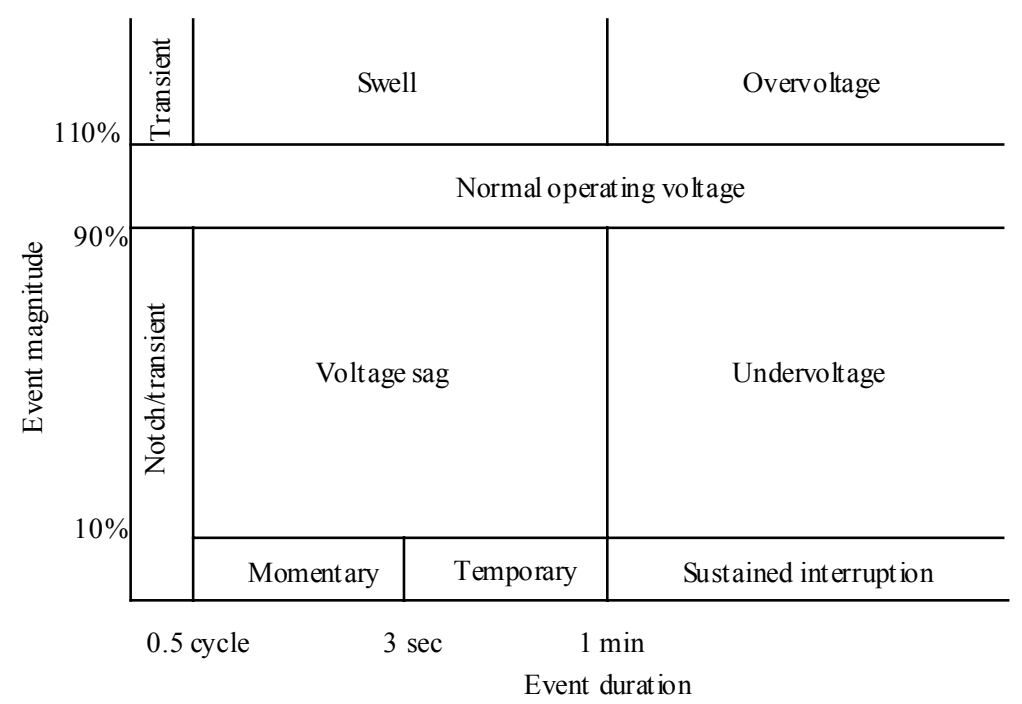

Source: Bollen (1999)

\section{Figure 2-1. Definitions of Voltage Events in IEEE Std. 1159-1995}

As useful as it is to have a consistent taxonomy for describing voltage events, the significance of specific events depends on characteristics of the customer experiencing them. All electrical equipment has tolerances for the duration of deviations under which it will continue to operate. Figure 2-2 illustrates the voltage tolerance of a sample of U.S. computers. The highest curve represents the computer most sensitive to voltage disturbances: it can tolerate zero voltage for less than one cycle, and requires a minimum of 80 percent of nominal voltage to operate. At the other end of the spectrum, the computer represented by the lowest curve could ride out an interruption of 15 cycles, and another could continue to operate at only 30 percent of nominal voltage. The user of the first computer would perceive many more voltage events as "interruptions" than would users of the less sensitive computers. 


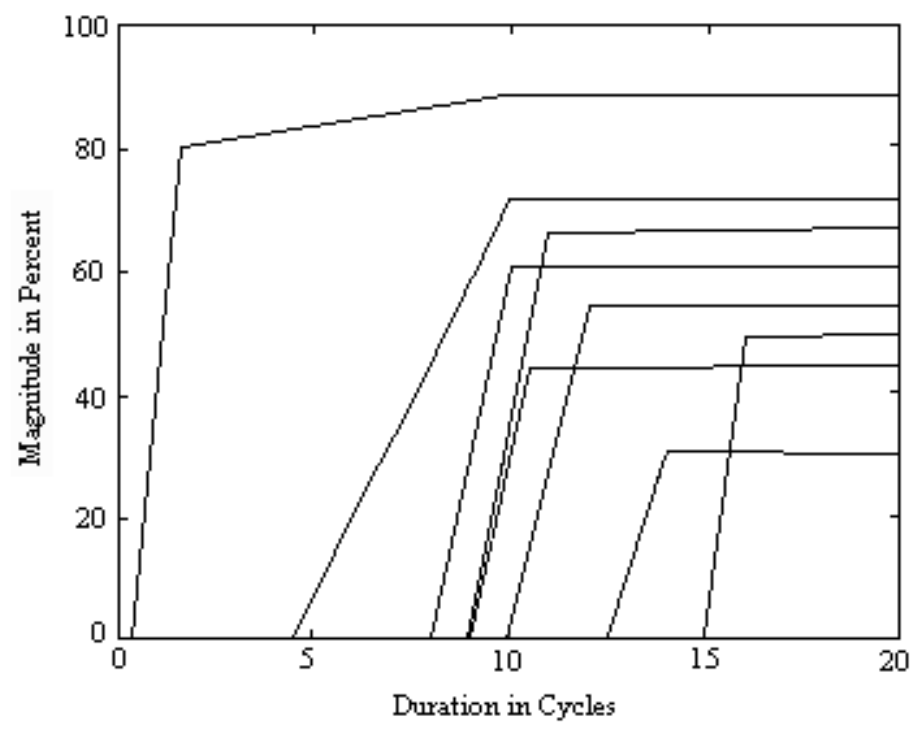

Source: Bollen (1999)

Figure 2-2. Voltage Tolerance Curves for Personal Computers

\subsubsection{The Cost of Unreliable Electricity to Customers}

When considering the cost of unreliable electricity to customers, it is important to first distinguish between the effects of reliability events on electricity-consuming equipment and the resulting cost of these effects to the customer. The effects of an electricity reliability event on a piece of equipment are easily quantified; either the equipment is operating normally or it is not. Whether non-normal operation of equipment creates additional costs for the customer depends on the role of affected equipment in meeting the customer's objectives. For example, an industrial customer may use a large number of electrical devices in its processes, some more critical than others and each with its own voltage tolerance. Depending on the processes and equipment involved, a momentary outage could cause no interruption at all or could shut down production for hours. Even when companies have similar processes and equipment, interruption impacts can differ significantly. For example, a factory ahead of its production schedule might experience little financial impact from an outage compared to one struggling to keep up.

Traditionally, the costs to customers of electricity reliability problems have been examined based on the magnitude, duration, and frequency of the events, when they occur, and the degree of advance notice (see Table 2-1). While useful as an initial categorization scheme, assessing costs involves considering several of these categories in conjunction with one another.

Frequency is an important characteristic of reliability events that is not captured by magnitude and duration. For example, a series of momentary outages can damage equipment and therefore may be more costly than a sustained outage lasting the same 
cumulative amount of time. Similarly, frequent outages are more likely than a few isolated incidents to spark customer investment in back-up equipment, fuel switching or other mitigation measures (including insurance).

\section{Table 2-1. Attributes of Electricity Reliability Problems}

\begin{tabular}{|ll|}
\hline Magnitude & $\begin{array}{l}\text { How much during the event does voltage deviate from nominal? Large } \\
\text { voltage deviations can interrupt or damage equipment. Voltage drop to zero } \\
\text { or near zero is called an outage or interruption. }\end{array}$ \\
\hline Duration & $\begin{array}{l}\text { How long does the event last? Deviations may last for less than a cycle. } \\
\text { Sustained interruptions may last for weeks or months. }\end{array}$ \\
\hline Frequency & $\begin{array}{l}\text { How often do the events occur? More frequent interruptions may increase } \\
\text { damage to sensitive equipment. }\end{array}$ \\
\hline Timing & $\begin{array}{l}\text { What time of day does the event occur? What day of the week? What } \\
\text { season of the year? The significance of electricity reliability events can vary } \\
\text { with heating/cooling load (season), daylight (time of day), and customer } \\
\text { behavior/production schedules (weekday/weekend). }\end{array}$ \\
\hline Advance & $\begin{array}{l}\text { Does the customer know in advance that there will be an interruption? How } \\
\text { much advance notice (minutes? hours? day ahead?) With sufficient advance } \\
\text { notice } \\
\text { notice, electricity-dependent activities could be rescheduled, and sensitive } \\
\text { equipment could be shut down properly. }\end{array}$ \\
\hline
\end{tabular}

The time of day, day of the week, and season when the event is experienced can also have an effect on costs. Weekday daytime events are more likely to cause business interruptions for commercial and industrial customers. Evening and weekend outages are most likely to inconvenience residential customers. Winter outages are likely to be more costly for residential customers that depend on electricity for heating, especially if the outage is prolonged.

Advance notice may allow customers sufficient time to make adjustments that reduce the cost of an interruption. For industrial firms, advance notice may allow controlled shutdown, preventing damage to equipment and raw material that might occur in an unexpected outage. For residential customers, advance notice may reduce the inconvenience of an outage by allowing time to prepare and make alternate plans.

The types of costs considered in examining reliability events depends on characteristics of the customers affected. Costs for residential customers are treated separately from costs for commercial and industrial customers.

Residential customers may experience out-of-pocket costs, inconvenience, lost leisure, and health impacts. Out-of-pocket costs might include dining out, purchasing candles or

\footnotetext{
${ }^{3}$ In this regard, predictability or advance notice must also be considered in assessing the trade-off involved in investing in these measures versus continuing to incur these costs.

${ }^{4}$ Widespread outages may produce additional social costs in the form of looting and other crime. We did not find recent literature addressing these costs and so will not report further on them.
} 
flashlights, or, in extreme cases, purchasing or renting a generator. Reliability events may affect residents' health by affecting electricity-dependent medical equipment present in the home. Some studies have also considered costs associated with the impacts of events on home-based employment, which fall into the categories of costs experienced by commercial and industrial customers.

The costs to commercial and industrial customers are more numerous and complex. For example, production by an industrial customer may be interrupted long after power (or voltage) has been restored, because of the time involved in restarting equipment and processes. Direct costs for commercial and industrial firms may include lost product, idlefactor costs, shutdown costs, restart costs, spoilage, damage to raw materials and equipment, back-up costs, and health and safety costs. Costs should be determined net of any savings on energy, materials, and labor during the event. In some cases, lost production can be made up, but the firm may incur additional expenses such as overtime. Indirect costs may include the costs to downstream firms and final consumers. Table 2-2 summarizes the types of costs experienced by commercial and industrial customers.

Table 2-2. Commercial and Industrial Electricity Reliability Cost Categories

\begin{tabular}{|l|l|}
\hline Production Losses & $\begin{array}{l}\text { The firm's change in revenue as a result of the event. Production } \\
\text { losses are net of production that the firm is able to make up (through } \\
\text { the use of overtime or extra shifts, for example) }\end{array}$ \\
\hline Loss Due to Damage & $\begin{array}{l}\text { Equipment damage } \\
\text { Damage to raw materials } \\
\text { Hazardous materials cost }\end{array}$ \\
\hline Labor Costs & $\begin{array}{l}\text { Costs to make up production (e.g. overtime costs) } \\
\text { Labor costs during restart }\end{array}$ \\
\hline Back-up Costs & Cost to run back-up generation, including fuel costs \\
\hline Restart Costs & $\begin{array}{l}\text { Cost to restart electrical equipment } \\
\text { Other restart costs }\end{array}$ \\
\hline Savings & $\begin{array}{l}\text { Savings on raw materials unused during the event } \\
\text { Savings on fuel and electricity unused during the event } \\
\text { Savings on unpaid wages during the event } \\
\text { Scrap value of damaged materials }\end{array}$ \\
\hline
\end{tabular}

Categories adapted from Sullivan et al. (1997)

\subsubsection{Electricity Reliability Cost Estimation}

Electricity reliability cost estimation methods fall into three broad categories: a) proxy methods, b) market-based methods and c) survey methods. Proxy methods use macroeconomic data or observable expenditures as a proxy for customers' willingness to pay for service reliability. These methods produce aggregate reliability worth estimates. One commonly cited example is calculating the value of production foregone due to an 
outage as GDP/kWh consumed. ${ }^{\text {G }}$ The wage rate can be used as a proxy for the value of foregone leisure, one component of residential outage costs. Back-up system expenditures can be used as a proxy to estimate a lower bound for outage costs.

Market-based methods infer reliability costs based on consumers' observed behavior. For example, where interruptible and curtailable electricity rates are available, customer subscription behavior can be used to estimate a market value for service reliability. Similarly, investment in back-up generation (or other mitigation approaches, such as insurance premiums for utility service interruption) can be used to indicate a preference for reliable electricity. Another method equates electricity reliability costs with the reduction in consumer surplus due to a reliability event. This method requires that the demand schedule for electricity be known for the time period of the event. The demand schedule represents the value of the last $\mathrm{kWh}$ for a given quantity of energy purchased. The consumer purchases additional $\mathrm{kWh}$ as long as the value exceeds the price. The difference between value and price represents consumer surplus. When an event occurs, some of this surplus is lost.

Survey methods take the direct approach of asking customers about their reliability experiences and perceptions. Customers may be asked to identify their costs during an actual event or to estimate their costs for a series of hypothetical events. Surveys can take one of two approaches: direct costing (also referred to as enumeration or cost decomposition) or contingent valuation.

In direct costing, customers are asked to estimate expenditures for a series of components, such as lost product, spoilage, damage to equipment, etc. In general, this method works better for commercial and industrial customers, the bulk of whose costs are monetary, than for residential customers, whose largest cost is often inconvenience.

Contingent valuation methods ask customers how much they would be willing to pay to avoid an event (willingness to pay) or how much they would be willing to accept in compensation for an event that has occurred (willingness to accept). Although in theory, these two should be equal, reported willingness to pay is usually less than willingness to accept. Most surveys therefore ask for both measures, and actual reliability costs are assumed to lie somewhere between the two.

Survey methods are often criticized as unreliable. One concern is that customers may strategically misrepresent their costs. For example, they may believe that exaggerating their costs will spur their utility company to improve reliability, or they may fear that their willingness to pay would be used to justify an increase in rates.

In addition, customers often lack recent experience with the events being studied, which reduces the reliability of their responses. Customers with recent outage experience, for

\footnotetext{
${ }^{5}$ The viability of this approach is explored in Section 4 as a means for identifying high-reliabilityrequirement customer market segments in the industrial sector.
} 
example, sometimes report lower interruption costs than customers who lack such experience, although there is also anecdotal information to the contrary.

\subsection{Database on Electricity Reliability Cost Literature}

The objective of our literature review is to supplement older reviews with more recent documents. For example, there have been several earlier reviews of outage cost estimates; however, they were published in the early 1990s and cover studies from 1970s and $80 \mathrm{~s}$. These studies were not included in this literature review. In addition, we also began the process of formally integrating the literature on outage costs with that on power quality costs.

We obtained 117 documents for our literature review on electricity reliability costs. The documents were located primarily through searches of bibliographic databases (in particular, the California Digital Library magazine and journal database). Articles from the IEEE Transactions (Power Systems Engineering and Industry Applications) were accessed from the IEEE website. Where appropriate, we obtained references cited in available documents. Hence, while we focused primarily on articles written after 1990, we did not reject older papers that were suggested to us through this process. Table 2-3 summarizes the documents we reviewed.

Table 2-3. Summary of Literature Reviewed by Source

\begin{tabular}{|l|l|}
\hline Source & $\begin{array}{l}\text { Number of } \\
\text { Documents }\end{array}$ \\
\hline IEEE Transactions on Power Systems & 19 \\
IEEE Transactions on Industry Applications & 19 \\
Business Insurance & 8 \\
Electrical World & 7 \\
IEEE Transactions on Power Delivery & 6 \\
Energy Journal & 4 \\
EPRI Journal & 4 \\
Electronic News & 3 \\
Energy User News & 3 \\
The American Economic Review & 2 \\
Far Eastern Economic Review & 2 \\
Energy Policy & 2 \\
Computer Reseller News & 2 \\
Other & 36 \\
\hline Total & 117 \\
\hline
\end{tabular}

After reviewing the documents, we created a database using a bibliographic software program. Fields were created for various types of descriptive information, such as the cost estimation method used, the kinds of costs considered, customer types, etc. (see Table 2-4). For each field we developed a set of keywords. The documents were then sorted by type (new outage cost estimates, applications, power quality, etc.). 
Table 2-4. Literature Review Database Fields

\begin{tabular}{|l|l|}
\hline Field Name & Examples of Entries \\
\hline Description & $\begin{array}{l}\text { Case study of an event, Power quality impacts, } \\
\text { Application, Old outage cost estimates, Reliability planning }\end{array}$ \\
\hline $\begin{array}{l}\text { Cost Estimation } \\
\text { Method }\end{array}$ & $\begin{array}{l}\text { Survey (N=487); } \\
\text { Direct costing }\end{array}$ \\
\hline Types of Costs & $\begin{array}{l}\text { Lost product, Restart costs, Damage to equipment, } \\
\text { Lost leisure }\end{array}$ \\
\hline Customer Types & $\begin{array}{l}\text { Residential, Commercial, Industrial; } \\
\text { Financial industry }\end{array}$ \\
\hline Event Descriptions & $\begin{array}{l}\text { Transient overvoltage; } \\
\text { One hour outage, Four hour outage, Eight hour outage; } \\
\text { August 10, 1996 western states power outage }\end{array}$ \\
\hline Equipment Types & Adjustable-speed drives, Computers, UPS \\
\hline Location & Israel; Canada; USA; California \\
\hline Vintage & $1991-1993$ data; 1996 event \\
\hline Type of Results & $\begin{array}{l}\text { Cost/event (aggregate), Costs are in 1998 US\$; } \\
\text { Cost } / \text { kWh unserved, Costs are in 1991 Israeli shekels; } \\
\text { Cost } / \text { kWh annual energy consumption, Costs are in 1981; } \\
\text { CAN\$ }\end{array}$ \\
\hline Key Results & $\begin{array}{l}\text { The Auckland outage cost businesses \$56 million (US); } \\
\text { Average residential outage costs are \$XX/kWh unserved; } \\
\text { See Table 4 of the article or report }\end{array}$ \\
\hline
\end{tabular}

\subsection{Summary of Literature}

We surveyed a broad selection of literature related to reliability costs (see Table 2-5). In this subsection, we present key findings from the literature organized in six topics. First, we consider the literature that addresses the aggregate costs of reliability problems at a national level. We then look at the cost of specific power system events; these span a wide variety of regions and events, and tend to focus on outages that had significant financial or social impacts. We then move into the literature containing new or original estimates of outage costs; these articles are divided into estimates from customer surveys and estimates developed using other methods. A list of surveys cited in the literature is provided. Applications of outage cost estimates are reviewed next. Many of these papers include outage cost data from previously published sources that are not in our database. Lastly, we discuss the power quality literature that does not fall into the previous categories. These articles address the types of power problems not addressed in the traditional interruption cost literature, e. g. very short (less than one-second) interruptions, voltage sags and swells, harmonics, etc. A final sub-section integrates and discusses the disaggregated estimates developed in these last four sub-sections.

Table 2.5. Summary of Literature Reviewed 


\begin{tabular}{|l|l|}
\hline & $\begin{array}{l}\text { of } \\
\text { Sources }\end{array}$ \\
\hline Original outage cost estimates & 15 \\
\hline Survey methods & 10 \\
\hline Market-based methods & 3 \\
\hline Proxy methods & 1 \\
\hline Other & 1 \\
\hline Papers citing previous outage cost estimates & 17 \\
\hline Applications & 17 \\
\hline Reliability planning & 11 \\
\hline System interruption costs & 5 \\
\hline Case studies & 40 \\
\hline Event & 26 \\
\hline Industry & 8 \\
\hline Site & 10 \\
\hline Power quality problems (not incl. sustained outages) & 38 \\
\hline Measurement and monitoring & 15 \\
\hline Impacts & 18 \\
\hline Mitigation & 23 \\
\hline Costs & 5 \\
\hline Sources & 5 \\
\hline Literature reviews & 8 \\
\hline Estimation methods & 4 \\
\hline
\end{tabular}

Note: Categories are not mutually exclusive.

\subsubsection{The Aggregate Cost of Electricity Reliability Problems}

We found very little research on the aggregate costs of electricity interruptions and other power quality problems. Documentation for these estimates are either absent or based on assumptions that warrant additional review. We found some information on aggregate spending on power quality equipment, which provides one element of a lower bound estimate on spending to mitigate the consequences of reliability problems.

Clemmensen (1993) provides very rough estimates of power quality costs to the U.S. manufacturing and commercial sectors. Clemmensen estimates that 1.5 to three cents of every manufacturing sales dollar are spent correcting power quality problems for a total of $\$ 25.6$ billion per year (based on 1987 sales of $\$ 853.6$ billion and the three-cent per $\$$ of sales expenditure estimate). Clemmensen also estimates commercial power quality costs at $\$ 13.3$ billion, based on a cost of $\$ 20.24 / \mathrm{kWh}$ unserved (for a 15 -minute outage, from a survey conducted in 1974), a probability of 0.001 for a 15-minute interruption, and 1987 commercial electricity use of 658 billion $\mathrm{kWh}$.

The Clemmensen estimate has been widely cited and used as the basis for subsequent estimates. Specifically, \$26 billion (based on the estimate for industrial power quality equipment spending) has been cited as a measure of the aggregate cost of all reliability 
problems to the U.S. economy, not just power quality (Swaminathan and Sen 1998). In addition, this estimate has also been the basis for a $\$ 50$ billion estimate of the cost of all reliability problems, which takes into account the effects of inflation since the time of Clemmensen's original work (Douglas 2000).

A Sandia National Laboratories report (Swaminathan and Sen 1998) estimates U.S. outage costs at $\$ 150$ billion per year. They obtain this estimate by extrapolating the results of a 1992 Duke Power outage cost survey to the entire U.S. based on total industrial electricity sales. The use of regional data biases the national estimates in two ways: the regional mix of industries may not reflect the national mix, and the weather in the region is not representative (the southeastern U.S. experiences frequent lightning storms compared to other parts of the country).

A brochure produced by EPRI (1995) estimates that workers were idle for 37.2 million hours in 1991 due to power quality problems, for a productivity loss of $\$ 400$ million. Total losses to U.S. businesses were estimated to be 1000 times larger, or $\$ 400$ billion.

Brender (1998) estimates the U.S. cost of lost productivity due to power quality problems as $\$ 15$ to $\$ 30$ billion, but no sources or supporting data were provided.

A 1999 Electronic News article yielded an interesting statistic on business investment in power quality. It reported that North American sales of uninterruptible power supplies or UPSs ( $5 \mathrm{kVA}$ and under) were more than $\$ 1$ billion in 1998 and expected to grow to $\$ 1.7$ billion by 2002 .

A more recent article by Clemmensen et al. (1999) estimates the market for power quality equipment and services at $\$ 5.13$ billion in 1999 . This estimate was developed through a survey of equipment manufacturers and service providers. It contrasts sharply with the earlier \$26 billion estimate developed by Clemmensen in 1993.

\subsubsection{The Cost of Specific Power System Events}

Reports of specific power system events tend to focus on large outages. However, estimates of costs associated with these events are not well documented and generally not useful for developing more aggregate estimates. Typically, rules of thumb developed from previous outages or studies are applied, rather than a bottom-up, new accounting of costs specific to the particular outage. An additional problem is that since outages are often caused by weather (e.g. lightning) or natural disasters (e.g. earthquakes), it is often impossible to isolate the effects of the outage from the other effects of these initiating events. A final problem is that some of the literature refers only to a specific instances of

\footnotetext{
${ }^{6}$ Additional citations for the cost of unreliable electricity for cleanrooms are presented in Section 5.

${ }^{7}$ Because some of this information comes from the insurance literature, a brief discussion of relevant insurance issues is warranted. Companies can purchase business interruption insurance, which compensates them if operations are interrupted. However, such policies do not typically cover interruptions resulting
} 
economic loss (e.g., to a single firm or line of business). In this case, we have only a partial estimate of the total economic costs to the affected region.

Twenty-five papers addressed specific outage events. Many of these were articles from such magazines as Business Insurance and Computing Canada. These articles tend to be topical and are printed as quickly as possible following the event (usually within a week or two, depending on the magazine's publishing schedule).

The 1998 Auckland, New Zealand power outage received a great deal of coverage particularly in the insurance press (Higgins 1998). A portion of downtown Auckland was without power for more than two months when four main power lines failed in succession. The total cost of the outage was estimated at NZ\$100 million or \$56 million U.S. (Time International 1998, Donmoyer 1998)

A 15-minute power outage in Vancouver, British Columbia, shut down the Vancouver Stock Exchange for an entire day (Wintrob 1995). The outage occurred after trading hours, and there seemed to be little cause for concern until the system was brought up the next morning. Data and the back-up file were both corrupted. The problem was not resolved in time to open the exchange that day. The lost revenue to the stock exchange was about CAN\$30,000, and lost commissions for member firms pushed losses into the millions.

A New York City power outage in 1990 cost Citicorp alone \$100 million (Schmerken 1990). Another New York City outage in 1999 prompted a \$3- million lawsuit against Consolidated Edison by the city and a class action lawsuit by business owners (Gordes 2000).

Two outages in the summer of 1996 affected the western U.S. The August 10 outage affected 14 western states and two Canadian provinces. Brown (1996) discusses the impact of the outages on semiconductor manufacturers. Most of the manufacturers reported some product damage, and one reported equipment damage. A firm that experienced the August event as a two-second brownout reported no losses at all. Only one manufacturer, American Microsystems, provided a dollar value for losses from the July 1996 outage but in a broad range, between \$50,000 and \$1 million. A California Energy Commission survey (CEC 1997) of customers affected by the August outage showed that only 8.8 percent of residential customers reported financial losses. Only one of 37 commercial and industrial customers reported no losses. The highest reported loss was $\$ 5$ million although most reported losses were less than $\$ 10,000$. The length of the outage varied in the affected territory from 20 minutes for some customers to more than a day for others.

from an off-site power failure although businesses may purchase supplemental insurance that provides this coverage. Business interruption policies also have a waiting period deductible, so even if a company has coverage for power outages, short-duration outages would not trigger coverage. See the longer discussion of this topic in Section 6. 
A two-minute power outage in Taiwan in May of 1997 reportedly cost Formosa Plastics and other petrochemical producers more than $\$ 11$ million (Oil and Gas Journal 1997). Production was interrupted for up to two hours by the outage. A China Petroleum Corp. refinery reported losses of $\$ 2.6-11$ million due to the event.

A power outage at the end of July, 1999 cost the entire Taiwan chip manufacturing industry \$62 million according to one source (Chen 1999) and \$40 million according to another (Haney 1999).

\subsubsection{Customer Surveys of Outage Costs}

Surveys of outage costs provided the richest source of information for tracking trends in reliability costs because they identify specific components of economic losses, distinguish among classes and types of customers bearing these losses, and consider the losses associated with a range of reliability events ( 1 minute interruption vs. 8 hour outage). Meta-analysis to synthesize and extrapolate from these surveys is difficult, however, due to inconsistencies in sampling, study design, and reporting conventions. Moreover, surveys do not consider the frequency of occurrences of outages.

Surveys of customer outage costs date back to at least the 1970's. The IEEE Gold Book (IEEE 1998) presents a summary of survey results for that era. We focused on more recent studies. Our literature review turned up 10 documents containing results from original outage cost surveys (see Table 2-6). However, three of the documents cite the same survey data. Several papers cite previously published survey results, notably surveys conducted by the University of Saskatchewan.

Studies of the following utilities: PG\&E, Niagara Mohawk, Southern Company, Southern California Edison, and BC Hydro were mentioned in the papers we reviewed; however, no data were presented. Sanghvi (1990) provides a list of major North American outage cost studies through 1989.

Four surveys conducted by the University of Saskatchewan were cited the most. At least 18 documents cited their sources as one or more of these four surveys. This total does not include documents that we categorized as applications literature, though only a few of these documents were included in our database.

Table 2-6. Customer Surveys of Outage Costs

\begin{tabular}{|l|l|l|l|}
\hline Survey Location & $\begin{array}{l}\text { Survey } \\
\text { Date }\end{array}$ & Customer Type & $\begin{array}{l}\text { Number of } \\
\text { Responses }\end{array}$ \\
\hline $\begin{array}{l}\text { U.S. and Canada (IEEE } \\
\text { Gold Book) }\end{array}$ & $\begin{array}{l}1973- \\
75\end{array}$ & $\begin{array}{l}\text { Lg. and Sm. Industrial, } \\
\text { Commercial, Office }\end{array}$ & Ind: 41, Com: 54 \\
\hline Duke Power & 1992 & Residential, Lg. Industrial \& & Res: 1,584 \\
\hline
\end{tabular}

\footnotetext{
${ }^{8}$ Note: this outage is incorrectly cited in Gordes (2000) as having a cost of $\$ 62$ million per episode for power interruption costs to an individual chip manufacturer.
} 


\begin{tabular}{|c|c|c|c|}
\hline & & $\begin{array}{l}\text { Commercial, Sm. \& Med. } \\
\text { Industrial \& Commercial }\end{array}$ & $\begin{array}{l}\text { Lg. C\&I: } 210 \\
\text { S/M C\&I: } 1080\end{array}$ \\
\hline Cascavel, Brazil & 1976 & Residential & 27 \\
\hline $\begin{array}{l}\text { Northern Electric } \\
\text { (Britain) }\end{array}$ & 1996 & Industrial & 64 \\
\hline $\begin{array}{l}\text { MANWEB, MEB and } \\
\text { NORWEB (Britain) }\end{array}$ & 1993 & Industrial & Unknown \\
\hline $\begin{array}{l}\text { University of } \\
\text { Saskatchewan/NSERC }\end{array}$ & 1990 & $\begin{array}{l}\text { Residential, Commercial, } \\
\text { Industrial }\end{array}$ & $\begin{array}{l}\text { Res: } 1,817 \\
\text { Com: } 657 \\
\text { Ind: } 819\end{array}$ \\
\hline $\begin{array}{l}\text { University of } \\
\text { Saskatchewan }\end{array}$ & 1995 & $\begin{array}{l}\text { Government, Institution, } \\
\text { and Office }\end{array}$ & 288 \\
\hline $\begin{array}{l}\text { University of } \\
\text { Saskatchewan/CEA }\end{array}$ & 1981 & $\begin{array}{l}\text { Residential, Commercial, } \\
\text { and Small Industrial }\end{array}$ & Unknown \\
\hline $\begin{array}{l}\text { University of } \\
\text { Saskatchewan }\end{array}$ & 1986 & Agricultural & Unknown \\
\hline Nepal & 1996 & Residential & 944 \\
\hline $\begin{array}{l}\text { Bonneville Power } \\
\text { Administration }\end{array}$ & $\begin{array}{l}\text { pre- } \\
1990\end{array}$ & $\begin{array}{l}\text { Residential, commercial, } \\
\text { industrial }\end{array}$ & $\begin{array}{l}\text { Res: } 944 \\
\text { C\&I: } 776\end{array}$ \\
\hline $\begin{array}{l}\text { Denmark, Finland, } \\
\text { Iceland }\end{array}$ & $\begin{array}{l}1992- \\
93\end{array}$ & $\begin{array}{l}\text { Residential, Agricultural, } \\
\text { Industrial, Commercial, } \\
\text { Public Sector }\end{array}$ & $\begin{array}{l}\text { Res: } 9,840 \\
\text { Ag: } 1,400 \\
\text { Ind, Com, } \\
\text { Public: unknown }\end{array}$ \\
\hline Taiwan & 1991 & Industrial & 353 \\
\hline $\begin{array}{l}\text { Unnamed large utility in } \\
\text { the Southeastern U.S. }\end{array}$ & $\begin{array}{l}\text { pre- } \\
1990\end{array}$ & $\begin{array}{l}\text { Residential, Commercial, } \\
\text { Industrial }\end{array}$ & $\begin{array}{l}\text { Res: } 1064 \\
\text { C\&I: } 1080\end{array}$ \\
\hline
\end{tabular}

Notes:

This list includes all the outage cost surveys for which we have results. Because some of the papers in our database include outage costs from previously published reports, we did not always have all the survey details (in particular the number of responses and date of the survey).

A typical approach for an outage cost survey is to list a set of hypothetical outage scenarios. The scenarios considered vary considerably among surveys. For example, one survey might ask for the cost of a one-hour outage while another might specify a one-hour outage occurring at $8 \mathrm{a} . \mathrm{m}$. on a winter weekday. Several also distinguished between outages with and without advance notice. In some cases, advance notice outages were presented as an explicit scenario (e.g. a one-hour outage with advance notice); in others, customers were simply asked if their costs would be reduced if they had advance notice of the outage. We found no surveys that asked about the cost of outages shorter than 1-2 seconds.

\subsubsection{Non-Survey-based Estimates of Outage Costs}

In addition to the survey literature, a number of other papers estimate interruption costs using some of the other methods described in section 2.1.3. 
Munasinghe (1980) uses the wage rate as a proxy for residential outage costs due to lost leisure, which is asserted to constitute the bulk of residential outage costs. Tishler (1993) estimates production functions for commercial and industrial customers in Israel and uses them to estimate outage costs, taking into account firms' response to outages as an aspect of their profit maximization process. Gilmer and Mack (1983) take a more conventional consumer surplus approach.

Two papers use discrete choice models to estimate outage costs from observed market behavior. Caves et al. (1992) use customer participation in interruptible and curtailable rate programs as the basis for their model. Beenstock (1997) uses data on firms' investment in back-up power sources.

Sullivan et al. (1996) address the issue of the high cost of collecting outage cost data and perform statistical analysis of detailed survey results to produce a series of regression equations that could be used to estimate customer outage costs from just a few inputs, such as customer energy use, the presence of certain equipment, types of processes used and presence of back-up equipment.

\subsubsection{Applications of Outage Cost Estimates}

Several papers estimated outage costs by citing data from previously published sources that we were not able to obtain for this literature review. Most of these papers addressed some aspect of utility reliability planning. For example, Neudorf et al. (1995) give two examples of utility cost-benefit transmission planning analyses, taking into account transmission alternatives, capital costs, operating costs, reliability indices, and unserved energy costs. Other papers illustrate a cost-benefit methodology using a hypothetical distribution system (Goel and Billinton 1994, Goel 1998). Several papers use Monte Carlo simulations to calculate total system interruption costs (Mello et al. 1994, Billinton and Wang 1998, Jonnavithula and Billinton 1997, Sankarakrishnan and Billinton 1996, Wang and Billinton 1999).

\subsubsection{Power Quality}

The power quality literature we reviewed encompasses documents on aspects of power quality distinct from outages of varying duration. In contrast to the other literatures we review, we did not identify any power quality documents that provided economic cost estimates of these power quality problems either in the form of surveys or case studies. The documents focus on power quality problem identification and mitigation. Although there are obvious economic implications of these problems and their remediation, cost information is not presented.

Power quality problems encompass a continuum of reliability events including voltage events of varying magnitude and duration, waveform deviations, etc. In principle, they also include outages (near-zero voltage events) of all durations. In literature we reviewed, 
however, there is a fairly distinct division between writing on outages and all other power quality problems; the literatures overlap only in considering momentary (one- to threesecond) outages.

The distinction between the literatures on outages and that on all other power quality events is customer awareness or understanding. The outage cost literature focuses on events that are readily identifiable to customers. Outages of more than a second are unmistakable because they affect a broad range of equipment. A shorter event or one that did not result in voltage dropping to near-zero affects a smaller subset of equipment and even then would not necessarily result in a power quality problem. Customers, particularly residential customers, may not have enough knowledge or experience to estimate their costs resulting from a two-cycle outage or a transient of 125 percent of nominal voltage.

Much of the power quality literature focuses on measurement and monitoring. We found several case studies of customers who approached their electric utilities with complaints or problems they believed were due to power quality. The literature reveals that diagnosing the source of the problem requires at least some monitoring to answer the following questions: What is the nature of the event (sag, swell, etc.)? Is the source of the problem on the utility or customer side of the meter (a reported 90 percent of power quality problems have their source on-site)?

Once the problem is diagnosed, the focus turns to mitigation. Several papers addressed electrical system design, particularly grounding. Where problems occur only for one particular piece of equipment, mitigation may be undertaken solely for that equipment. Adjustable-speed drives may be protected with harmonic filters, and computers may be run off an uninterruptible power supply.

Several papers discuss particular types of equipment that are sensitive to (or cause) certain types of power quality problems. Adjustable-speed drives, programmable logic controllers, all types of computer equipment, and high-intensity-discharge (HID) lighting are examples of the types of equipment that can be affected. Equipment -- sometimes the same types of equipment that are sensitive to problems -- can also be the source of power quality problems. Computers use switched-mode power supplies that produce harmonics. Other types of equipment that can cause problems are adjustable-speed drives, uninterruptible power supplies, arc furnaces, and other arc devices.

\subsubsection{Summary of Outage and Power Quality Event Costs}

Tables 2-7, 2-8, and 2-9 present the cost findings from our database for residential customers, commercial and industrial customers, and power quality events (voltage sags), respectively. All costs have been converted to 2000 US\$. The residential, and commercial and industrial customer tables are organized to capture primarily variation in costs as a function of outage duration. Specific qualifications to the duration of the outage are noted on the right-hand side of the tables (e.g., season, time of day, estimation 
method, advance notice).

Studies that present findings in units consistent with other studies are grouped together. A fundamental challenge to comparing results is the many different, irreconcilable metrics used to express findings. Common metrics include: cost/interruption event, cost $/ \mathrm{kWh}$ annual energy consumption, cost $/ \mathrm{kW}$ annual peak demand, and cost $/ \mathrm{kWh}$ unserved electricity. Some sources include the probability of an interruption and report expected costs/yr.

Another issue affecting the comparability of results is the existence of regional differences, particularly in the industrial sector. Industrial companies are not distributed randomly across the country (or the world) but tend to cluster in certain areas. Availability of raw materials, skilled labor, and low energy costs are just a few reasons for this. Semiconductor manufacturers concentrated in the Silicon Valley are one obvious example of an industry clustered in a single geographic area. Because surveys focus on a single utility's service territory, this geographic bias may come through in the cost data.

Preliminary observations from the information presented in these tables include:

1. Costs vary by season and time of day and especially advance notice

2. Residential costs tend to be lower than commercial or industrial sector customer costs, even when normalized for differences in total consumption

3. Residential customer costs tend to increase with outage duration in greater proportion to the amount time they are without power (e.g. a single 8 hour outage is more costly than the sum of eight 1 hour outages)

4. In contrast, commercial and industrial customers costs tend to decrease with outage duration in greater proportion to the amount time they are without power (e.g. a single 1 hour outage is less costly than the sum of sixty 1 minute outages) 


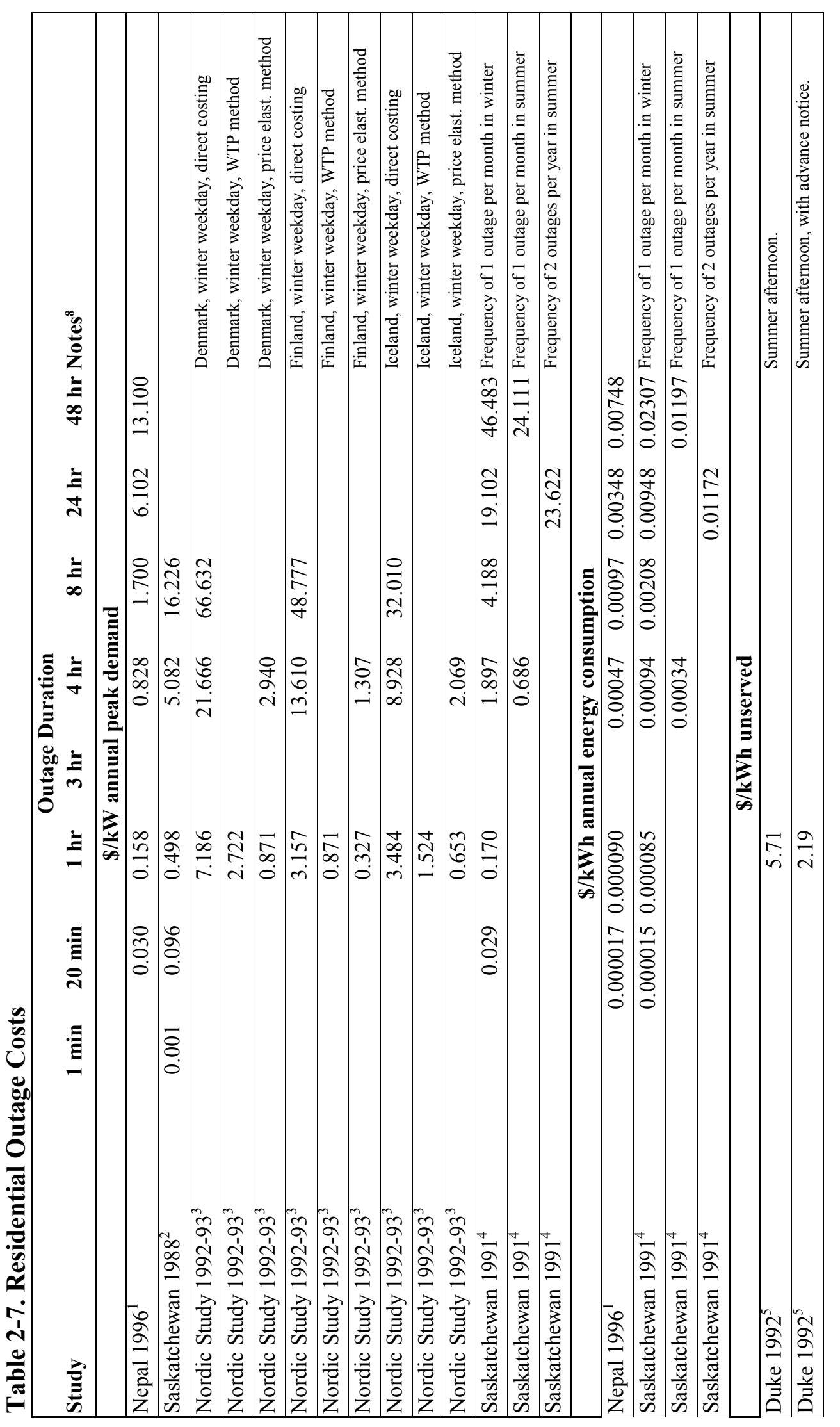




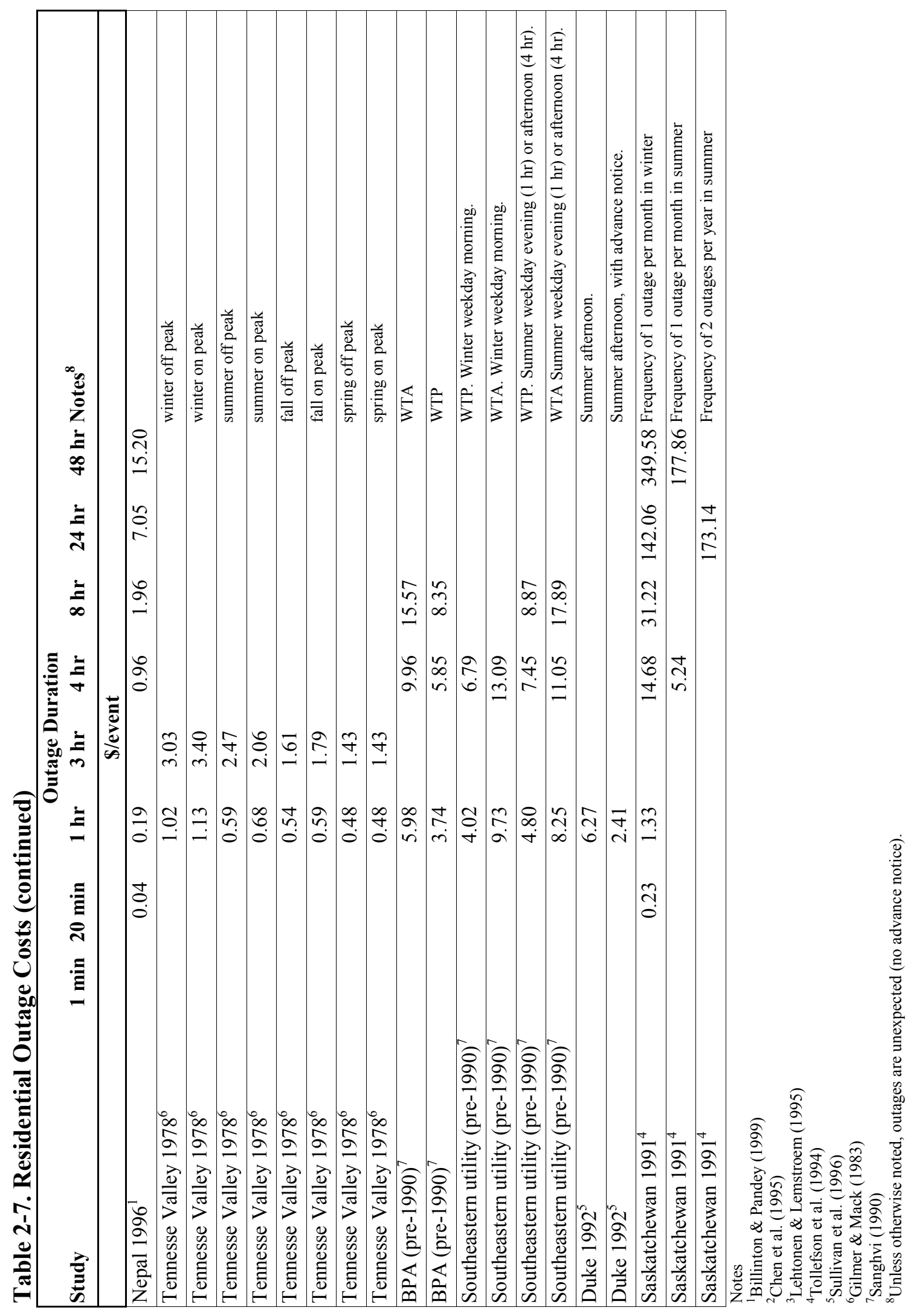




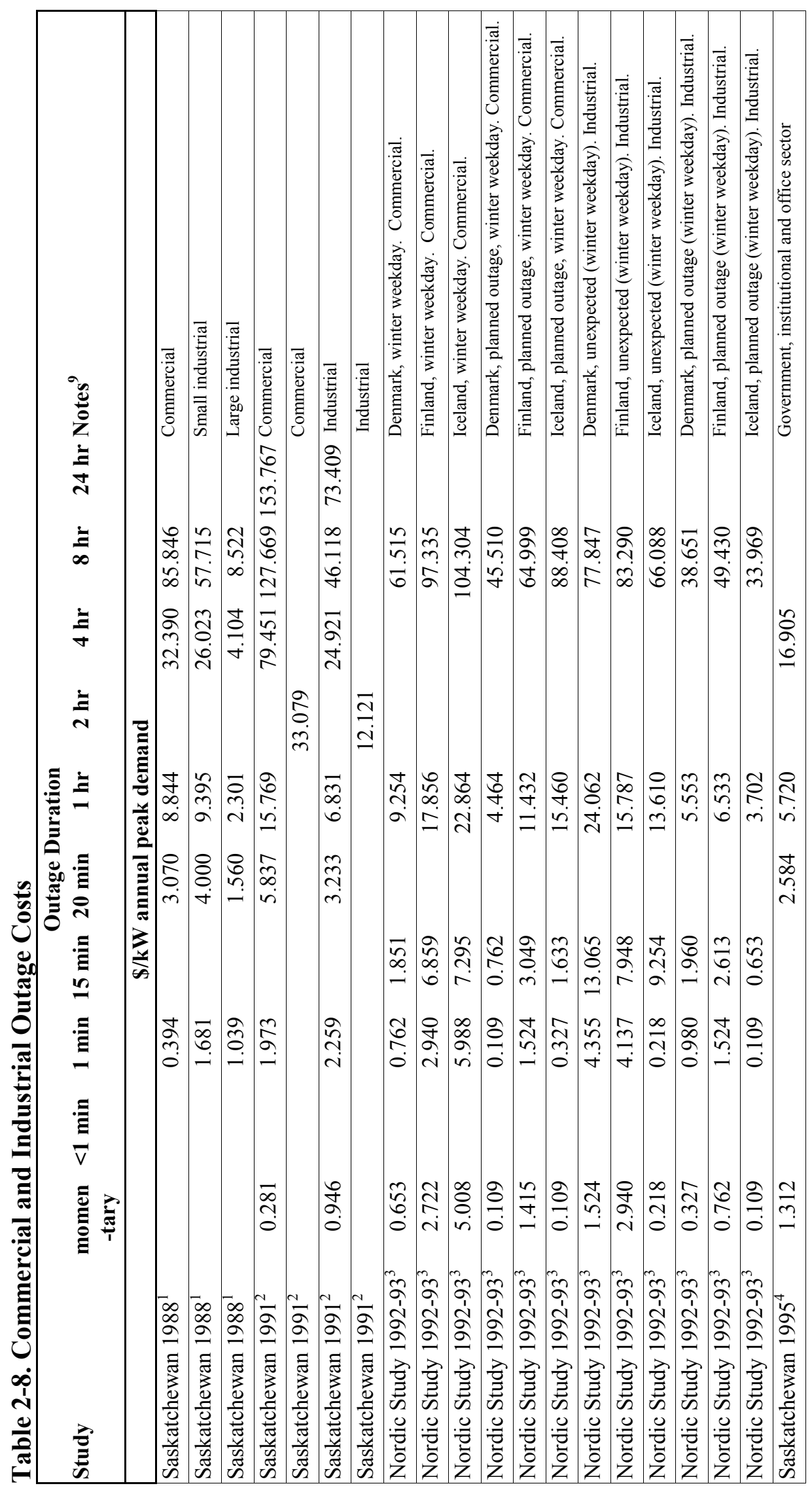




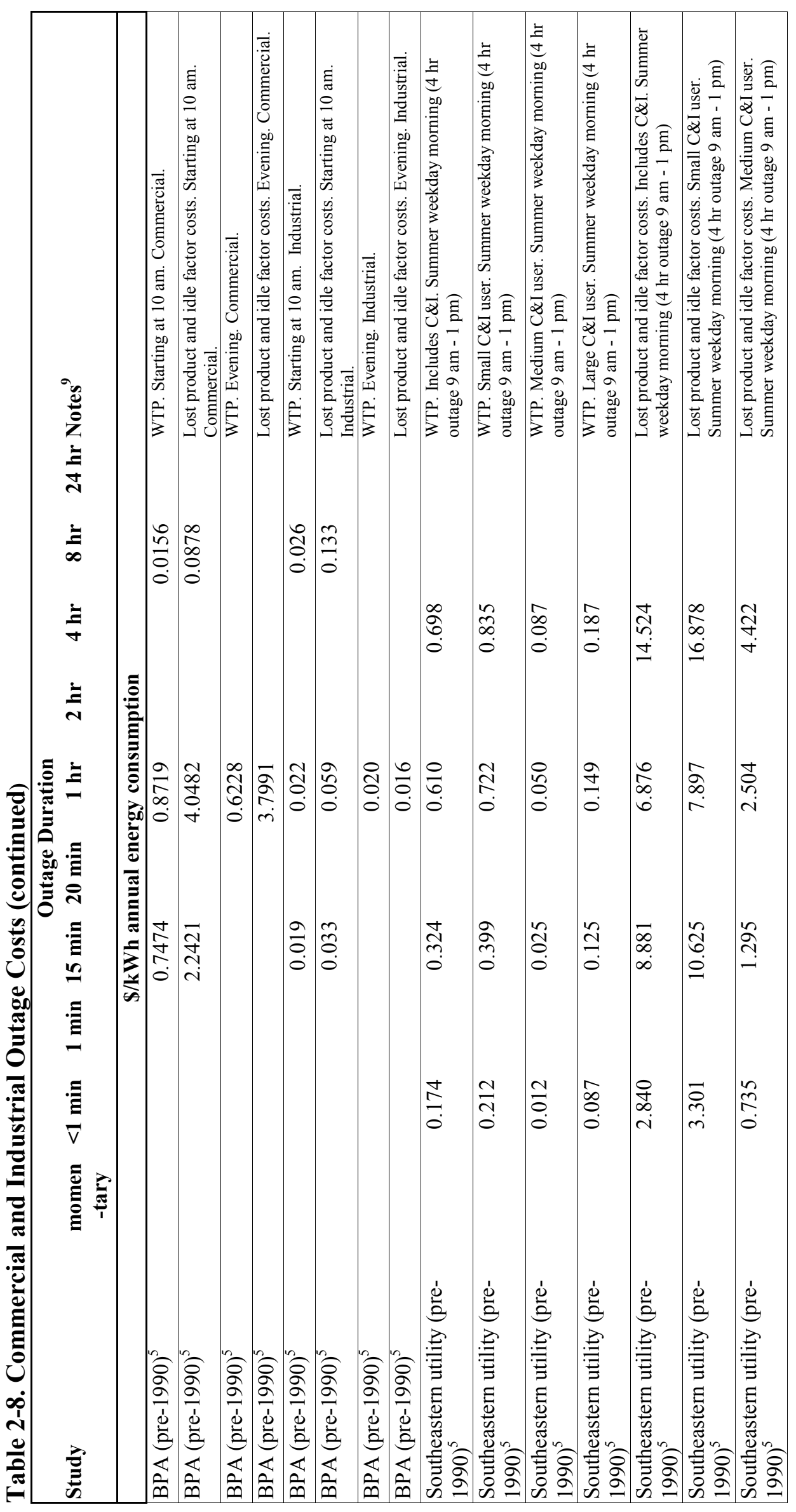




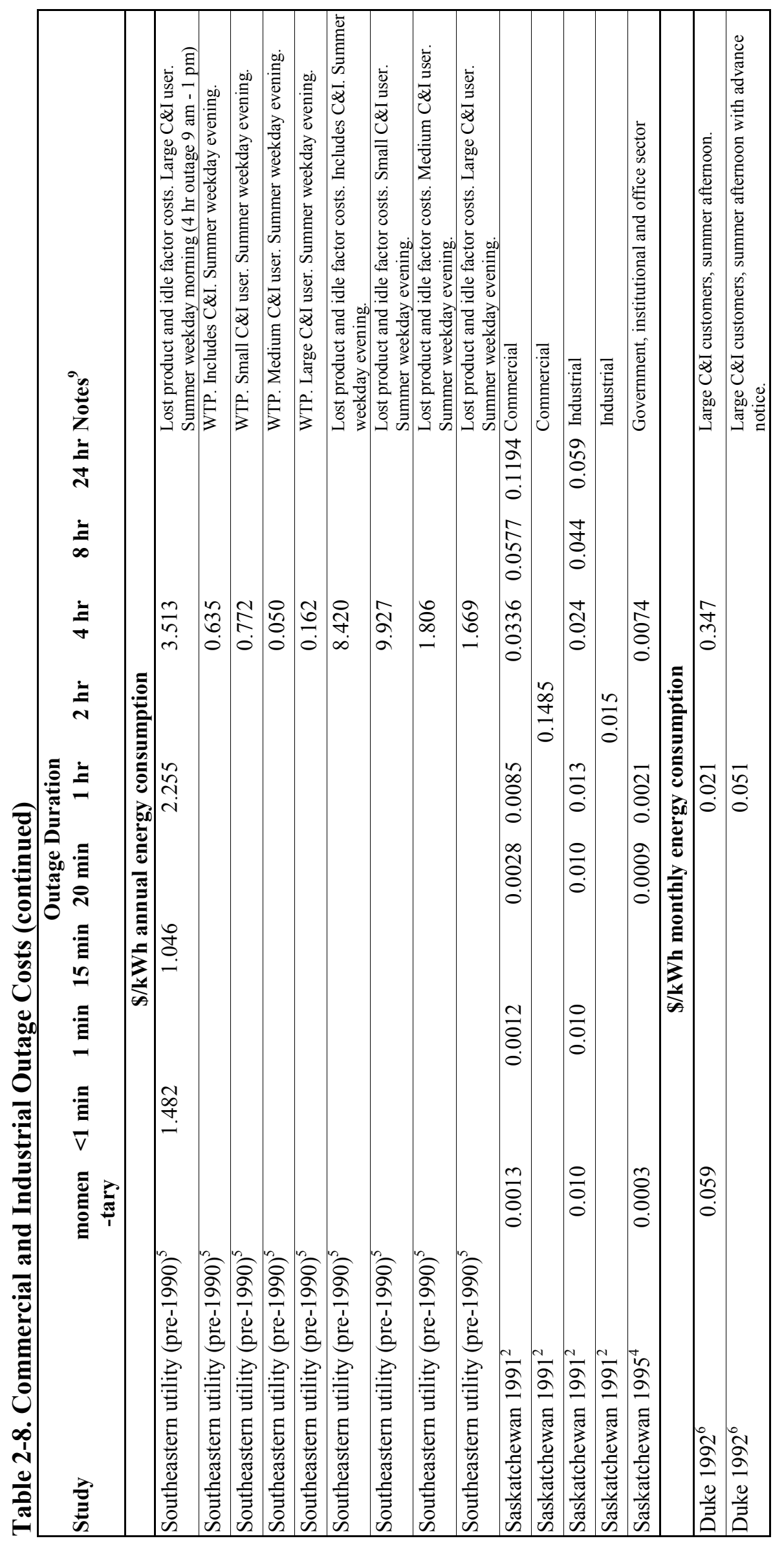




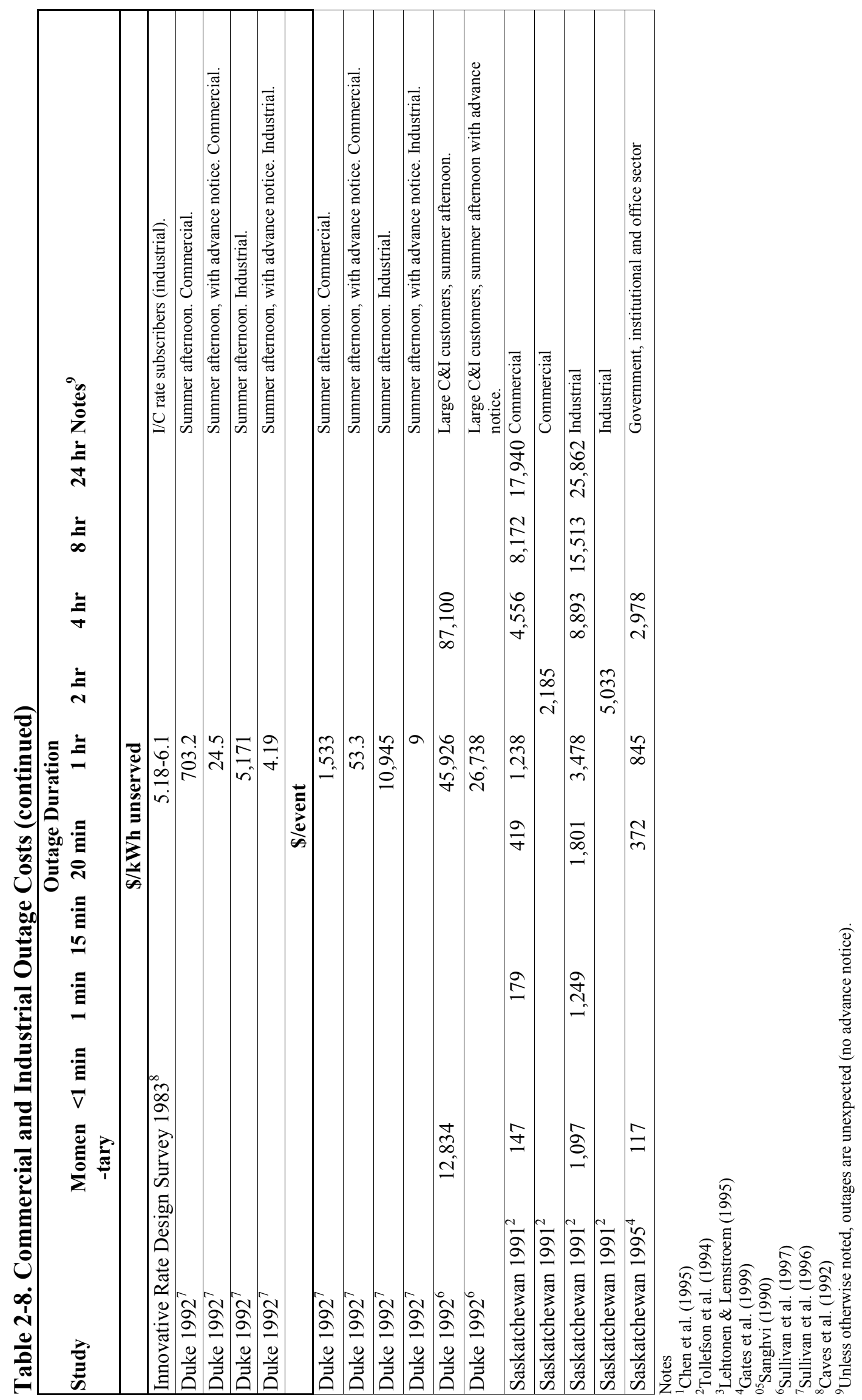




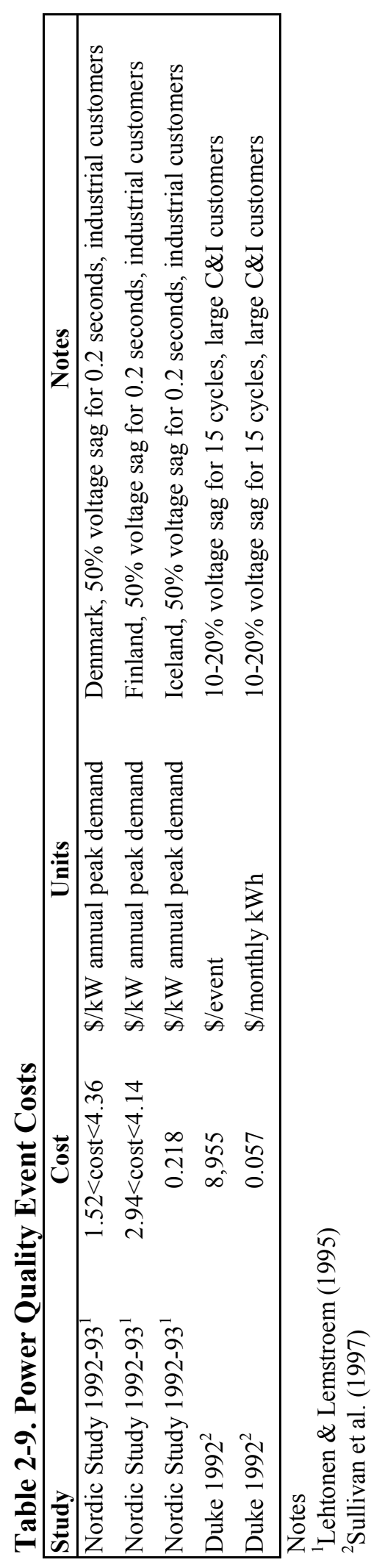




\subsection{Key Findings and Recommendations for Next Steps}

We developed a database reporting on 117 documents. We grouped the findings from these documents in six categories: the aggregate cost of reliability problems; the cost of specific power system events; customer surveys of outage costs; other estimates of outage costs; applications of outage cost estimates (which cite additional estimates of outage costs); and site-specific power quality studies.

Key Findings:

1. There are few estimates of the aggregate cost of unreliable power to the U.S. economy. Documentation for existing estimates is either absent or based on assumptions that need additional review.

2. Reports on the costs of large outage events are not well documented; they are often developed based on applying rules of thumb derived from existing studies extrapolated to a current situation. There have been few systematic studies of the costs of actual large-scale outages. In reviewing costs reported for some events, we encountered complications in tying reported costs uniquely to electricity (e.g., much of the literature includes other costs from the natural disasters that precipitate outages). Insurance claims as a measure of cost are reported on in separate section of this report.

3. Studies of hypothetical outages are typically organized in ways that appear to support extrapolation of outage costs to the preparation of aggregate estimates of these costs. However, differences in methodology and data limitations prevent rigorous metaanalysis. Caution must be used in extrapolating results from existing studies to larger populations.

4. Studies of power quality generally involve case studies of specific sites and do not focus on cost issues.

Recommendations for Next Steps:

1. Extend the database on outage and power quality event costs to include older assessments, including work summarized in earlier surveys of the literature, and to include studies in the "gray" literature. By design, this study: 1) complemented the older body of work with information on newer estimates, and 2) focused on published estimates, which for example do not include utility-sponsored studies that have not led to formal publications. A comprehensive database that includes all available estimates will facilitate meta-analysis and extrapolation.

2. Conduct meta-analysis to synthesize and better understand the limits of extrapolation of the database toward supporting development of a comprehensive national estimate and related sub-analyses. For any given event, location, or customer type, we are limited by available data. Meta-analysis can help to improve confidence in extrapolating from existing data. 
3. Integrate information on costs of outages and power quality events with information on frequency of occurrence. Economic damage is a function of both the cost per event and the frequency of events; our work to date has focused only on costs per event.

4. Collect additional information on customer power quality costs. The paucity of data on power quality is a limitation of the current database for supporting the development of a national estimate or sub-analyses of the cost of reliable electricity. Case studies, such as those pursued to varying degrees in sections 3 and 5 of this report, should be considered (rather than limiting additional data collection to review of secondary data).

5. Consider establishing common guidelines and participating in development of new primary survey information to address key empirical gaps in our current understanding of outage and power quality event costs. Common guidelines would increase comparability and analysis of future findings. Directed co-sponsorship for additional surveys or studies would help ensure key uncertainties are framed appropriately and targeted meaningfully. 


\section{Office Equipment Electricity Use in the Commercial Sector}

Electricity use in the commercial sector is traditionally examined by considering variations in use by building type and end use. From the perspective of electricity reliability, office equipment is both a key enabling technology for the economic productivity of commercial firms and at the same time one that is known to be especially vulnerable to electricity interruptions and power quality problems. There are also differences of opinion regarding the total U.S. electricity use by office equipment.

We develop estimates of electricity use by office equipment according to commercial building type. This is accomplished by combining recently developed information on total U.S. electricity use by office equipment with survey information on commercial building office equipment stocks by building type. The framework developed for assembling this information can be used to evaluate scenarios for future office equipment load growth.

\subsection{Assessing High Reliability Requirements Within the Commercial Sector}

The importance of power reliability in the commercial and industrial sectors can be determined in various ways. One way, undertaken in Section 4 of this report, is to analyze the energy used by industrial activity, classifying activities as having low, medium, and high needs for reliability. Another way commonly used to analyze commercial sector energy use is to estimate the electricity used by building type and end use. Categorizing the data in this way can provide task and technology-specific insights unavailable from other approaches. The data sources needed to conduct such a buildingtype-by-building-type end-use assessment currently only exist for the commercial sector and have been developed for EPRI's COMMEND modeling framework, among others (Koomey et al. 1995).

The most detailed recent analysis that cross tabulates office equipment loads by equipment type and building type was conducted by LBNL in 1995 (Koomey et al.). The 1995 report assessed electricity used by office equipment in 1995 and forecasted office equipment electricity use for all years to 2010. Electricity use was examined separately for nine building types and nine end-use categories, relying on a combination of measured data, surveys, and industry forecasts of equipment shipments. The result was an end-use and building-type electricity use assessment and the accompanying forecast of electricity use.

LBNL's more recent 2000 report (Kawamoto et al. 2000) shows that the market for office equipment has shifted considerably since 1995. For example, Kawamoto et al's work shows that the actual shipments of office equipment used to develop the year 2000 equipment stock are significantly different than the industry forecasts used in the 1995 report. Some of the electricity use numbers have also changed; for example, typical computer monitors are now larger in size than anticipated in the 1995 work. 
However, the 2000 report only estimates the electricity used by all office equipment in the year 2000 and does not separate out electricity used by building type. The 2000 report analyzes 11 separate end-uses and explicitly separates servers and laptop computers from desktop machines, which the 1995 report did not do.

\subsection{Methodology}

The main goal of our calculation is to determine which end uses and building types consume the largest amount of electricity for office equipment activities. To update the 1995 analysis to better reflect year 2000 conditions, we calculate the fraction of electricity consumption by commercial building type attributable to each equipment type from the 1995 report's forecast for 2000, and apply those fractions to the energy used by equipment type from the year 2000 work.

We believe that the 2000 report more accurately portrays current office equipment electricity use by end use than does the forecast for 2000 from the 1995 report. We rely on the building type data from the 1995 report because the 2000 report does not present comparable information. This approach assumes that the distribution of office equipment electricity use among building types has not changed significantly from 1995 to 2000 . We found no information to contradict this assumption.

For Point-Of-Sale (POS) terminals, which were not treated in the 2000 work because of data and time limitations, we made a simple modification to the 1995 estimates by assuming that half of the electricity used by POS terminals in 1995 was for the displays, that the number of POS terminals increased by 50 percent from 1995 to 2000, that the electricity used by the displays in 1995 is reduced in 2000 to one-third of 1995 levels because of the use of liquid crystal display (LCD) screens, and that electricity used by the central processing units (CPUs) is reduced to 75 percent of 1995 levels in 2000 because POS terminals can use low-power, relatively efficient chips.

These assumptions are based on our general knowledge of POS terminals, but we recognize that they are rough estimates, which should be refined by collecting additional data. Use of this assumption leads to our estimate of a small decline in total electricity used by POS terminals in 2000 compared to the total for 1995 . We distribute the electricity used for POS terminals throughout the building types in the same proportions as used in the 1995 report (in the same way as energy use is distributed among building types for the other office equipment types).

\subsection{Office Equipment Electricity Use in the Commercial Sector}

Table 3-1 summarizes electricity used by commercial building type and office equipment type in the U.S. commercial sector in 2000 derived as described below. Total office equipment electricity use for this sector is about $58 \mathrm{TWh}$, which is less than two percent of total U.S. electricity use and represents about 0.7 percent of U.S. primary energy use. PCs, Monitors, and Minicomputers (a category that includes servers, which comprise 
about $15 \%$ of the electricity used by that category) are the three most energy-consuming equipment types. Offices are the largest building type accounting for almost half of all commercial-sector office equipment electricity use. Retail, Schools, and Warehouses follow far behind.

Table 3-1: Electricity Used by Office Equipment Type and Building Type in the U.S. Commercial Sector in 2000 (TWh)

\begin{tabular}{|l|ccccccccc|c|}
\hline & Offices & Retail & Groceries Schools Hosp- & Hotels & $\begin{array}{c}\text { Miscel- } \\
\text { laneous }\end{array}$ & $\begin{array}{c}\text { Restaur- } \\
\text { ants }\end{array}$ & $\begin{array}{c}\text { Ware- } \\
\text { houses }\end{array}$ & Total \\
\hline PC's & 7.2 & 0.9 & 0.0 & 1.0 & 0.1 & 0.3 & 0.6 & 0.1 & 0.1 & 10.3 \\
Monitors & 7.2 & 1.0 & 0.0 & 1.7 & 0.3 & 0.4 & 0.6 & 0.1 & 0.5 & 11.6 \\
Laser printers & 2.9 & 0.5 & 0.0 & 0.4 & 0.3 & 0.1 & 0.5 & 0.0 & 0.5 & 5.4 \\
Serial printers & 0.9 & 0.1 & 0.0 & 0.1 & 0.1 & 0.0 & 0.2 & 0.0 & 0.1 & 1.6 \\
Copiers & 2.2 & 0.8 & 0.0 & 0.6 & 0.2 & 0.0 & 1.3 & 0.0 & 0.6 & 5.7 \\
Faxes & 1.2 & 0.2 & 0.0 & 0.2 & 0.1 & 0.0 & 0.2 & 0.0 & 0.4 & 2.3 \\
POS Terminals & 0.2 & 3.9 & 0.3 & 0.0 & 0.1 & 0.1 & 0.2 & 0.6 & 0.0 & 5.4 \\
Mainframes & 3.0 & 0.6 & 0.0 & 0.7 & 0.1 & 0.1 & 0.2 & 0.0 & 0.9 & 5.6 \\
Minicomputers & 4.6 & 1.5 & 0.0 & 1.6 & 0.2 & 0.2 & 0.5 & 0.0 & 1.9 & 10.5 \\
\hline Total & 29.4 & 9.5 & 0.4 & 6.4 & 1.5 & 1.2 & 4.1 & 0.8 & 5.0 & 58.3 \\
\hline
\end{tabular}

Note: This table does not include electricity used by other end uses, such as lighting; in particular, it does not include HVAC electricity use associated with use of office equipment.

Figures 3-1 and 3-2 summarize the results of calculations for all equipment types and building types (which are two different ways to plot the data from Table 3-1).

Table 3-2 shows the "Top Ten" end-use/building type categories for total electricity consumption. The most important categories by far are PCs and Monitors in Offices, together accounting for about 40 percent of the electricity used by the Top Ten and for almost one-quarter of all commercial sector office equipment electricity use. POS terminals in Retail buildings and minicomputers in Offices are also important. The Top Ten uses make up more than 60 percent of total commercial-sector use.

Table 3.2: Top Ten List of Commercial Sector Office Equipment End Uses in 2000

\begin{tabular}{|l|ccc|}
\hline & TWh & \% of top ten & $\%$ of total \\
\hline PCs in offices & 7.2 & $20 \%$ & $12 \%$ \\
Monitors in offices & 7.2 & $20 \%$ & $12 \%$ \\
POS terminals in retail & 3.9 & $11 \%$ & $7 \%$ \\
Minicomputers in offices & 3.6 & $13 \%$ & $8 \%$ \\
Mainframes in offices & 3.0 & $8 \%$ & $5 \%$ \\
Laser printers in offices spacing & 2.9 & $8 \%$ & $5 \%$ \\
Copiers in offices & 2.2 & $6 \%$ & $4 \%$ \\
Minicomputers in warehouses & 1.9 & $5 \%$ & $3 \%$ \\
Monitors in schools & 1.7 & $5 \%$ & $3 \%$ \\
Minicomputers in schools & 1.6 & $5 \%$ & $3 \%$ \\
\hline Total & 36.3 & $100 \%$ & $62 \%$ \\
\hline
\end{tabular}




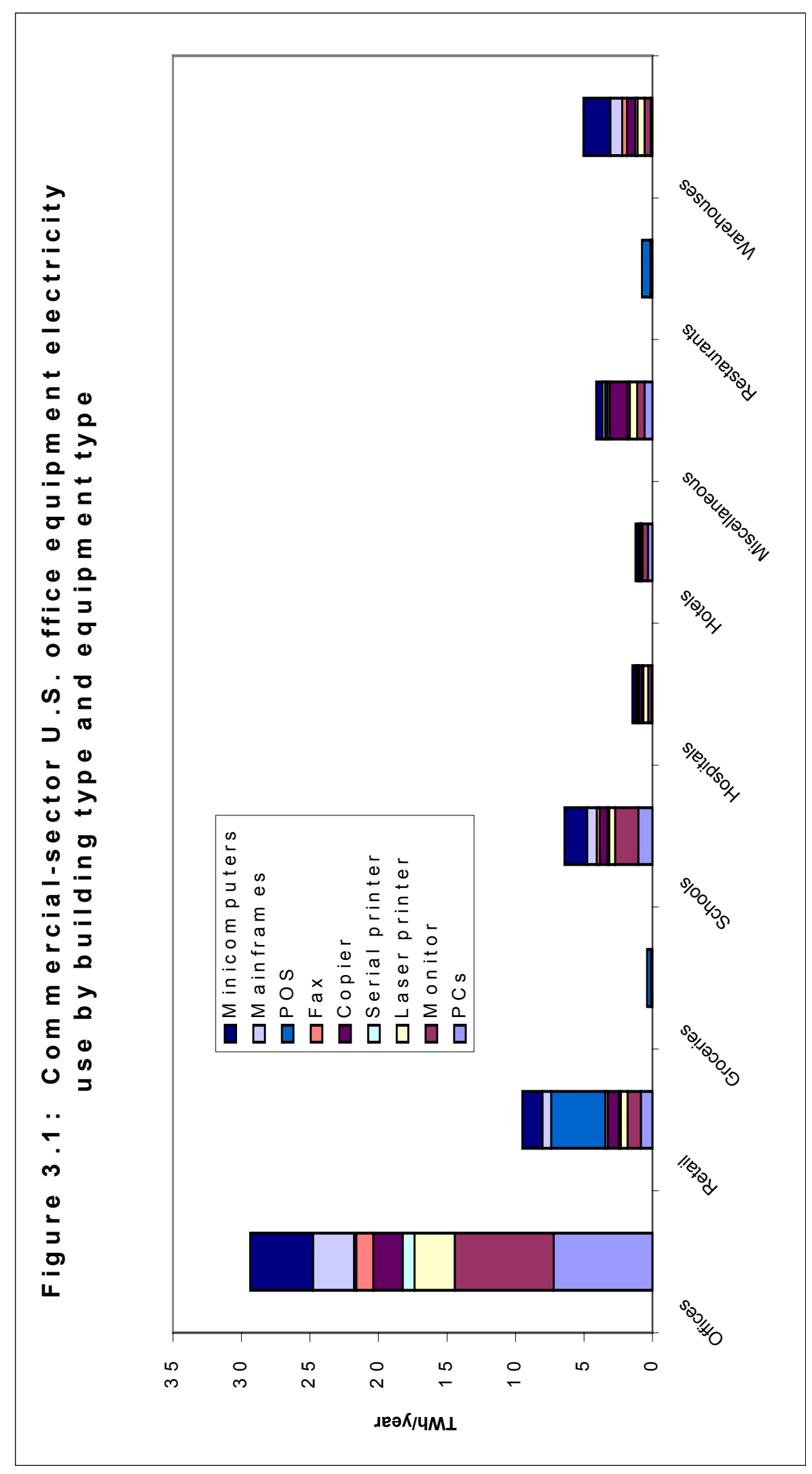




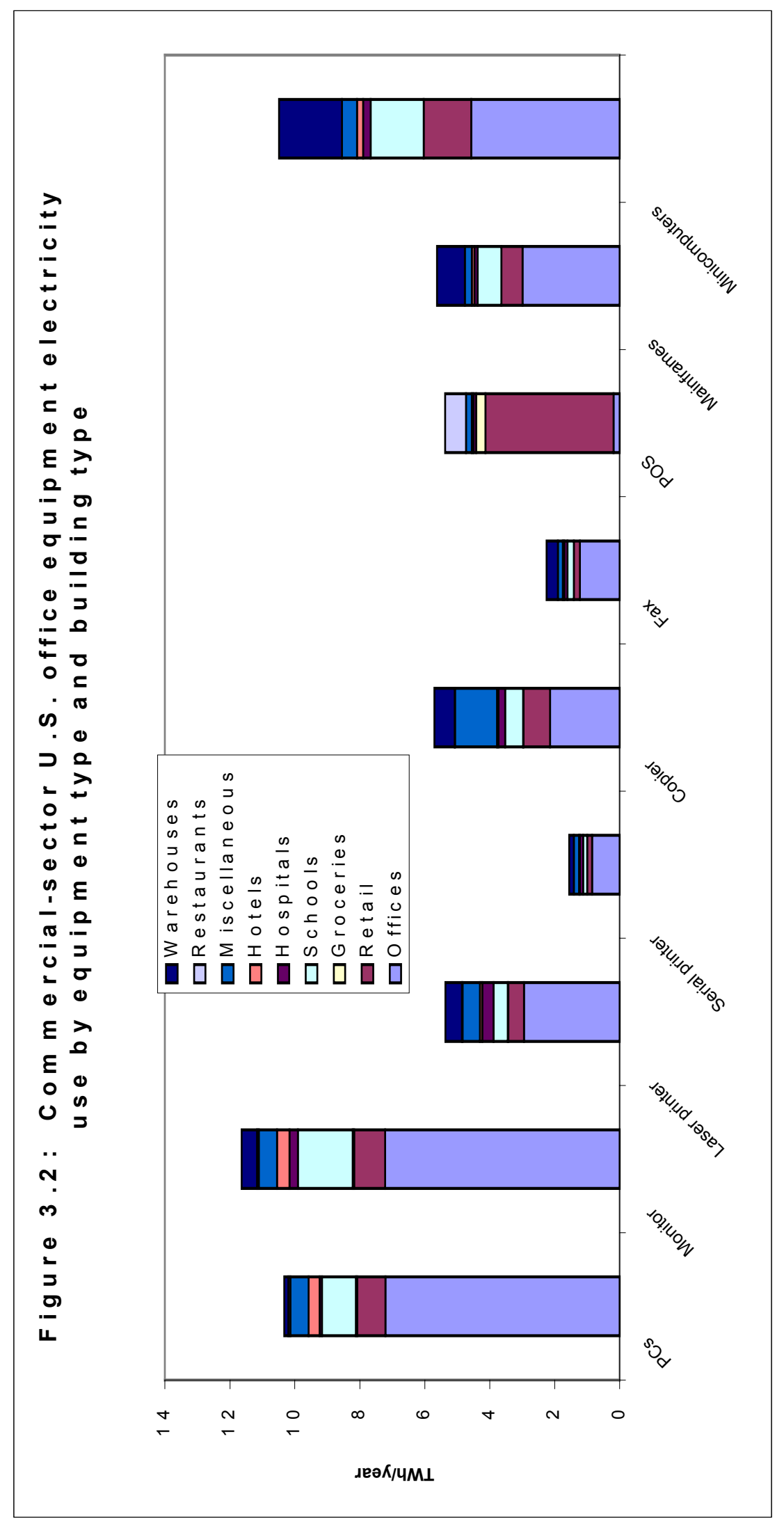

$n$ 


\subsection{Key Findings and Recommendations for Next Steps}

We developed estimates of electricity use by office equipment according to commercial building type. We accomplished this by combining information developed previously on total U.S. electricity use by office equipment with information on commercial building office equipment stocks. The framework developed for assembling this information can be used to evaluate scenarios for future office equipment load growth.

Key Findings:

1. Total U.S. office equipment electricity use in the commercial sector is about 58 $\mathrm{TWh} / \mathrm{yr}$., which is less than 2 percent of total U.S. electricity use.

2. Pe.rsonal Computers (PCs), Monitors, and Minicomputers together account for more than half of all commercial sector office equipment electricity use.

3. Offices account for almost half of all commercial sector office equipment electricity use.

4. PCs and Monitors in offices account for almost one-quarter of all commercial sector office equipment electricity use.

5. Because electronic technologies change quickly, there are significant uncertainties in these calculations.

Recommendations for Next Steps:

1. Analyze the applications for office equipment and other reliability-sensitive equipment in the "top ten" end uses identified above. Some of these applications will be more sensitive to reliability concerns than others, and it is critically important to understand how this equipment is used in these top ten applications.

2. More accurate data about the stocks of different kinds of equipment are urgently needed. The last Commercial Buildings Energy Consumption Survey (CBECS) was conducted for 1995 data (a 1999 version is under way now). CBECS does not contain data on some of the equipment types of interest for our research, so it must be supplemented by other surveys. More information is also needed on how equipment stocks are distributed among the residential, commercial, and industrial sectors.

3. Because of their relative importance, it is critical to measure the electricity use of some representative POS terminals and collect data on ownership levels to determine whether the assumptions we have made are accurate.

4. We have little data on the prevalence and characteristics of back-up power systems and uninterruptible power supplies in the commercial sector, so surveys of the stocks of such equipment and measurements of their efficiency and electricity use are important to improving our understanding.

5. The prevalence of UPSs gives some indication of the need for reliable electricity in a particular sector, and the costs per $\mathrm{kWh}$ of storage for these systems give some idea of the willingness to pay for reliability. It is critical to undertake an economic analysis of UPSs, for an order-of-magnitude assessment of just what it costs to have such a system. These costs, combined with statistics on the prevalence of these systems, gives a lower-bound indication of how much those who own back-up systems are willing to pay to avoid supply interruptions. 
6. Office equipment end uses are always changing, and new products are constantly being introduced. Quick surveys and spot measurements of power use for these equipment types should be continually undertaken to determine the impact of current technology trends on our findings . 


\section{Statistical Indicators of Manufacturing Sub-Sectors with High Reliability Requirements}

The relationship between overall measures of economic productivity and electricity use is a direct approach for identifying and tracking customers with high-reliability requirements. Examining this relationship is especially appropriate for the industrial sector because the end uses relevant for studying commercial building electricity use are typically a small portion of electricity use compared to that use in the production processes of firms. These processes, themselves, are either somewhat idiosyncratic (i.e., not common to all industries) or highly variable in their relationship to the value of goods produced.

Our objective is to use a statistical approach to determine which U.S. manufacturing subsectors are likely to be most affected by interruptions in electricity supply. Our hypothesis is that the strength of a manufacturing sector's dependence on electricity and hence sensitivity to interruptions can be inferred from the relationship between its use of electricity and various measures of the economic outputs or inputs associated with its use of electricity. Toward this end, we develop and report findings from an examination of three classes of indices: 1) electricity intensity as a function of economic output, 2) employment as a function of economic output (where employment is used as a proxy for the degree of automation/electricity use), and 3) electricity costs as a function of total energy expenditures.

In this section, we present initial results from a using this direct approach to better understand the variations in sensitivity to power-quality and reliability issues among industrial subsectors. We create a database (spreadsheet) of 1995 electricity consumption and economic data by SIC code (Section 4.1). We then develop statistical indicators of electricity use intensity as a function of various economic indices and use these indicators to identify high-reliability-requirements customer market segments (Section 4.2). We discuss the strengths and limitations of this approach and how it may be used to complement other end-use analysis approaches (Section 4.3).

\subsection{Census Data and the Development of Statistical Indicators}

The Annual Survey of Manufacturers (ASM) provides detailed data on the location, activities, and products of U.S. manufacturers (U.S. Department of Commerce 2000). For establishments classified in the manufacturing sector with at least one employee, response is mandatory. The data in the ASM, which include employment, economic indicators, and energy consumption and expenditures, have been published since 1949 and are available through 1998. 
We examine industries at the four-digit Standard Industrial Classification (SIC) code level, which is the lowest level of aggregation for which historical data are available. For the purposes of this analysis, we examine the data for 1995.

More recent data for 1996-1998 are available on the ASM website. However, as a result of international agreements, the data starting with the 1998 ASM Statistics for Industry Groups and Industries are classified according to the North American Industry Classification System (NAICS).

This change in classification systems sharply limits the comparability of the more recent data with the historical data available for our analysis. Roughly half of the industries in the manufacturing sector classified according to NAICS cannot be mapped directly into comparable SIC-classified industries. ${ }^{10}$ Thus, to examine historical changes in intensities, one must look separately at SIC-classified data for the time period up to 1996 and at NAICS classified data for the time period 1997-1998.

For our analysis, we examine data on: cost of fuels, cost of purchased electricity, quantity of electrical energy purchased, quantity of electricity generated less the amount sold, value of industry shipments, value added by manufacture, number of employees, annual payroll, production workers, production worker hours and wages, cost of materials, new capital expenditures, and inventories. We used a subset of these data to construct three classes of indicators for a total of five distinct indicators.

The first class of indicator expresses the relationship between electricity use and economic output where economic output is measured by either value of shipments $(\mathrm{VOS}){ }^{1 \mathrm{~W}}$ or value added (VA) ${ }^{12}$. This ratio reflects to a first approximation the

\footnotetext{
${ }^{9}$ Economic data are available back to 1949; however, energy data have only been published since 1987. Currently, the data are only available electronically through 1995.

${ }^{10}$ It is possible to map some SIC industries to NAICS industries by hand using a Census-published guide. However, we concluded that this approach would not be appropriate given the resources available and the number of industries for which the mapping is likely to be feasible.

${ }^{11}$ Value of Shipments covers the received or receivable net selling values, f.o.b. plant (exclusive of freight and taxes), of all products shipped, both primary and secondary, as well as all miscellaneous receipts, such as receipts for contract work performed for others, installation and repair, sales of scrap, and sales of products bought and resold without further processing. Included are all items made by or for the establishments from materials owned by it, whether sold, transferred to other plants of the same company, or shipped on consignment. The net selling value of products made in one plant on a contract basis from materials owned by another was reported by the plant providing the material.

${ }^{12}$ Value Added by manufacture is derived by subtracting the cost of materials (including materials, supplies, containers, fuel, purchased electricity, and cost of contract work) from the value of shipments (products manufactured plus receipts for services rendered). The result of this calculation is adjusted by the addition of value added by merchandising operations (the difference between the sales value and the cost of merchandise sold without further manufacture, processing, or assembly) plus the net change between beginning- and end-of-year finished goods and work-in-process inventories. Value added by manufacture avoids the duplication in the value of shipments that results when the products of one establishment are used as materials by another. Value added by manufacture is considered the best value measure available for assessing the relative economic importance of manufacturing among industries and geographic areas.
} 
importance of electricity use in relation to the economic value of products using, among other inputs, electricity.

The second class of indicator expresses the relationship between economic output and employment where economic output is again measured by either value of shipments (VOS) or value added (VA). This ratio is a partial proxy for the extent of automation in the production process, which is, in turn, a proxy for reliance on electricity in the production process. However, it is also a measure of the value of the products as function of human capital.

The final class of indicator expresses electricity spending as a percentage of total spending for all energy (fuels and electricity). This ratio examines the importance of electricity with respect to other energy inputs to the production process.

\subsection{Manufacturing Sub-Sectors with High Reliability Requirements}

Tables 4-1 and 4-2 list the top 20 users of electricity with respect to economic output (Value of Shipments in Table 4-1, Value Added in Table 4-2). The top 10 electricityintensive U.S. industrial subsectors with respect to both value of shipments and value added almost all belong to the metals, chemicals, or cement industries. In both tables, aluminum is the most electricity-intensive industry by a large margin. Several of the subsectors are in the primary metals category, (both ferrous and nonferrous). Several subsectors of the chemicals industry are also significant energy users. As expected, there is a high degree of overlap between these two indices.

Tables 4-3 and 4-4 list the top 20 U.S. economic producers with respect to the number of employees working in the subsector. Table 4-3 shows the value of shipments per employee, and Table 4-4 lists value added per employee. Once again, there is a fair amount of overlap between the tables. In simple terms, industries examined in these tables make the most money per employee because of either a high degree of mechanization, or the high value associated with the product. Almost every sub-sector is a member of the food processing, tobacco, or chemicals industries.

Tables 4-5 and 4-6 examine the amount of electricity each industrial subsector spends as a proportion of total energy expenditures. Table 4-5 lists the top 20 industries, each of which individually spends more than $\$ 10$ million per year on total energy. Table 4-6 provides this same ranking, based on all industries. These tables show a much more varied grouping of industries than do Tables 4-1 through 4-4. Table 4-6, for example, lists industries such as clothing manufacture, metals, chemicals, electronic goods, textile mills, and chemicals; Table 4-5 adds food processing and printing.

Table 4-1. Electricity Intensity of Economic Output (kWh / '000 US\$ Value of Shipments) in 1995

\begin{tabular}{|ll|l|l|r|}
\hline RANK & SIC & INDUSTRY & Electricity/VOS (kWh/1000\$) \\
& 1 & 3334 & Primary Production of Aluminum \\
7,154
\end{tabular} \mid




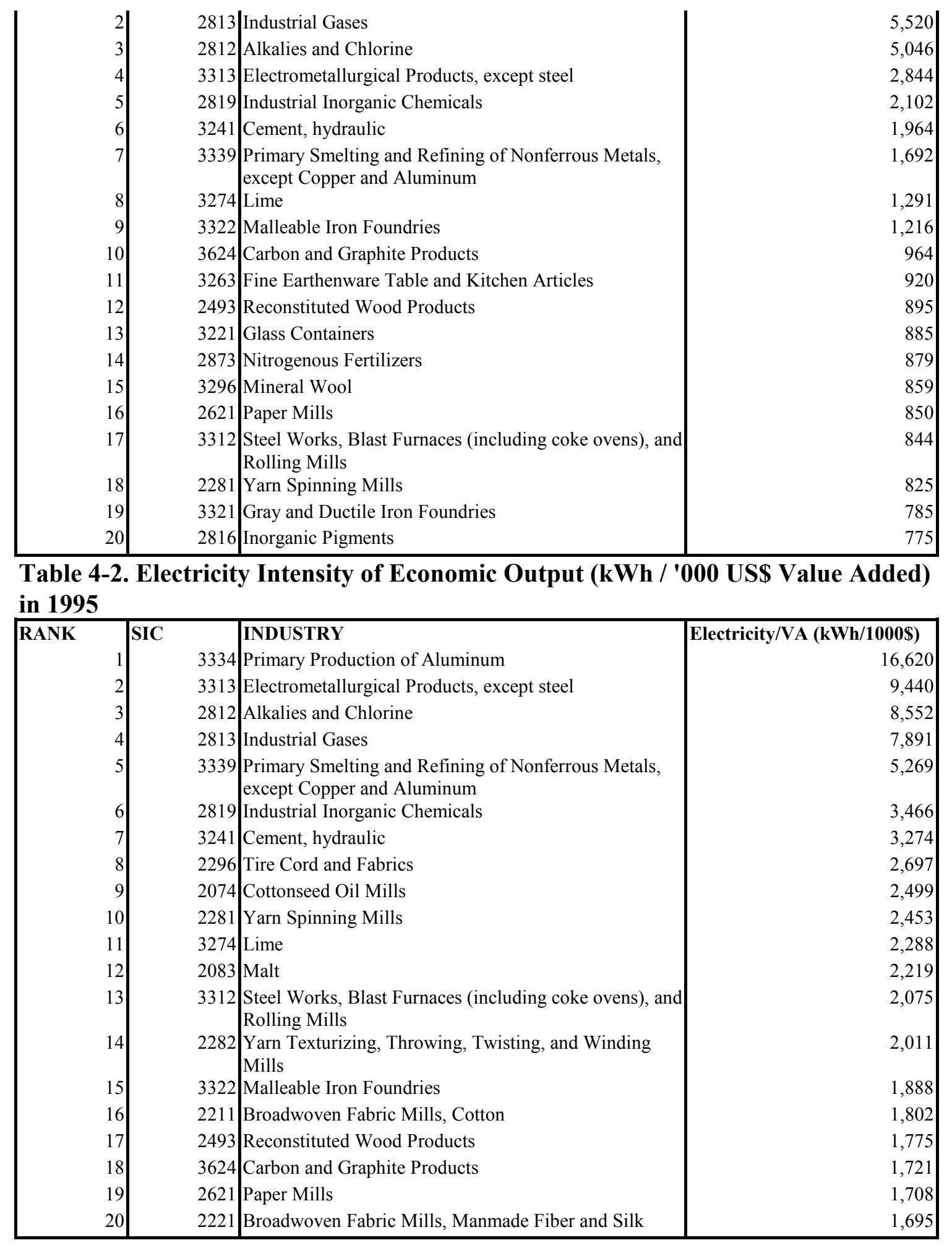


Table 4-3. Economic Intensity of Employment ('000 US\$ Value of Shipments / Employee) in 1995

\begin{tabular}{|c|c|c|c|}
\hline RANK & SIC & INDUSTRY & VOS/Employee (1000\$/EMP) \\
\hline 1 & 2911 & Petroleum Refining & 1,932 \\
\hline 2 & 2075 & Soybean Oil Mills & 1,794 \\
\hline 3 & 2111 & Cigarettes & 1,374 \\
\hline 4 & 3331 & Primary Smelting and Refining of Copper & 1,332 \\
\hline 5 & 2046 & Wet Corn Milling & 927 \\
\hline 6 & 2076 & Vegetable Oil Mills, except Corn, Cottonseed, and Soybean & 902 \\
\hline 7 & 3711 & Motor Vehicles and Passenger Car Bodies & 850 \\
\hline 8 & 2062 & Cane Sugar Refining & 759 \\
\hline 9 & 2043 & Cereal Breakfast Foods & 755 \\
\hline 10 & 2087 & Flavoring Extracts and Flavoring Syrups, not elsewhere classified & 704 \\
\hline 11 & 2869 & Industrial Organic Chemicals, not elsewhere classified & 687 \\
\hline 12 & 2879 & Pesticide and Agricultural Chemicals, not elsewhere classified & 681 \\
\hline 13 & 2131 & Chewing and Smoking Tobacco and Snuff & 681 \\
\hline 14 & 2079 & Shortening, Cooking Oils & 667 \\
\hline 15 & 2095 & Roasted Coffee & 648 \\
\hline 16 & 2021 & Creamery Butter & 631 \\
\hline 17 & 2821 & Plastics Materials, Synthetic Resins, and Nonvulcanizable Elastomers & 625 \\
\hline 18 & 2874 & Phosphatic Fertilizers & 623 \\
\hline 19 & 2843 & $\begin{array}{l}\text { Surface Active Agents, Finishing Agents, Sulfonated Oils, and } \\
\text { Assistants }\end{array}$ & 611 \\
\hline 20 & 2873 & Nitrogenous Fertilizers & 609 \\
\hline
\end{tabular}

Table 4.4 Economic Intensity of Employment ('000 US\$ Value Added / Employee) in 1995

\begin{tabular}{|r|r|l|r|}
\hline RANK & SIC & INDUSTRY & VA/Employee (1000\$/EMP) \\
& 2111 & Cigarettes & 1,108 \\
2 & 2043 & Cereal Breakfast Foods & 601 \\
3 & 2131 & Chewing and Smoking Tobacco and Snuff & 552 \\
4 & 2087 & Flavoring Extracts and Flavoring Syrups, not elsewhere classified & 521 \\
5 & 2046 & Wet Corn Milling & 443 \\
6 & 2879 & Pesticide and Agricultural Chemicals, not elsewhere classified & 416 \\
7 & 2911 & Petroleum Refining & 373 \\
8 & 2873 & Nitrogenous Fertilizers & 337 \\
9 & 2082 & Malt Beverages & 316 \\
10 & 2085 & Distilled and Blended Liquors \\
11 & 2813 & Industrial Gases & 315 \\
12 & 2843 & Surface Active Agents, Finishing Agents, Sulfonated Oils, and & 311 \\
13 & 2869 & Assistants & 310 \\
14 & 2611 & Pulp Mills & 307 \\
15 & 2841 & Soap and other Detergents, except Specialty Cleaners \\
16 & 2834 & Pharmaceutical Preparations & 292 \\
17 & 3331 & Primary Smelting and Refining of Copper & 289 \\
18 & 2075 & Soybean Oil Mills & 289 \\
19 & 3674 & Semiconductors and Related Devices & 284 \\
20 & 2833 & Medicinal Chemicals and Botanical Products \\
\hline
\end{tabular}


Table 4-5 Electricity Spending as a Proportion of Total Energy Expenditures in Industries with Total Energy Expenditures Greater than \$10 Million per Year(\%) in 1995

\begin{tabular}{|r|r|l|r|}
\hline RANK & SIC & INDUSTRY & Electricity Share (Elec\$/Tot\$) \\
1 & 3085 & Plastics Bottles & $96 \%$ \\
2 & 3084 & Plastics Pipe & $94 \%$ \\
3 & 3334 & Primary Production of Aluminum & \\
4 & 2281 & Yarn Spinning Mills & $93 \%$ \\
5 & 3812 & Search, Detection, Navigation, Guidance, Aeronautical, and Nautical & $92 \%$ \\
6 & 2813 & Systems and Instruments & $92 \%$ \\
7 & 3559 & Special Industry Machinery, not elsewhere classified & $91 \%$ \\
8 & 3761 & Guided Missiles and Space Vehicles & $90 \%$ \\
9 & 2282 & Yarn Texturizing, Throwing, Twisting, and Winding Mills \\
10 & 3663 & Radio and Television Broadcasting and Communications Equipment & $90 \%$ \\
11 & 3143 & Mens' Footwear, except Athletic & $90 \%$ \\
12 & 2673 & Plastics, Foil, and Coated Paper Bags & $90 \%$ \\
13 & 3678 & Electronic Connectors & $90 \%$ \\
14 & 3594 & Fluid Power Pumps and Motors & $89 \%$ \\
15 & 3571 & Electronic Computers & $89 \%$ \\
16 & 2041 & Flour and Other Grain Mill Products & $89 \%$ \\
17 & 3841 & Surgical and Medical Instruments and Apparatus & $89 \%$ \\
18 & 2024 & Ice Cream and Frozen Desserts & $88 \%$ \\
19 & 2771 & Greeting Cards & $87 \%$ \\
20 & 3577 & Computer Peripheral Equipment, not elsewhere classified & $87 \%$ \\
\hline
\end{tabular}

Table 4-6 Electricity Spending as a Proportion of Total Energy Expenditures (\%) in 1995

\begin{tabular}{|r|r|l|r|}
\hline RANK & SIC & INDUSTRY & Electricity Share (Elec\$/Tot\$) \\
1 & 2369 & Girls', Children's and Infants' Outerwear, not elsewhere classified \\
2 & 3085 & Plastics Bottles & $98 \%$ \\
3 & 2091 & Canned and Cured Fish and Seafoods & $96 \%$ \\
4 & 3084 & Plastics Pipe & $94 \%$ \\
5 & 3334 & Primary Production of Aluminum & $94 \%$ \\
6 & 2389 & Apparel and Accessories, not elsewhere classified & $93 \%$ \\
7 & 2281 & Yarn Spinning Mills & $92 \%$ \\
8 & 3812 & Search, Detection, Navigation, Guidance, Aeronautical, and Nautical & $92 \%$ \\
9 & 2813 & Industrial Gases & $92 \%$ \\
10 & 2519 & Household Furniture, not elsewhere classified & $91 \%$ \\
11 & 3559 & Special Industry Machinery, not elsewhere classified & $91 \%$ \\
12 & 3761 & Guided Missiles and Space Vehicles & $90 \%$ \\
13 & 2282 & Yarn Texturizing, Throwing, Twisting, and Winding Mills \\
14 & 3663 & Radio and Television Broadcasting and Communications Equipment & $90 \%$ \\
15 & 3143 & Mens' Footwear, except Athletic & $90 \%$ \\
16 & 3578 & Calculating and Accounting Machines, except Electronic Computers & $90 \%$ \\
17 & 2673 & Plastics, Foil, and Coated Paper Bags & $90 \%$ \\
18 & 3678 & Electronic Connectors & $89 \%$ \\
19 & 3594 & Fluid Power Pumps and Motors & $89 \%$ \\
20 & 3571 & Electronic Computers & $89 \%$ \\
& & & $89 \%$ \\
& & $89 \%$ \\
\end{tabular}


Figure 4-1 plots economic intensity (in terms of value added per employee) versus electricity intensity (in terms of electricity consumption per unit value added) to determine which industries rank highly in both of these categories. We hypothesize that industries that rank high in both economic and electricity intensity are the most vulnerable to interruptions in electricity supply. A majority of industries produce less than $\$ 250,000$ value added per employee and use less than 1,500 $\mathrm{kWh}$ per thousand dollars of value added. Hence, although these bounds are somewhat arbitrary, we focus initially on the remaining industries as fitting our criteria for electricity supply disruption vulnerability.

Figure 4-2 shows only these industries. As in previous rankings, a few industrial categories dominate the subsector mix. Primary metals, chemicals, and food processing are among the most notable.

Table 4-7 lists the industries selected as most vulnerable to electricity supply disruptions showing total purchased electricity along with energy intensity to indicate the magnitude of each industry's susceptibility. Steel works, for example, which have a high economic and energy intensity, use 45.7 TWh per year; carbon black production, which also has high economic and energy intensities, only uses $0.5 \mathrm{TWh}$ per year.

\footnotetext{
${ }^{13}$ Note that, for ease of presentation, this figure does not include a few extreme outliers, specifically industries with SIC codes 2111, 2812, 2813, 3313, and 3334. These industries are, however, included in our subsequent analysis.
} 


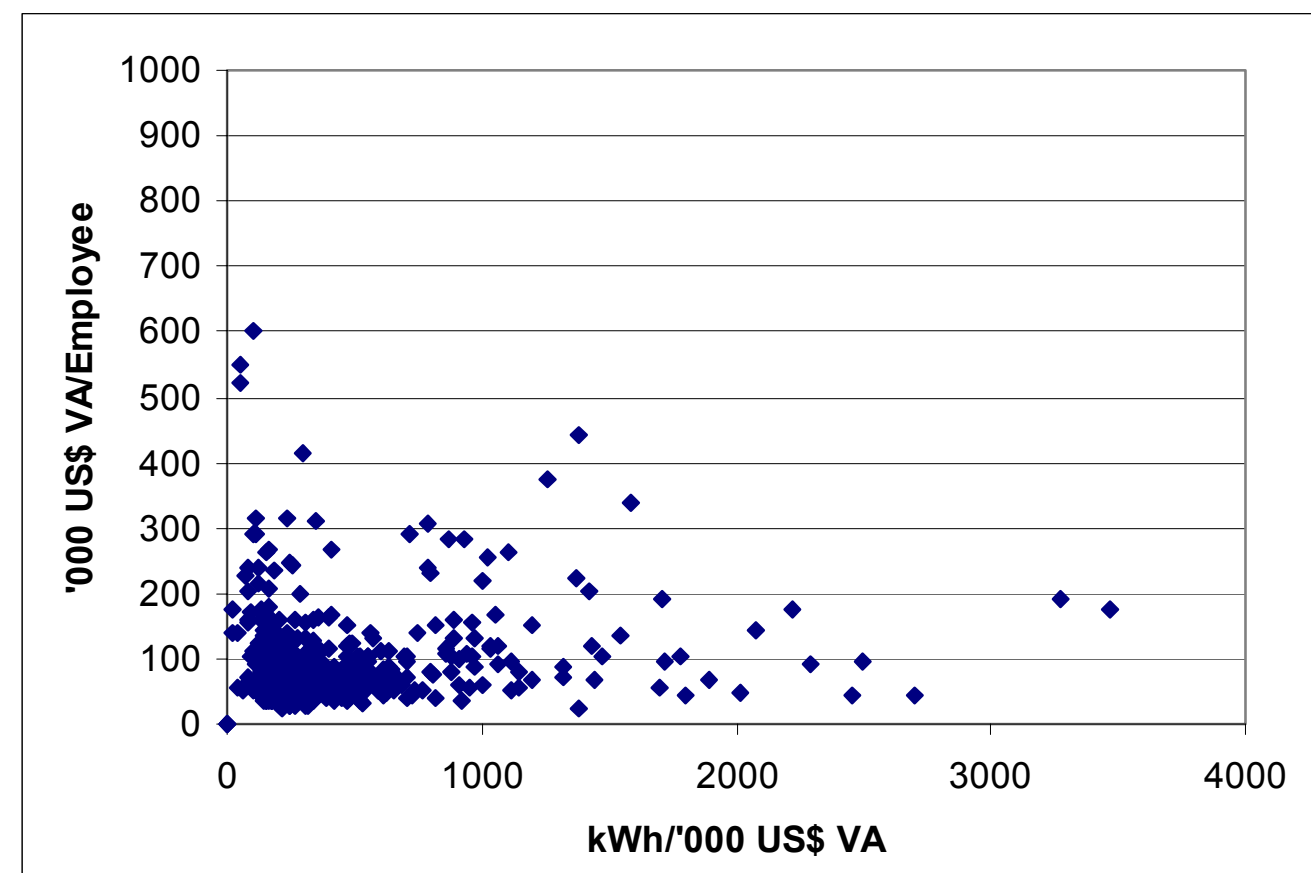

Figure 4-1. Economic Intensity ('000 US\$ Value Added/Employee) vs. Electricity Intensity (kWh/'000 US\$ Value Added) in 1995

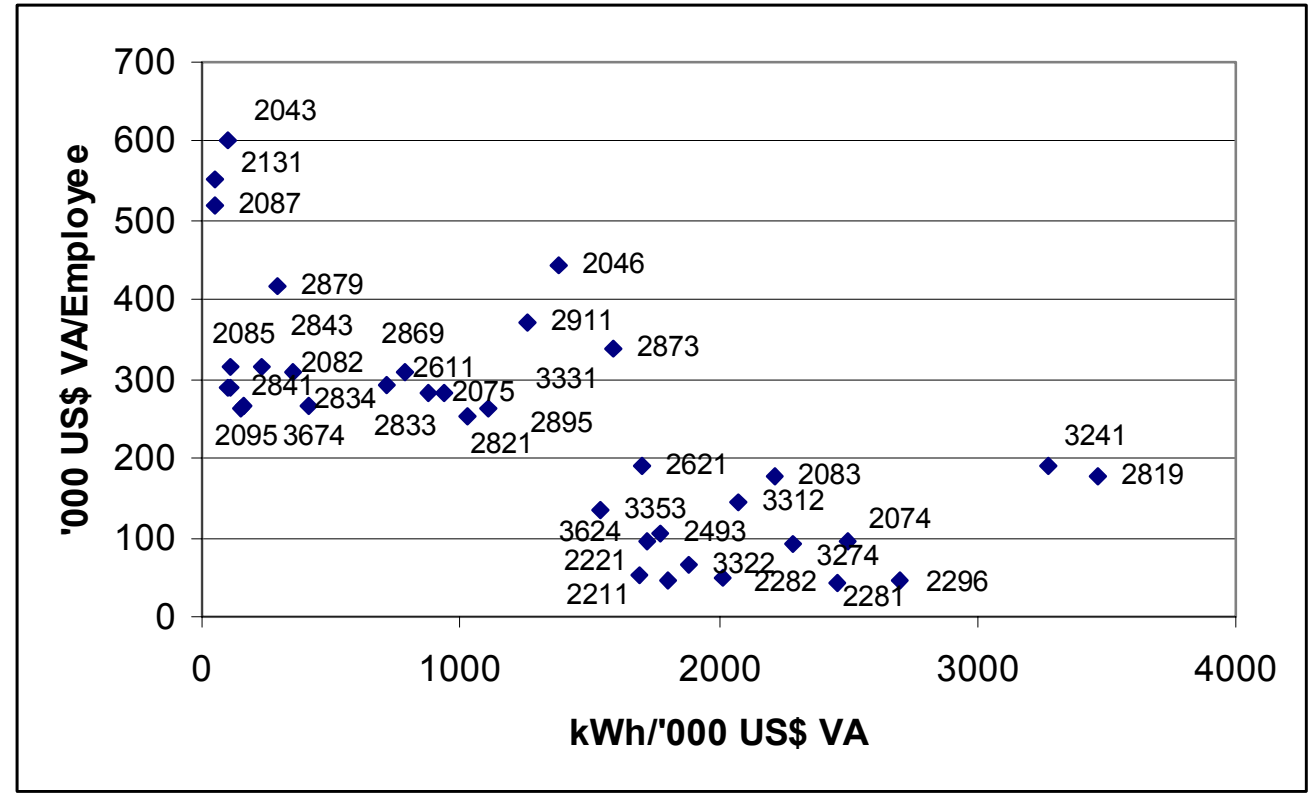

Figure 4-2. Economic Intensity ('000 US\$ Value Added/Employee) vs. Electricity Intensity (kWh/'000 US\$ Value Added) for Selected Industries in 1995 
Table 4-7. Purchased Electricity (TWh), Electricity Intensity (kWh/'000 US\$ Value Added), Economic Intensity ('000 US\$ Value Added/Employee) in 1995

\begin{tabular}{|c|c|c|c|c|c|}
\hline RANK & SIC & INDUSTRY & ELEC & $\mathbf{k W h} / \mathbf{V A}$ & VA/EMP \\
\hline 1 & 3334 & Primary Production of Aluminum & 47.8 & $16,619.9$ & 158.8 \\
\hline 2 & 3312 & $\begin{array}{l}\text { Steel Works, Blast Furnaces (including coke ovens), and Rolling } \\
\text { Mills }\end{array}$ & 45.7 & $2,075.4$ & 143.8 \\
\hline 3 & 2621 & Paper Mills & 38.4 & $1,707.7$ & 189.3 \\
\hline 4 & 2819 & Industrial Inorganic Chemicals & 36.1 & $3,465.9$ & 176.8 \\
\hline 5 & 2911 & Petroleum Refining & 33.1 & $1,260.7$ & 372.8 \\
\hline 6 & 2869 & Industrial Organic Chemicals, not elsewhere classified & 22.2 & 786.0 & 307.3 \\
\hline 7 & 2813 & Industrial Gases & 19.9 & $7,891.0$ & 311.4 \\
\hline 8 & 2821 & $\begin{array}{l}\text { Plastics Materials, Synthetics Resins, and Nonvulcanizable } \\
\text { Elastomers }\end{array}$ & 18.2 & $1,026.1$ & 254.1 \\
\hline 9 & 2812 & Alkalies and Chlorine & 13.8 & $8,552.3$ & 264.0 \\
\hline 10 & 3241 & Cement, hydraulic & 10.5 & $3,273.8$ & 190.8 \\
\hline 11 & 3674 & Semiconductors and Related Devices & 8.4 & 163.9 & 265.1 \\
\hline 12 & 2221 & Broadwoven Fabric Mills, Manmade Fiber and Silk & 7.3 & $1,694.8$ & 54.0 \\
\hline 13 & 2281 & Yarn Spinning Mills & 7.0 & $2,453.4$ & 44.2 \\
\hline 14 & 2046 & Wet Corn Milling & 5.6 & $1,384.2$ & 442.5 \\
\hline 15 & 3339 & $\begin{array}{l}\text { Primary Smelting and Refining of Nonferrous Metals, except } \\
\text { Copper and Aluminum }\end{array}$ & 5.2 & $5,268.6$ & 105.3 \\
\hline 16 & 3353 & Aluminum Sheet, Plate, and Foil & 4.8 & $1,543.3$ & 135.9 \\
\hline 17 & 2834 & Pharmaceutical Preparations & 4.8 & 115.6 & 289.2 \\
\hline 18 & 2493 & Reconstituted Wood Products & 4.7 & $1,775.4$ & 105.2 \\
\hline 19 & 2211 & Broadwoven Fabric Mills, Cotton & 4.5 & $1,801.7$ & 45.2 \\
\hline 20 & 2873 & Nitrogenous Fertilizers & 3.9 & $1,587.6$ & 337.3 \\
\hline 21 & 3313 & Electrometallurgical Products, except steel & 3.4 & $9,439.8$ & 89.0 \\
\hline 22 & 2611 & Pulp Mills & 2.8 & 713.6 & 292.3 \\
\hline 23 & 2082 & Malt Beverages & 2.4 & 233.9 & 316.2 \\
\hline 24 & 2075 & Soybean Oil Mills & 1.8 & 874.1 & 282.0 \\
\hline 25 & 2879 & Pesticide and Agricultural Chemicals, not elsewhere classified & 1.8 & 296.0 & 416.3 \\
\hline 26 & 3331 & Primary Smelting and Refining of Copper & 1.7 & 933.6 & 283.9 \\
\hline 27 & 2282 & Yarn Texturizing, Throwing, Twisting, and Winding Mills & 1.7 & $2,011.3$ & 47.8 \\
\hline 28 & 3624 & Carbon and Graphite Products & 1.6 & $1,721.2$ & 94.6 \\
\hline 29 & 2833 & Medicinal Chemicals and Botanical Products & 1.6 & 414.0 & 265.0 \\
\hline 30 & 2111 & Cigarettes & 1.1 & 49.8 & $1,107.7$ \\
\hline 31 & 3274 & Lime & 1.1 & $2,288.4$ & 91.0 \\
\hline 32 & 2043 & Cereal Breakfast Foods & 1.1 & 105.7 & 601.1 \\
\hline 33 & 2841 & Soap and other Detergents, except Specialty Cleaners & 1.0 & 103.7 & 289.3 \\
\hline 34 & 2843 & $\begin{array}{l}\text { Surface Active Agents, Finishing Agents, Sulfonated Oils, and } \\
\text { Assistants }\end{array}$ & 0.9 & 351.5 & 310.3 \\
\hline 35 & 2296 & Tire Cord and Fabrics & 0.6 & $2,696.5$ & 45.1 \\
\hline 36 & 2895 & Carbon Black & 0.5 & $1,109.1$ & 262.2 \\
\hline 37 & 2074 & Cottonseed Oil Mills & 0.5 & $2,499.3$ & 96.1 \\
\hline 38 & 2083 & Malt & 0.5 & $2,219.1$ & 177.3 \\
\hline 39 & 2095 & Roasted Coffee & 0.4 & 150.4 & 262.9 \\
\hline 40 & 3322 & Malleable Iron Foundries & 0.4 & $1,888.2$ & 67.1 \\
\hline 41 & 2087 & Flavoring Extracts and Flavoring Syrups, not elsewhere classified & 0.3 & 53.2 & 520.5 \\
\hline 42 & 2085 & Distilled and Blended Liquors & 0.2 & 111.8 & 315.1 \\
\hline 43 & 2131 & Chewing and Smoking Tobacco and Snuff & 0.1 & 53.4 & 551.7 \\
\hline
\end{tabular}




\subsection{Discussion}

We have used aggregate information on electricity use, economic productivity, and related factors to prepare a direct assessment of industrial sectors that are highly dependent on electricity. Dependence on electricity, measured in this fashion, is suggested as a proxy for identifying and tracking industrial sectors with high reliability requirements.

While this approach has allowed us to identify 47 industrial sub-sectors that would appear to have high reliability requirements, we believe that these indicators must be complemented by more detailed examinations in order to better understand how these requirements translate into values for the cost of reliable electricity for the economy.

There are inherent limitations in using data from the four-digit SIC categories. The relatively heterogeneous nature of some of the SIC groupings means that it is difficult to accurately describe the industries represented. For example, SIC 3674, "semiconductors and related devices," includes establishments engaged in manufacturing such disparate products as diodes, fuel cells, solid-state memories, microprocessors, photovoltaic devices, random access memories, and solar cells. It is likely that there are differences in energy consumption and economic output within each of these specific subindustries. Thus, it is difficult to describe some of the industries discussed in this paper with a high level of accuracy because an amalgamation of products and processes is included in the relevant SIC category. Data are collected for the more detailed five-digit and six-digit categories, but these data are not currently available historically in electronic format.

More importantly, aggregate indicators (and hence conclusions drawn solely from the findings in this section) are incomplete measures of the value of reliability in several important respects. As noted in Section 2, the ratio of economic productivity (such as value of shipments or value added) to electricity use is sometimes used as a direct measure of the value of reliability. However, Section 2 also identified several aspects of electricity interruptions that have material effects on the costs of unreliable electricity, including duration/frequency of the outage/power quality problem, amount/type of advance warning, ability to make-up for lost production through overtime/extra shifts (net of additional costs), and interdependencies with other upstream and downstream market participants.

A key facet of reliability from the viewpoint of customers is the sensitivity of equipment to power quality problems. Equipment that is sensitive to power quality includes all equipment that uses rectifiers, e.g., micro-processor-equipped equipment like adjustablespeed drives (ASDs). This equipment is not only sensitive to disruptions, but the rectifier also introduces harmonic distortion.

ASDs are a prime candidate for further study. In 1994, ASDs were used in 4.4 percent of industrial motors, equivalent to an electricity consumption of about $11 \mathrm{TWh}$ (Xenergy 1998). The potential growth of this market is estimated at 14 percent of industrial motor 
use (equivalent to $78 \mathrm{TWh}$ ). Yet, not all ASD designs are vulnerable to harmonics. The majority of modern ASDs are less vulnerable to power quality disruptions. Pulse width modulated (PWM) drives are less sensitive to harmonics and do also not cause harmonic problems. PWMs are the state of the art in ASD design, so harmonics can be expected to have less of an impact on ASD use in the future. However, filters may still be used to reduce harmonic problems. PWMs are still sensitive to peak current problems.

In summary, aggregate indicators alone do not provide information on sensitivity of electricity using equipment to loss of power or poor power quality, the specific impacts of loss of power or poor power quality on economic productivity, or finally efforts firms may have already taken to mitigate these potential impacts. It is in this context that the information in the following Sections 5 and 6 compliments this Section.

\subsection{Key Findings and Recommendations for Next Steps}

We implemented a direct approach to better understand the variations in sensitivity to power-quality and reliability issues among industrial subsectors. Specifically, we developed and evaluated statistical indicators for high-reliability-requirement customer market segments based on aggregate data on industrial sector electricity use and economic activity.

Key Findings:

1. We identify 43 industries likely to be most susceptible to economic harm from disruptions in electricity supply. Together these industries consume almost 370 $\mathrm{TWh} / \mathrm{yr}$.

2. The method provides a direct approach for identifying high-reliability-requirement market segments in the U.S. economy. Nevertheless, it should be recognized that these data by themselves cannot be used to formulate mitigation strategies to address these requirements or to find the particular electricity uses in those sectors that have high reliability demands.

3. The method is not sufficient to provide information on the need for high quality power needs, aside from the possibility of economic damage resulting from delivery disruptions.

4. To identify specific electricity applications with high reliability requirements a bottom-up analysis is needed. A bottom-up analysis would start by identifying the electricity end uses that are most sensitive to changes in power quality, e.g. adjustable-speed drives (ASDs).

Recommendations for Next Steps:

1. Extend the analysis to consider the specific process steps in the 47 industry segments. The steps in the manufacturing process of these industries vary in electricity demand and power quality needs and hence in vulnerability to disruptions in power supply or quality. To better understand the vulnerability issues facing these industries, a more detailed understanding of the underlying electricity consuming processes is required. This "bottom-up" analysis should start by looking at technologies with high power 
quality and availability demands, e.g., sensitive equipment in critical phases of production processes.

2. The NAICS system should be reviewed. There are inherent limitations in using data from the four-digit SIC categories. The relatively heterogeneous nature of some of the SIC groupings means that it is difficult to accurately describe the industries represented. 


\section{High Reliability Requirements Case Study - Cleanrooms}

A final approach to studying customers with high reliability requirements involves identification of particular end-use functions, which are both vulnerable to electricity interruptions and power quality problems, and common to more than one industry. This is an intermediate approach between the highly dis-aggregate examination of office equipment (Section 3 ) and the highly aggregate review of industrial subsectors (Section 4).

As an example of this approach, we review the importance of electricity reliability to cleanrooms, which typically combine production of highly valuable products (e.g., computer chips) with $24 / 7$ operation. We describe the diversity of cleanroom types and applications (by industry), the costs of power disruptions, and risk-management strategies currently in use. We propose this case study as a model for future case studies of other high-reliability-requirement processes or industries.

\subsection{Overview of Cleanrooms}

Cleanrooms are specially constructed enclosed areas that are environmentally controlled for airborne particulates, air-flow patterns, air motion, temperature, humidity, and lighting. Cleanrooms are sealed, with specialized air-handling and filtration systems to minimize static electricity and the concentrations of particles or other contaminants that could interfere with manufacturing, medical operations, scientific research, and other activities. Typically, cleanrooms produce a vertical laminar flow of air throughout a large area. The air is filtered, and contaminants are purged through this large continuous flow of air. Because of the need for high, controlled air velocities, along with regulation of other environmental factors within tightly prescribed limits, cleanrooms use large amounts of energy.

Cleanrooms can be divided into two general categories: those that maintain aseptic environments designed to minimize bacterial contamination, such as in pharmaceuticals manufacturing and hospitals, and those requiring extremely clean air without special regard for bacterial contamination (non-aseptic), such as in computer chip manufacturing.

Table 5-1 lists an example of hospital cleanroom standards based on levels of contamination. Hospital cleanroom standards for bacterial exposure are often expressed as colony forming units (CFUs) per unit volume. CFUs are usually larger than one micron, and they are effectively controlled by HEPA (high-efficiency particulate air) filters. Aseptic clean room design and construction firms are relatively few in number; a larger number of firms construct the non-aseptic facilities typical in semiconductor manufacturer and other industries (MSS Clean Technology 2000).

Table 5-2 shows the classes of cleanroom and their typical applications. Non-aseptic cleanrooms are usually defined in terms of six "classes:" 1, 10, 100, 1,000, 10,000, and 100,000 . The number stands for the maximum number of particles greater than or equal 
to 0.5 micrometers (microns) permitted per cubic foot of air. Thus, in a Class 100 cleanroom, there can be no more than 100 particles of this size per cubic foot. Subclass 1 cleanrooms are now coming into use and are the most energy-intensive of all cleanroom types.

Table 5-1. Hospital Cleanroom Standards

\begin{tabular}{|l|l|}
\hline Level of Cleanliness $\left(\mathbf{C F U} \mathbf{s} \mathbf{m}^{\mathbf{2}}\right)$ & Applications \\
\hline Less than 10 & $\begin{array}{l}\text { Special operating theatres for transplants, } \\
\text { heart surgery, burn wards, etc. }\end{array}$ \\
\hline $50-200$ & $\begin{array}{l}\text { Typical operating theatres, incl. those for } \\
\text { accident surgery }\end{array}$ \\
\hline $200-500=$ outside airs germ level & $\begin{array}{l}\text { Intensive care for coronary patients, } \\
\text { delivery rooms, emergency wards }\end{array}$ \\
\hline Patients' rooms with contaminated air & Infection wards \\
\hline Other rooms & \\
\hline
\end{tabular}

Source: Mills et al. 1996

Table 5-2. Cleanroom Classes and Typical Applications

\begin{tabular}{|l|l|}
\hline Class & Typical Application \\
\hline 1 & Integrated circuit manufacturing, sub-micron scale \\
\hline 10 & $\begin{array}{l}\text { Integrated circuit manufacturing, two microns or below; allograft tissue } \\
\text { processing }\end{array}$ \\
\hline 100 & $\begin{array}{l}\text { Manufacture of injectible medicines; aseptic pharmaceutical packaging; } \\
\text { selected surgical operations and other hospital functions; integrated circuit } \\
\text { manufacturing; dairy products; isolation of immuno-suppressed patients }\end{array}$ \\
\hline 1,000 & $\begin{array}{l}\text { High-quality optical equipment; assembly of precision instruments; assembly } \\
\text { of miniaturized bearings }\end{array}$ \\
\hline 10,000 & $\begin{array}{l}\text { Precision hydraulic/pneumatic equipment assembly, precision timing } \\
\text { devices; high-grade gearing; servo-control valves }\end{array}$ \\
\hline 100,000 & $\begin{array}{l}\text { General optical work; electronic device and component assembly; } \\
\text { hydraulic/pneumatic assembly; printing and photographic work. }\end{array}$ \\
\hline
\end{tabular}

Source: Mills et al. 1996

Table 5-3 lists the SIC codes of a variety of industry segments that use cleanrooms. Although typically associated with semiconductor manufacturing, cleanrooms are currently used in connection with hundreds of products or processes. 
Table 5-3. Standard Industrial Classification (SIC) for Industries that Use Cleanrooms*

\begin{tabular}{|l|l|l|l|}
\hline SIC & Industry & SIC & Industry \\
\hline 202 & Dairy industry & 3669 & Other \\
\hline 2026 & Milk and yogurt & 367 & Electronic components and accessories \\
\hline 203 & $\begin{array}{l}\text { Canned, frozen and } \\
\text { preserved food }\end{array}$ & 3671 & Electron tubes \\
\hline 275 & Commercial printing & 3672 & Printed circuit boards \\
\hline 283 & Pharmaceuticals & 3674 & Semiconductor devices \\
\hline 2833 & Medical chemicals & 3695 & Magnetic and optical recording media \\
\hline 2834 & Pharmaceutical preparations & 3711 & Automotive manufacturing (spray painting) \\
\hline 2835 & In-vitro preparations & 38 & Instruments \\
\hline 2836 & Biological products & 3812 & Navigation instruments \\
\hline 357 & $\begin{array}{l}\text { Computer and office } \\
\text { equipment }\end{array}$ & 3823 & Industrial instruments \\
\hline 3571 & Electronic computers & 3827 & Optical instruments \\
\hline 3572 & Computer storage devices & 3841 & Surgical and medical \\
\hline 3575 & Computer terminals & 3851 & Ophthalmic goods \\
\hline 3577 & Computer peripherals & 3861 & Photographic goods \\
\hline 3578 & Calculating and accounting & 3873 & Clocks and watches \\
\hline 3579 & Office machines & 8221 & Universities and colleges \\
\hline 366 & Communication equipment & 8062 & General medical and surgical hospitals \\
\hline 3661 & Telephones & 8071 & Medical laboratories \\
\hline 3663 & Radio and TV & & \\
\hline
\end{tabular}

* SIC codes based on 1987 classifications. The U.S. has now moved to the use of the North American Industrial Classification System (NAICS). The translation of particular sectors from the SIC to the NAIC is not always direct. For more information see http://www.census.gov/epcd/www/naics.html, Also, not all sectors listed in the table were accounted for in the McKilvane data used for Figure 1 below.

Although Class 100,000 represents one of the largest segments of the cleanroom market in terms of floor area, it is far less energy intensive than the higher classes. The fastestgrowing type is also the most energy-intensive type (Class 1-10), and within this class, floor area is projected to grow most quickly in the Pharmaceutical/Biotechnology segment. The fastest growing industry segment is the miscellaneous category, which includes non-traditional applications of cleanrooms, as described below. The miscellaneous category is apportioned approximately as follows: 20 percent aerospace, 20 percent food, 20 percent hospital and medical devices, and 40 percent other. ${ }^{14}$

Figure 5-1 characterizes the U.S. cleanroom market, both in terms of distribution according to class and according to major industry segment. The total estimated floorspace for cleanrooms in 2000 was 24.6 million square feet (as shown in the figure) with an expected growth of more than 10 percent annually (Mcllvane Co 1996). As of the

${ }^{14}$ Personal communication, Robert W. McIlvaine, McIlvaine Co., 19 September 1995. 
early 1990s, Texas had the largest stock of cleanroom space, followed by California (Mills et al. 1996). For the electronics manufacturing segment, California was the lead state, exceeding the second state (New York) in floorspace by a factor of two.

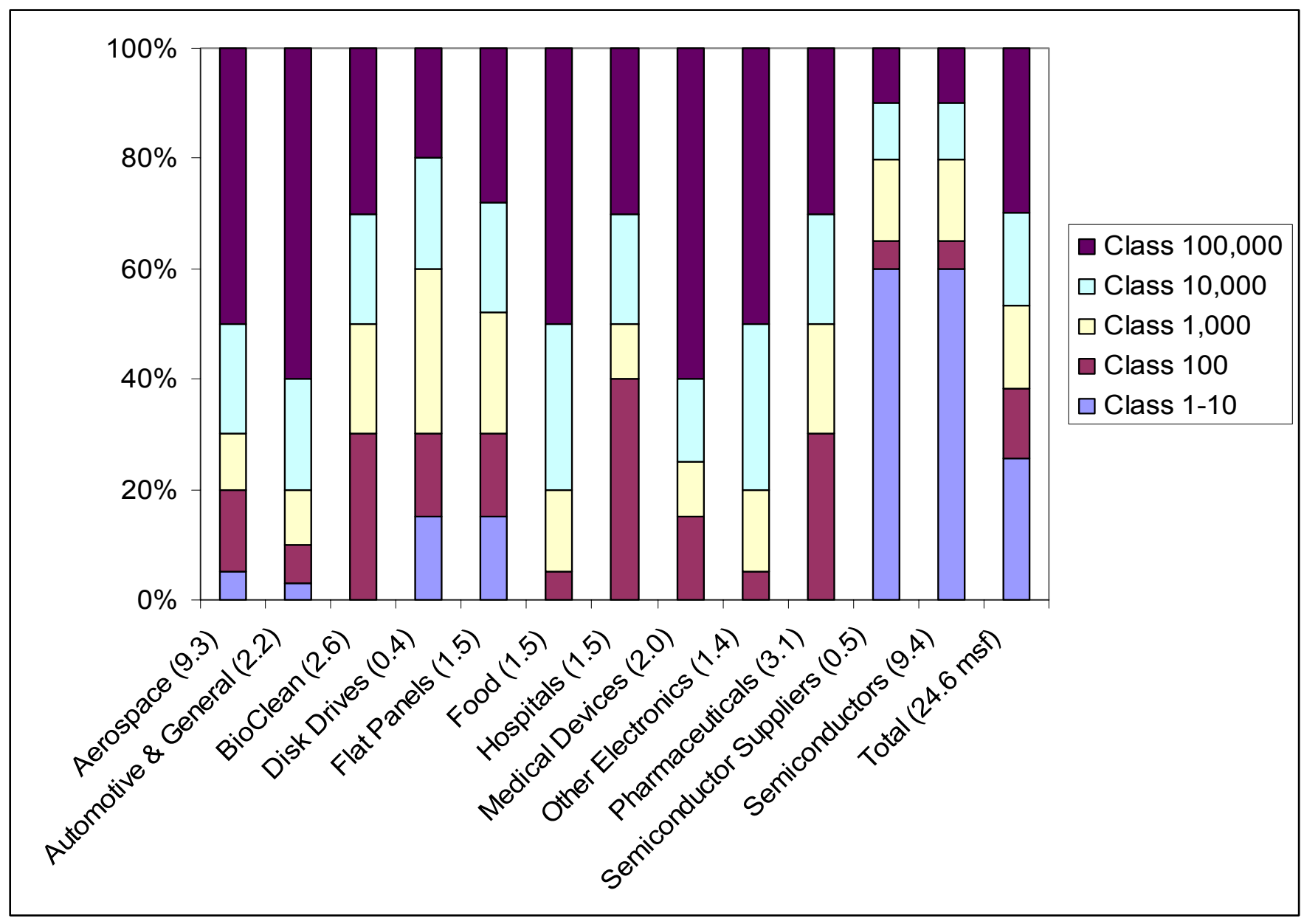

Figure 5-1. U.S. Cleanroom Type by Industry Segment. Source: McIlvane $1996^{15}$

\footnotetext{
${ }^{15}$ Note: The McIlvaine data omit certain industrial activities that take place in cleanrooms. Some manufacturing activities in SIC codes 38 (instruments) and 35 (computer and office equipment) require cleanroom conditions. Among the manufacturers included in these categories are those for navigational, optical, and photographic instruments (under SIC 38) and high-capacity disk drives (SIC 35). These activities represent an extremely small percentage of the total cleanroom activity. However, McIlvaine estimates that 75 percent to 80 percent of California's cleanroom activity is accounted for by the manufacture of semiconductors and electronic components and by pharmaceuticals, either for biotechnology or the aseptic packaging of drugs. No more than 5 percent each remains for such categories as long-shelf-life dairy products, instruments, and electronic office equipment not including semiconductors and electronic components.
} 


\subsection{Cleanroom Energy Use}

Overall energy consumption for cleanrooms is not reported in national statistics. HVAC electricity intensities can range from $150-950 \mathrm{kWh} / \mathrm{sf}$ depending on the level of cleanliness required in the cleanroom environment. Based on detailed analysis of hightech facilities in California (Mills et al.1996), we estimate cleanroom electricity consumption for HVAC in 2000 at $12 \mathrm{TWh} /$ year across all classes, based on an average weighted energy intensity of $480 \mathrm{kWh} / \mathrm{sf}$. Energy used by the equipment in cleanrooms varies widely depending on the activities and processes involved. Figure 5-2 identifies HVAC electricity consumption by cleanroom market segment based on Mills et al. (1996). As the figure indicates, semiconductors and related industries account for twothirds of all cleanroom HVAC electricity consumption.

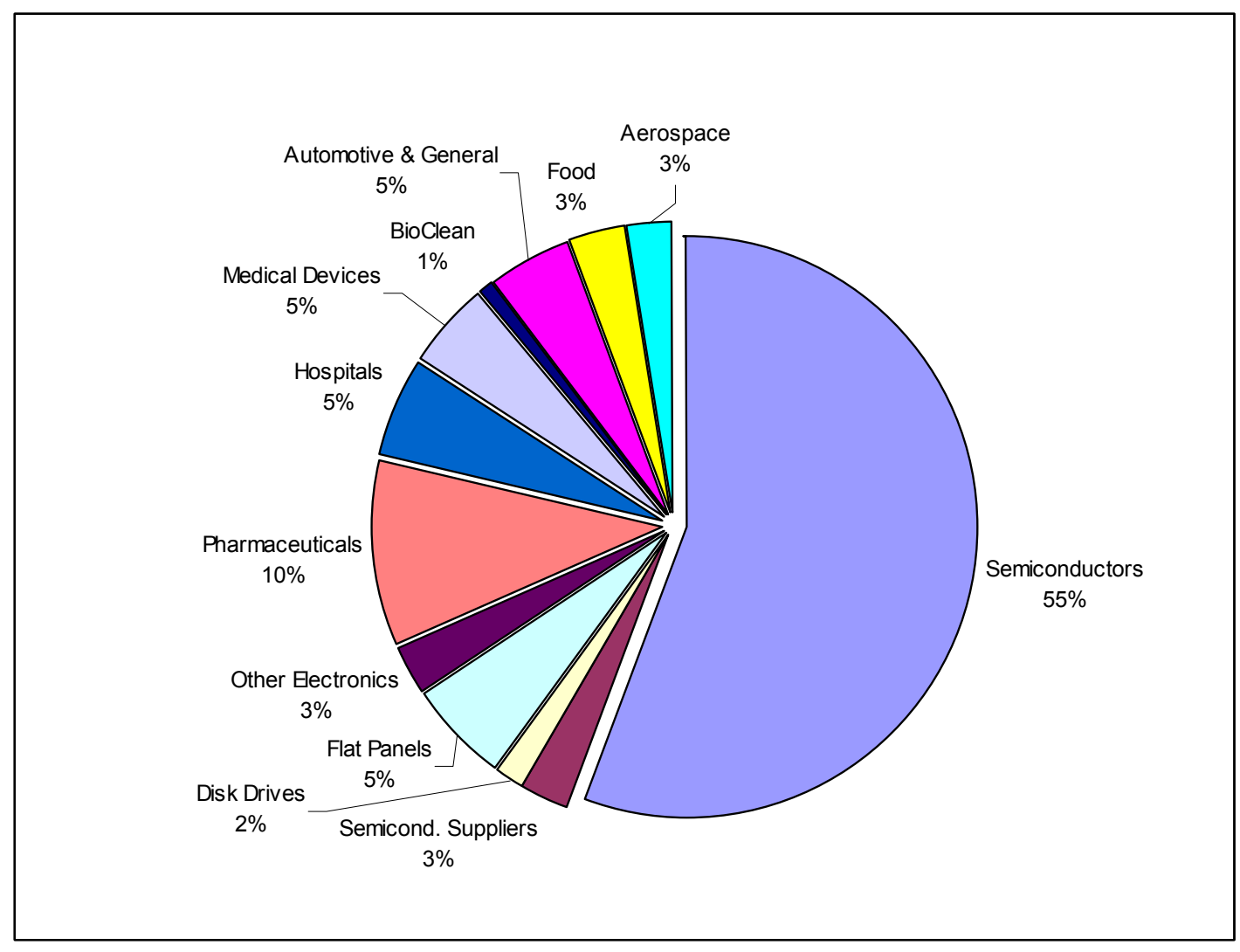

Figure 5-2: Share of HVAC Electricity Consumption for Cleanrooms

Note: electricity consumption intensities are based on the assumption of 24-hour operation.

The Annual Survey of Manufacturers (U.S. Department of Commerce 1995) reports an electricity consumption of 8,404 million $\mathrm{kWh}$ for semiconductors and related devices (SIC 3674). The Mcllvane data for that year report a square footage of $5.638 \mathrm{msf}$, giving an electricity intensity of $1,490 \mathrm{kWh} / \mathrm{sf}$. One can compare this to our calculated weighted average HVAC electricity intensity for this category of $700 \mathrm{kWh} / \mathrm{sf}$; subtract these two figures and one can conclude that the energy not used for space conditioning is consumed by manufacturing equipment (a very small portion goes to lighting). This would imply, at 
least for semiconductors, a total electricity consumption in 2000 of 14 TWh or 146 TBTU on a primary energy basis for this segment. We estimate a total primary energy consumption of 230-260 TBTU for 2000.

\subsection{Cleanrooms in Manufacturing Settings}

In manufacturing settings, cleanrooms are most commonly associated with production of semiconductor-based integrated circuits (ICs) and other electronic components, and with the pharmaceutical and biotechnology industries. The latter includes the manufacture of traditional pharmaceuticals, biotechnology-derived products, and the aseptic (sterile) packaging of these products. Together, these industries account for more than 70 percent of cleanroom square footage in the U.S. The IC manufacturers in particular require the highest standards of cleanliness and are most associated with efforts to advance the state of the art to a level beyond Class 1 . It is also likely that the IC manufacturers require some of the highest standards of reliability in electricity supply although more research would be needed to confirm this. Although semiconductor manufacturing receives considerable attention, the importance of electricity reliability to other cleanroom segments should not be understated. Production value is also quite high in the pharmaceutical sector, for example, and supply chain vulnerabilities in the electronics manufacturing sector have considerable vulnerability to power (and thus manufacturing) disruptions.

Other industries use cleanrooms, although with less rigorous cleanliness standards than the semiconductor and pharmaceutical industries. Instrumentation manufacture, including fine optical, navigation, and aerospace components and systems, requires clean conditions as do standards laboratories, and photographic-developing and high-quality printing facilities. In addition to integrated circuits, electronic devices such as circuit boards, disk drives, flat panel displays, computers, and consumer electronics require clean conditions for manufacture. Chemical manufacturing requires cleanliness to make high-purity products. Automobile manufacturers are increasingly using cleanroom conditions to produce highquality paint finishes on their cars as well as more defect-free parts.

Cleanrooms are becoming increasingly common in the food industry. Long-shelf-life dairy products such as milk and yogurt, often stored at room temperature in groceries, have been common in Europe for years, and their popularity is growing in the U.S. Manufacturing requires clean conditions to keep the products free of pathogenic bacteria. Cleanrooms also have applications for other types of food processing, such as making orange juice and packing meat and chilled foods.

As noted in Table 5-1, cleanrooms are used in hospital operating rooms and other healthcare environments ranging from burn wards to intensive care rooms to delivery rooms. The focus in these environments is on controlling patient and worker exposure to bacteria and viruses. Viral particles are much smaller than bacteria, ranging from 0.003 to 0.05 microns; no filters are known to be effective against viruses. Hospitals generally aim for Class 100 conditions in operating rooms, and cleanroom conditions are increasingly being sought for other types of hospital environments as well. 


\subsection{The Semiconductor Industry}

Based on the large share of cleanroom energy consumed for semiconductor manufacture, we focus our discussion of reliability on this industry segment. Semiconductor fabrication facilities account for the vast majority of integrated circuit manfuacturing at the submicron scale in the U.S. (Class 1-10 cleanrooms). Globally the semiconductor industry is a $\$ 200$ billion market and growing rapidly, with the North American market estimated at around \$60-70 billion (Wassmer and Frey 1999; Semiconductor Industry Association 2000).

The construction cost for a semiconductor fabrication facility is $\$ 1.2$ to 1.5 billion (Wassmer and Frey 1999). The value of output is dependent on the product produced. The value of a fabricator's in-process inventory at any given time can easily exceed $\$ 30$ million, and the monetary impact of a one-day business interruption is typically more than $\$ 1.0$ million.

Energy expenditures in a typical fabrication facility are small; typically one to two percent of total operating costs (Mannion 2000). However, because of the exceptionally high value of production and 24/7 operation, electric power interruptions result in substantial costs both through reduced output and possible damage to goods or equipment (Brown 1996).

Recent estimates for the semiconductor industry suggest that the breakdown of electricity systems amounted to 7 percent of industry losses between 1986 and 1995 (Wassmer and Frey 1999; D’Esposo 1997). These same data suggest that the losses were at least $\$ 1.4$ billion.

\subsection{Electricity Reliability and Semiconductor Manufacturing ${ }^{16}$}

Electricity outages have affected cleanroom operations in several states. The losses can sometimes be evaluated in terms of damage. For each initial loss of power, there is often a substantial cost. The longer the outage continues, the more costs can accrue from ongoing lost production. It is likely the damage function for facilities with rigorus cleanroom environments is fairly steep (Fairfax 2000). Power interruptions of as little as two hours have resulted in losses of wafers (losses that the plant operators declined to quantify, but which are assumed to be economically significant).

- During outages on August 10, 1996, cleanroom fabricators in five states experienced power disruptions (Brown 1996). National Semiconductor, Applied Materials, LSI Logic, and KLA instruments had uninterruptible power supplies in place; Intel and Motorola did not, and both suffered losses. Motorola states that "The amount of back-up you would have to contain at each [fabrication facility] would be tremendous. The cost would exceed anything we or any other big company would be willing to

\footnotetext{
${ }^{16}$ The information in this section supplements the more comprehensive information in the outage cost literature review (Section 2).
} 
pay," while Fugitsu and HP said they had no plans (in Oregon) to take preventive measures given the rarity of outages (Brown 1996).

- The Intel plant in Chandler, Arizona lost grid electricity when a crane severed the connection to the plant's utility feeders. The backup-power systems (UPSs and batteries) burned themselves out and the plant lost 1,000 eight-inch wafers, which represents a significant investment (Fairfax, 2000; Robertson, 2000).

- An 18-hour power outage at a fabrication facility in Texas cost the company about $\$ 1.5$ million (Robertson 2000).

- A recent rolling blackout in the greater San Francisco Bay Area caused an estimated $\$ 75$ million in losses in Silicon valley, some of this connected to cleanroom operation (Mannion 2000).

These losses are not confined to the specific fabrication facilities where the power outages occurs, because production operations and supply chains are global, a disruption in the supply chain in North America can affect production and output in other regions.

\subsection{Current Strategies For Electricity Reliability Risk Management}

Although some cleanroom fabrication facilities spend money on back-up power, there is anecdotal evidence that the industry's willingness to invest in reliability, even with two year paybacks is somewhat limited (Fairfax 2000; Robertson 2000). At the same time, there is definitely a strong concern about and expectation of reliable sources of power. One consultant who surveyed fabrication managers about electricity reliability found that they would like to be able to expect from one to three hours of an outage over the next decade. This translates into a reliability requirement of nearly "5 nines" (99.999\%)-- very high performance criteria (Fairfax 2000).

According to the Annual Survey of Manufacturers, capital expenditures by the semiconductor industry are on the order of $\$ 10$ billion annually, mainly on fabrication equipment (U.S. Department of Commerce 1998). However, many fabrication facilities spend one percent or less of their capital budget on UPS's, and the expenditure is often dedicated to control systems, not to process equipment or tools (Fairfax 2000; Brown, 1996; Robertson 2000). A key explanation for this apparent low level of investment is that reliability expenditures are embedded in the original construction cost of the facilities and thus not a part of on-going capital expenditures for reliability.

Still, another part of the reasoning for this approach is that the investment in back up power for tools (e.g. large infrared heaters) may be viewed as unjustifiably expensive. Investment in back-up for computer controls (i.e., process programming) means saving the time-consuming step of reprogramming complex production algorithms after an outage, so it is viewed as justified. Tools, by contrast, can more easily be cleaned out after an outage and prepared for a new run. Obviously, frequency of occurrences traceable to power quality or reliability events plays a major role in these assessments. For example, given the recent dramatic changes in electricity markets in California, it is likely that the industry's willingness to invest will increase significantly. 
Aside from investing in back-up power semiconductor manufacturers can manage the power outage by establishing consistent standards for power sag tolerance for the key equipment at fabrication facilities. This is the case with a company called Semi, a producer of equipment, in conjunction with SRP utility in Arizona. By working with the utility, the company hopes to avoid expensive downstream investment in additional backup power systems (Farifax 2000).

Finally, clean room facilities are good candidates for the development of off-grid electricity systems fueled by combined heat and power turbine or fuel cell systems. Companies like Sure Power are specializing in marketing fuel cell systems to this industry segment, but it is not clear whether the clean-room industry is willing to make the investments necessary.

\subsection{Key Findings and Recommendations for Next Steps}

We have reviewed the importance of electricity reliability for cleanrooms, which typically combine production of highly valuable products (e.g., computer chips fabrication) with $24 / 7$ operation. We describe the diversity of cleanroom types and applications (by industry), the costs of power disruptions to cleanrooms, and risk-management strategies currently in use.

Key Findings:

1. Cleanrooms are a fast-growing part of the industrial sector; floorspace growth rates are forecasted at greater than $10 \%$ annually.

2. While cleanrooms are typically associated with high-tech manufacturing (production of semiconductor-based integrated circuits and other electronic components, and with the pharmaceutical and biotechnology industries), they are found throughout many other sectors, ranging from optics, to food, to medical settings. Cleanrooms can be found in at least 37 SIC categories.

3. Primary energy consumption for cleanrooms is estimated at 230-260 TBTU/yr.

4. Semiconductor manufacturing and related industries account for two-thirds of cleanroom heating, ventilation, and air conditioning (HVAC) electricity use.

5. Class 1-10 cleanrooms, which include those used for semiconductor manufacturing, tend to have high reliability demands and can experience significant losses from disruptions in electricity service.

6. While some cleanroom fabrication facilities do spend money to support backup power for improved power quality and reliability, there is anecdotal evidence that over the past decade the willingness of industry to invest in reliability, even with two-year paybacks, may be limited.

Recommendations for Next Steps:

1. Explore current strategies for risk management in the industry and what motivates the investment in backup power or off-grid electricity systems. Given the possibility of rolling blackouts in the summer of 2001, it may be useful to track back-up power investment activity with selected manufacturers throughout this period. 
2. National energy consumption data for cleanrooms are extremely limited. Given the importance of this rapidly changing market segment, it would be useful to periodically update the energy use estimates presented in this section as well as to evaluate the potential for load management in the sector. 


\section{An Insurance Perspective on Electric Power Reliability Issues}

A final perspective on the costs of electricity reliability to the US economy involves developing a comprehensive inventory of the range of options (technological, operational, and financial) currently available to customers and information on their current satisfaction with these options. EPRI has already conducted a number of studies on specific technological and operational options for addressing customer's reliability needs, such as back-up generation, uninterruptible power supply (UPS) systems, and other power-quality-enhancing technologies and approaches.

We complement EPRI's existing work with new information on insurance as an indicator of the costs of electricity outages and reliability problems, and as a strategy for managing risk. From an electricity end user's perspective, purchasing insurance is one way to manage the economic risks of power interruptions. Insurers are accordingly interested in collecting data and promoting risk-management or "loss-control" strategies to reduce the likelihood or magnitude of losses in the event of power outages. Insurers' own operations are also increasingly vulnerable to power outages given the central role played by computer systems that are vulnerable to outages.

In this section, we: 1) review the relevance of electricity reliability for North American insurers and look at how the issue is regarded today within the industry; 2) describe the specific types of insurance that address reliability-related incidents (e.g., property, business interruption, machinery breakdown);3) describe the nature of events triggering electricity reliability losses; and 4) provide selected examples of electricity reliability risk management tools used by insurers.

\subsection{Overview}

Focusing on the relationship of insurance to electricity reliability is relevant and timely because custemer vulnerabilities to outages are growing, recent legal decisions include "data losses" 17 as claimable property damages under conventional property insurance policies, and some natural hazards that trigger power outages may be on the rise. Businesses are also increasingly vulnerable to interruptions to the distribution chain (Webb et al. 2000), e.g., as a result of "just-in-time" inventory management (Zolkos 1998, Zolkos 1997) and increasing reliance on information technology and networks.

The most obvious form of outage cost is business interruption, for which larger companies often carry special insurance policies. Power surges and outages also cause direct damage to commercial and residential structures and their contents. Likewise, surges can cause fires and damage electrical equipment. Further, they can allow for

\footnotetext{
${ }^{17}$ Insurance for what some insurers are calling "cyber risks" is on the rise. One company has recently introduced products that cover damages to digital assets and business income as well as the extra expenses associated with the loss of data with limits up to $\$ 5$ million per loss (National Underwriter 2000).
} 
power failures that interrupt a structure's space-conditioning systems and thereby permit frozen piping or rooftop ice dams, which, in turn, precipitate water damage to structures and contents. Additionally outages can disrupt security systems, and facilitate burglary losses, and delay the response of police and fire services. Electricity interruptions also interfere with traffic signal lighting, which can cause roadway accidents and associated losses.

Insurers have also noted new forms of liability associated with power outages, as pointed out by a representative of CGU: (Dlugolecki 2001).

Another byproduct of deregulation could be a change in judicial attitudes regarding power interruptions from 'absence of blame' in the public interest towards 'duty of care' to customers in a competitive market. Currently supplier of public goods are often not held liable for non-performance e.g., the mail service, the weather forecasts. But in a competitive market, the suppliers will be liable for non-delivery because customers had a choice, and the supplier misled them.

Insurers have expressed concern about the reliability issues (Aldred 2000); it made the cover of one of the main industry trade journals for three weeks running in January 2001 (Ceniceros 2001a, Ceniceros 2001b, Business Insurance 2001). Insurers have also warned of the effect of utility deregulation on resources for utility system maintenance and reserve margins and, thus, electricity reliability (Tronsberg 1997). The importance of electricity reliability to insurers is increasing, as is evidenced by the emergence of new insurance products tailored to this problem and by the considerable attention being paid to the issue in the insurance and risk-management literature.

Loss control is a high priority for the insurance sector, especially given a protracted "soft market" in which the core business has been unprofitable for many years (Figure 6-1). Although, investment income generally compensates for core business' losses, reducing claims also improves profitability. 
Figure 6-1 Sensitivity of U.S. Property/Casualty Insurance Sector Net Financial

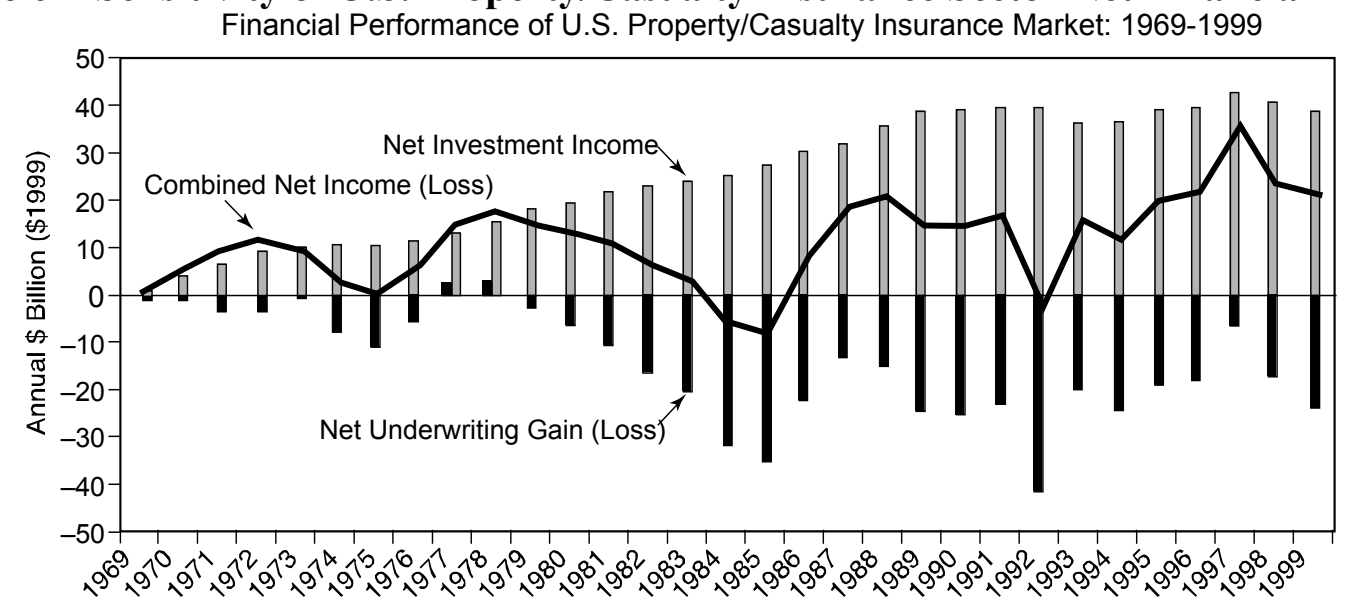

U.S. Catastrophe Losses and Insurer Insolvencies: 1969-1999

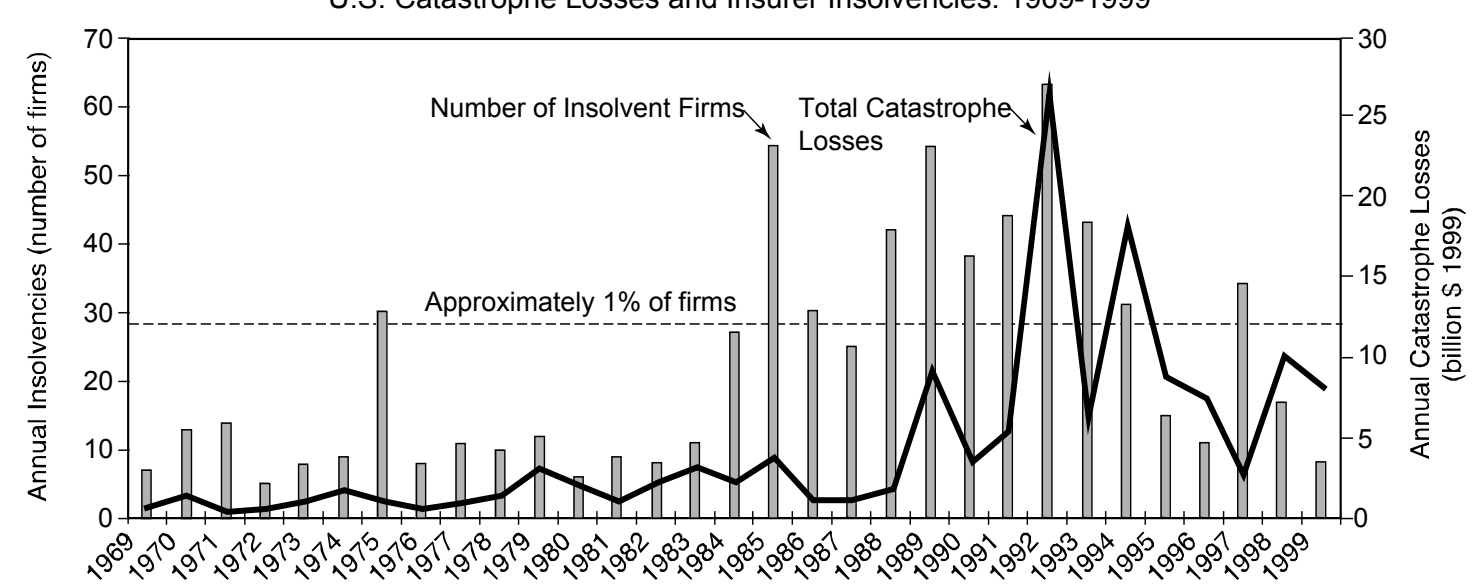

Sources: Insurance Information Institute (1997,1999, 2000a); Matheval. (1999);

Gastel (2000); Property Claim Services (2000)

\section{Results to Investment Income and Underwriting Gain/Loss}

Electricity interruptions and the events that cause them can trigger a wide variety of insurance claims, each of which corresponds to a different type of insurance coverage, as shown in Table 6-1. Electricity interruptions can interfere with business's ability to provide customer service or to sustain manufacturing processes (e.g., see the discussion of cleanrooms in Section 5), and they can lead to the loss of valuable merchandise (e.g., refrigerated pharmaceuticals or food products) or data. Interruptions also adversely effect utilities, both through lost sales and infrastructure damage that can precipitate service interruptions (see Appendix B). Power outages can also be implicated in environmental releases of pollutants. In insurance parlance, these exposures fall under various categories including "property," "business interruption," "machinery breakdown," "general liability," "environmental liability," "inland marine," "earthquake," and "additional living/relocation" expenses for homeowners or firms who must temporarily relocate following a loss. 
Bounding the insurance costs associated with electric reliability problems is complicated by a number of factors. These include the non-divisibility of premiums that include but are not limited to the coverages of interest, and the proprietary nature of disaggregated loss data. There are also multiple types of insurance that can be invoked by outages, as described Table 6-1, and summing multiple non-divisible amounts naturally compounds the uncertainties. Examples include residential losses due to "fire, lightning and debris removal", "commercial multiple peril insurance", and "boiler \& machinery insurance". We can, however, tabulate the premium and sector profitability information for several relevant categories shown in Table 6-1, with the proviso that these are not simple upper estimates given that the majority of losses and premiums do not pertain to reliability concerns (Table 6-2). While electricity outage costs are surely a small share of these premiums, the unprofitability of most of the relevant insurance segments during the 1990s suggests that any growth in losses is particularly undesirable, while any reduction of existing losses can have a material effect on profits. We can also present quantitative information on U.S. catastrophe losses (Figure 6-1), with the aforementioned caveats. These data all pertain to upper limits; there is no way to readily establish a lower limit of losses or premiums attributable to electricity reliability concerns.

Table 6-1. Mapping of Types of Damage Caused by Power Disruptions onto the Applicable Form of Insurance.

\begin{tabular}{|c|c|c|c|}
\hline & Residential & Commercial & Utility \\
\hline \multirow{4}{*}{$\begin{array}{l}\text { Property Insurance } \\
\text {-damage to electronics equipment, } \\
\text { materials, utility infrastructure }\end{array}$} & & & \\
\hline & & $\begin{array}{l}\text { property, machinery } \\
\text { breakdown }\end{array}$ & $\begin{array}{l}\text { property, machnery breakdown, inlan } \\
\text { marine, earthquake }\end{array}$ \\
\hline & & "cyber risks" & \\
\hline & property & property & \\
\hline \\
\hline \multirow{6}{*}{$\begin{array}{l}\text { Business Interruption Insurance } \\
\text {-power loss (on-site cause) } \\
\text {-power loss (remote cause) } \\
\text {-costs to avert shutdown } \\
\text {-increase cost of production } \\
\text {-supply chain disruption } \\
\text {-loss of electricity sales }\end{array}$} & & service interruption & \\
\hline & & service interruption & \\
\hline & & extra expenses & \\
\hline & & contingent extra expense & \\
\hline & & contingent bus interruption & \\
\hline & & & bus. interruption, financial guarantee \\
\hline Temporary Relocation Insurance & additional living expenses & disrupted operations & \\
\hline \multirow{3}{*}{$\begin{array}{l}\text { Liability Insurance } \\
\text {-insurers' efforts to recover business } \\
\text { interruption losses if utility perceived as } \\
\text { fault } \\
\text {-associated pollutant releases or other } \\
\text { environmental damages }\end{array}$} & & & \\
\hline & at & & commercial liability \\
\hline & & environmental liability & environmental liability \\
\hline Life/Health Insurance & & injury/mortality/workers comp & iniury/mortality/workers comp \\
\hline
\end{tabular}


Table 6-2. Size and Profitability of Several Insurance Lines Under Which Electricity Outage Losses Would be Tabulated.

\begin{tabular}{|lccc|}
\hline & $\begin{array}{c}\text { Net Premiums Written } \\
-\$ \text { billion } \\
(1999)\end{array}$ & $\begin{array}{c}\text { Combined Ratio after } \\
\text { Dividend } \\
\text { (avg. 1990s) }\end{array}$ & $\begin{array}{c}\text { Combined Ratio after } \\
\text { Dividend } \\
\text { (Range: 1990-99) }\end{array}$ \\
\hline Commercial Multiple Peril & 18.98 & 0.9 & 107.8 to 126.8 \\
Homeowners Multiple Peril & 29.78 & 116.3 & 101.0 to 158.4 \\
Inland Marine & 5.68 & 98.1 & 91.9 to 101.9 \\
Fire & 4.74 & 103.9 & 94.2 to 116.1 \\
Boiler \& Machinery & 0.78 & 101.0 & 90.2 to 158.6 \\
Earthquake & 0.67 & 125.7 & 32.0 to 889.0 \\
\hline
\end{tabular}

*Source: AM Best's Aggregates and Averages, 2000

The combined Ratio after dividend is the most widely recognized measure of insurance underwriting profitability representing operating costs versus revenue. The ratio does not reflect investment income and taxes. A combined ratio below 100 indicates a company that is making an underwriting profit.

The $\$ 700 \mathrm{~B} /$ year U.S. insurance "industry" is hardly a monolith, and the relevance of electricity reliability to insurers varies depending on the market segments addressed and types of business under written by a given insurer. The types of insured and specific risks written ("book of business") vary widely among firms; thus some insurers are more sensitive to electricity reliability issues than others. For example, medical malpractice insurers are relatively unconcerned with electricity reliability whereas business interruption insurers are keenly interested.

Certain kinds of insurers are particularly sensitive to electricity reliability issues. In the words of the Director of Research at FM Global (Fitzgerald 2000):

Electric reliability problems have a profound impact in our niche of the market because of the growth of Service Interruption Coverage for semiconductor manufacturing, pharmaceuticals, chemical processing, etc. A blip of only a few $\mathrm{Hz}$ can result in the loss of six to seven figures and even more if the [cleanroom] becomes contaminated.

Electrical-related equipment failures are clearly of concern to insurers. A major "boiler \& machinery" insurer, Hartford Steam Boiler (HSB), has observed a consistent trend toward higher electrical equipment losses during summertime (Figures 6-2 and 6-3).

Approximately 80 percent of HSBs losses from storm events involve damage to electrical equipment (transformers, office equipment, refrigeration equipment), averaging $\$ 115,000$ per claim and amounting to $\$ 100$ million during the past two decades (Kochaniec 1999). These include both property losses and business interruption losses and likely reflect the combined effects of longer operating hours (e.g., for air conditioning systems) and the probability of power interruptions during summer. 


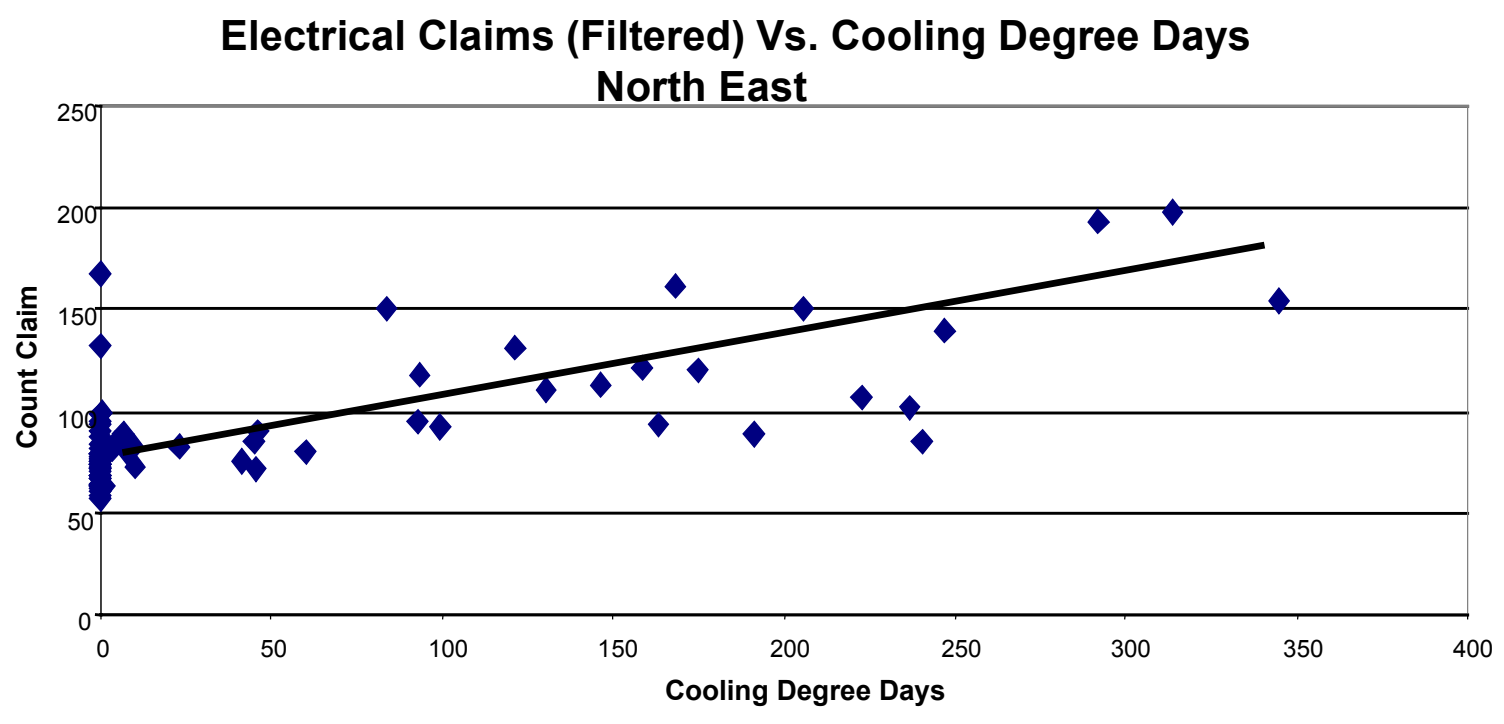

Figure 6-2. Claims Involving Electrical Equipment, As a Function of Cooling Degree-Days. Source: Hartford Steam Boiler Inspection \& Insurance Company (2000).

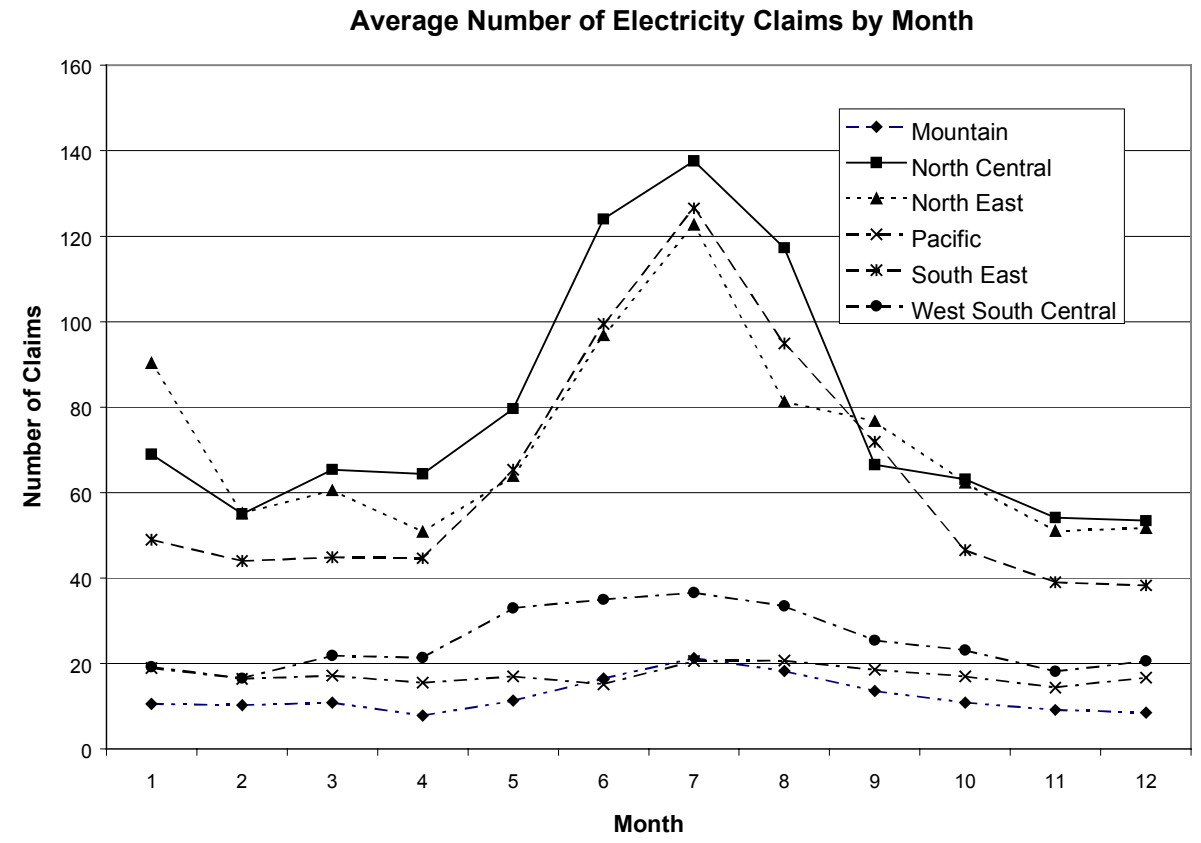

Figure 6-3. Claims Involving Electrical Equipment by Time of Year. Source:

Hartford Steam Boiler Inspection \& Insurance Company 2000. 


\subsection{Insurance Data Uses and Limitations}

In principle, the insurance and risk management communities offer three quantitative and qualitative metrics of electricity reliability costs: 1) premiums, 2) claims, and 3) losscontrol investments. Considerable information is available although much of it turns out to be in the form of case studies and anecdotes rather than nationwide data.

Ideally, data on the premiums paid for the relevant forms of insurance could be taken as a proxy for the value that insured firms place on avoiding power disruptions. However, while total U.S. property/casualty insurance premiums are approximately $\$ 280$ billion each year, and self-insurance represents another $\$ 180$ billion, it is unfortunately not possible to isolate the portion of premiums attributed to coverage related to power outages.

Insured losses are only a partial indicator of total costs because:

- Not all citizens and businesses carry the appropriate form of insurance, e.g. perhaps $20 \%$ of business interruption losses are insured (Dlugolecki 2001).

- Insured parties pay deductibles.

- Payable losses can be capped.

- Not all risks associated with electricity interruptions are insured.

- Individuals or firms not carrying commercial insurance are formally or effectively "self-insured."

- In many cases, governmental entities (local, state, or federal) assume part of the costs (through disaster preparedness, flood insurance, reconstruction loans, etc.).

Data on losses specifically attributed to electricity interruptions are difficult to come by. This is because of proprietary protection of loss information, and the fact that the associated premiums and losses are typically subsumed under more generalized policy categories (e.g., property insurance) and are not "divisible" in insurance parlance (Reed and Thomas 1969). Insurance regulation and ratemaking rules do not require that data be reported at this level of detail. Further complicating matters, only some business interruption policies cover power outages (especially if the precipitating "damage" occurs away from the insured location). Because many policies are "manuscripted," i.e. customized for the insured, it is not possible to generalize about the nature of coverage suggested by standard policy contract wording. Nonetheless, insurers can be important allies in collecting useful data, as evidenced by the formation of a special committee within the Industrial Machinery Insurance Association (IMIA) to examine the causes of increasing losses due to failures of large oil-cooled transformers (IMIA 1996).

One would expect to find power outage cost data within the "catastrophe" loss time series maintained by the insurance industry's Property Claim Service (PCS). However, PCS

\footnotetext{
${ }^{18}$ Formalized self insurance, through wholly owned internal ("captive") insurance companies, is becoming popular among utilities as well (O’Dwyer 1998).

${ }^{19}$ Deductibles can often be in the millions or tens of millions of dollars (Rodentis 1999).
} 
only includes events resulting in more than 1,000 claims and a total insured loss of \$25 million. Thus, individual events such as lightning strikes would not be included even though the collective insured damages from them are estimated at $\$ 1$ billion each year. PCS does provide estimates for catastrophes (floods, hurricanes, ice storms, etc.) in which power outages are a component of total losses. But does not capture events that are solely due to a power outage; and in addition, events meeting the PCS criteria (e.g., earthquakes, hurricanes, floods) typically include many types of losses in addition to those associated with power outages.

Despite these limitations, insurance data can contribute to a broad understanding of the power outage-related losses, and the discipline of insurance risk management offers tools for minimizing these losses in the future. And, as reported below, some useful data are available on a per-company or per-event basis; in some cases, industry-wide estimates have been published.

For our research, we consulted the following insurance industry sources:

-A.M. Best \& Co.

- College of Insurance Library (New York)

-Emergency Preparedness Canada

Industrial Machinery Insurers Association (IMIA)

-Inland Marine Underwriters Association (IMUA)

-Institute for Business and Home Safety

-Insurance Information Institute (III)

-Insurance Library Association of Boston

-Insurance Services Office (ISO)

-National Association of Insurance Commissioners

-Property Claim Service (PCS)

-Scientific literature on natural disasters

-Trade literature (Best's Review, Business Insurance, National Underwriter, Reinsurance, Risk Management, Natural Hazards Review)

\subsection{Business Interruption Insurance}

Business interruptions appear to be a major source of losses for property-casualty insurers. Business interruption (BI) insurance covers loss of net profit, property damage, continuing expenses (e.g., employees who stay on salary during disruption), and costs incurred when insured of parties are required to take "expediting measures," i.e., to expedite repairs in real time (these costs are paid by insurer). Utilities also carry certain forms of BI insurance to protect against lost sales during forced outages.

\footnotetext{
${ }^{20}$ For example, Duke Energy is a member of Nuclear Electric Insurance Limited (NEIL), which provides property and business interruption insurance coverages for Duke Energy's nuclear facilities. This policy provides business interruption and/or extra expense coverage resulting from an accidental outage of a nuclear unit. Each unit of the McGuire and Catawba Nuclear Stations is insured for up to approximately $\$ 4$ million per week, and the Oconee Nuclear Station units are insured for up to approximately \$3 million per week. Coverage amounts per unit decline if more than one unit is involved in an accidental outage.
} 
Although business interruptions can be triggered by a range of events, electric power interruptions are responsible 70 percent of the time, according to one source (Figure 6-4). Power outage losses can result from various causes, including direct interruption of operations, impeded ability of customers to access the business, disruption to employees or owners at home, and supply-chain disruptions. One case litigated in Arizona recognized eight hours of business interruption at six locations caused by a relatively brief (30-minute) power outage at a company's data center (Gordes 2000).

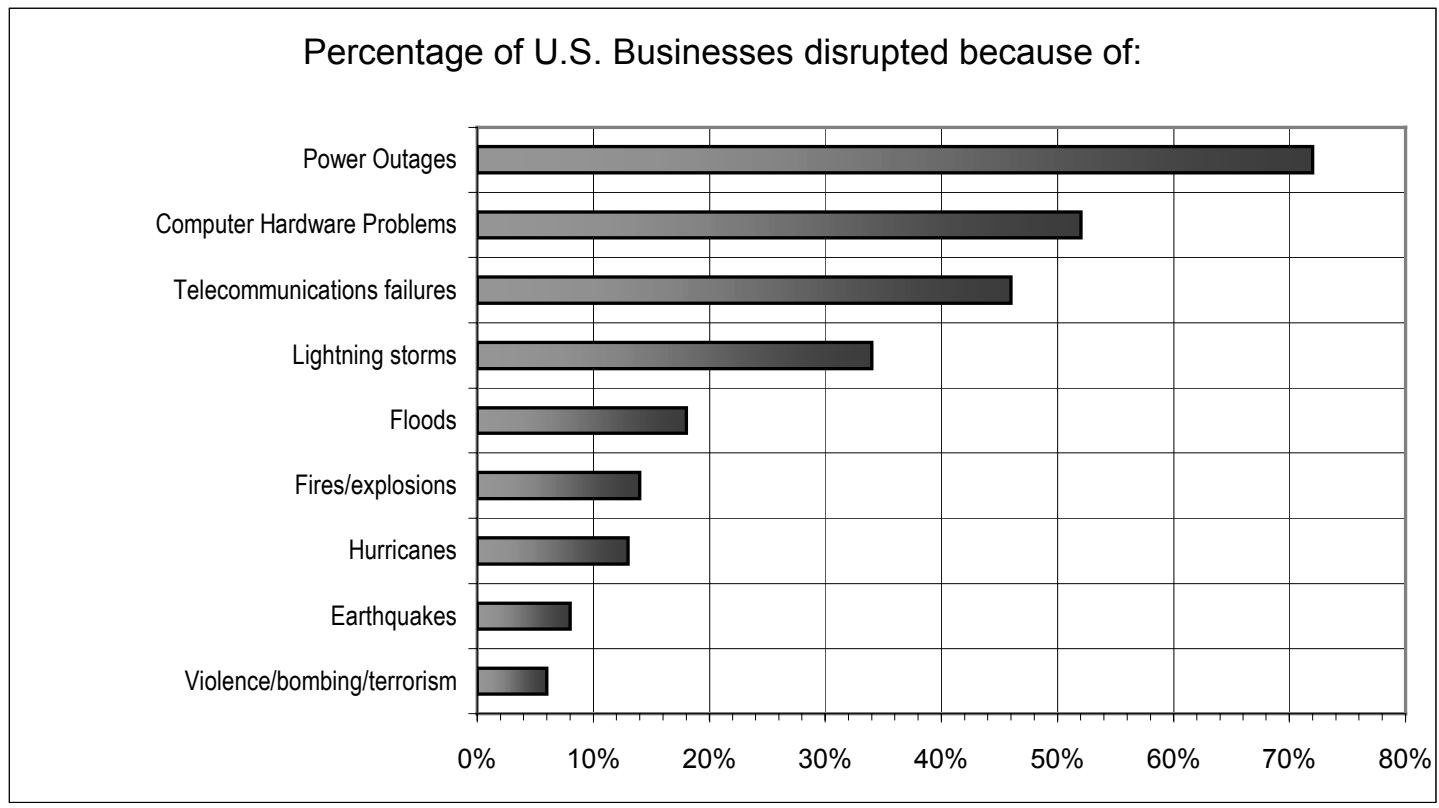

Figure 6-4. Causes of Business Disruptions

Source: Rodentis 1999.

To understand how convoluted business interruption losses can be, consider the following. After the December 1998 blackout in San Francisco, the City of San Francisco brought claims to PG\&E for lost parking ticket revenues because parking control officers were taken off of duty to direct traffic in areas with failed signals (Wojcik 1998).

Property losses triggered by power outages can precipitate protracted periods of business interruption. In the wake of a June 2000 power outage in Silicon Valley, electronic manufacturer SDL noted that gas purifiers vulnerable to power outages could take six months to replace, potentially causing \$200 million in lost revenue (in addition to loss of market share) (Mulligan 2000).

Initial coverage begins after a 17 -week deductible period and continues at 100 percent for 52 weeks and 80 percent for the next 104 weeks.

See http://media.corporate-ir.net/media_files/NYS/DUK/reports/ar_98/note14.html. 
Insurance losses from business interruptions are particularly awkward for insurers because the losses can continue to develop over long periods following the initiating event and the restoration of power.

Natural disasters cause extensive business interruptions. Following Hurricane Andrew in 1992 , about 20 percent ( $\$ 8$ billion) of total losses were related to business interruption (40 percent or $\$ 5$ billion in the case of Hurricane Hugo in 1989). Analyses of a potential magnitude-6.8 earthquake along the Newport/Inglewood Fault Zone in Southern California have projected business-interruption losses at 41 percent of the total $\$ 80$ billion nationwide economic loss that might result (Gordon and Richardson 1992). For this scenario, "local" power stations are expected to generate electricity at 50 percent of capacity for the first 30-60 days.

Under the broad heading of business interruption, specific "service disruption" endorsements are required to ensure that policies will cover losses associated with power outages; otherwise, losses must be paid by the insured. Small businesses rarely purchase insurance with coverages extending to events occurring away from the customer's premises, but this practice is said to be common among large companies (Stauffer 1995). As an example of distant events resulting from a natural catastrophe, the Northridge (California) earthquake caused 150,000 customers in rural Idaho to be without power for three hours (Stauffer 1995).

"Contingent business interruption" insurance also exists which covers loss of earnings for an insured party because of a loss to another business that is one of the insured party's suppliers or customer. "Contingent extra expense" coverage functions similarly in cases where production continuity is maintained, but operating costs temporarily increase as a result (Bowers 2000).

In 2000, there was a legal test of the premise that computer data lost during power disruptions would be insured under BI policies (Rutkin 2000). The case in question involved Ingram Micro Inc, which claimed that a 20-minute power disruption resulted in $\$ 4$ million in lost profits. Insurers argued that this did not constitute "physical damage" as specified in the policy, but the courts decided in favor of Ingram Micro. This decision sets an important precedent, but insurers may exclude such exposures as they write future policies.

Data on insured business interruption costs are scarce because the premiums and loss costs are typically nested within "commercial general liability" insurance, i.e., are "indivisible" in insurance parlance. Conflicting and fragmented information can be found in the literature. According to one source, BI losses under the commercial property category between 1987 and 1996 totaled $\$ 2.54$ billion for U.S. businesses (Bowers 2000) or an average of $\$ 254$ million per year (including but not limited to losses related to power outages). This result seems implausibly low given reported BI losses from single major events. As described below, total BI losses from individual natural catastrophes occurring during this period amounted to several billion dollars. 
There are indications that BI losses are on the rise, both as a result of increased vulnerability and of changes in the frequency and intensity of the triggering events (often weather related). However, much prior work has focused on aggregate impacts or on other segments rather than on impacts at the level of individual firms. In 1993, the Disaster Research Center initiated a series of surveys attempting to fill this void, with more than 5000 businesses surveyed in the course of a series of studies. In two of these surveys (Memphis and Los Angeles/Santa Monica) it was found that 25-30 percent of the businesses carried BI insurance and that approximately 15 percent of the total number of businesses possessed a back-up electric generator. The studies generally found that the level of preparedness was low and that the overall emphasis of risk-management efforts was more on life safety than business continuity. They also found, not surprisingly, that larger firms were more prepared than smaller ones, and facility owners were more prepared than those who leased. However, of particular concern, the large retail and service sector segments were found to be particularly unprepared.

The following accounts illustrate how electricity reliability events affects insurers:

- Summer storms in 1998 on the East Coast and Midwest resulted in insurance claims exceeding \$100 million, including losses from power outages that affected hundreds of thousands of customers and the Metro-North Railroad (Business Insurance 1998b).

- The Disaster Research Center Study found that damage and disruption to utility and transportation "lifelines" contributes significantly to disaster-related losses (Webb et al. 2000). During the 1993 Midwest floods, for example, power stations were flooded, resulting in power outages affecting 35,000 households. While 15 percent of the businesses experienced physical damage, 33 percent were without power. More than 40 percent of the businesses were forced to close for some period of time.

- In 1992, the Chicago River flooded an underground tunnel system below the Chicago Loop. All businesses in the area were unable to operate because of a loss of power.

- Loss of power was a significant contributor to the dollar losses following the Northridge Earthquake (\$15.3 billion insured; $\$ 44$ billion total) (University of Surrey and IIASA 2000). Nearly 80 percent of Los Angeles businesses reported some degree of business interruption; the most common type was non-structural (68\% of the total). BI losses amounted to $\$ 6.5$ billion. Approximately $\$ 1.5$ billion or 11 percent of the total insured loss was business interruption (Institute for Business and Home Safety 1999). Physical damages to "lifelines" (power, gas, water) were estimated at $\$ 2$ billion. For businesses that closed, loss of electricity was the second-most-common reason, responsible for 58.7 percent of the total.

- Citing the rapid growth in PC usage, a recent insurance trade press article stated that power failures and surges account for more than 45 percent of computer data loss and that these losses were particularly likely during periods of peak summertime temperatures (Best's Review 1999).

- The BI losses (insured and uninsured) from the Great Midwest Flood of 1993 were at \$200-\$500 million in Des Moines, Iowa alone (Stauffer 1995).

- Chevron's Pascagoula MI refinery experienced BI losses as a result of power outages caused by Hurricane George. The first in a series of payments from their insurer was for $\$ 15$ million (Reuters 1999). 


\subsection{Causes of Losses}

\subsubsection{Internal vs. External Events / Direct Damage vs. Consequential Loss}

Claims can be triggered by what might be termed "internal" and "external" events. In insurance parlance, the terms "direct damage" and "consequential loss" are used to represent these two types of situations. Internal events can include equipment breakdown or malfunction on the end user's premises or analogous problems on the utility side of the meter. External events include lightning strikes and natural or human-caused disasters (intentional or accidental). A study of 75 large oil-cooled transformer failures found 57 percent to be due to internal causes, 17 percent to external causes, and the remainder unknown (IMIA 1996).

As can be seen by the events noted in subsection 6.3, natural disasters play an important role in electric power disruptions. Relevant events include lightning, geomagnetic storms, floods, earthquakes, ice storms, and windstorms. The Great Midwest Flood of 1993 resulted in $\$ 135$ million in physical damages to utility infrastructure, in addition to the consequent business interruption losses. As discussed briefly below, there are some indications that the frequency and severity of some of these extreme weather events is on the rise.

\subsubsection{External Events: Lightning}

Lightning is a major cause of insurance claims and can trigger losses in a number of ways (Odam 2000). Swiss Re reports \$5-6 billion in lighting-related damages annually, including "loss of electronic equipment due to power surges and problems with electric power grids" (Swiss Re 2000). A review by Kithil (1995) placed the national cost of lighting strikes (insured and uninsured) at $\$ 4-5$ billion annually, noting thatinsured losses were estimated by the Insurance Information Institute at \$1 billion in 1990.1

Lightning has been cited as responsible for five percent of insurance (presumably property) claims (Kithil 1995), but estimates vary widely. St. Paul Insurance Co. reported paying an average of \$332 million in lightning-related claims annually between 1992 and 1996 (Kithil 2000). The portion of these costs related to electricity disturbances is not known. One report from the Department of Energy states that, of the lightning-related losses experienced at its own facilities, 80 percent were due to voltage surges (Kithil 2000).

One insurer -- Hartford Steam Boiler Insurance \& Inspection Company -- provided detailed claims data on lightning-related losses (Figure 6-5). Claims during warm periods

\footnotetext{
${ }^{21}$ Another estimate from Insurance Information Institute (2000) estimated insured losses at far less.
} 
are far more common. Approaches to lighting risk management are described in publications from the Lightning Safety Institute. ${ }^{2}$

\section{Correlation: Lightning - Temperature}

Northern Exposure: 1990-1996 (August)

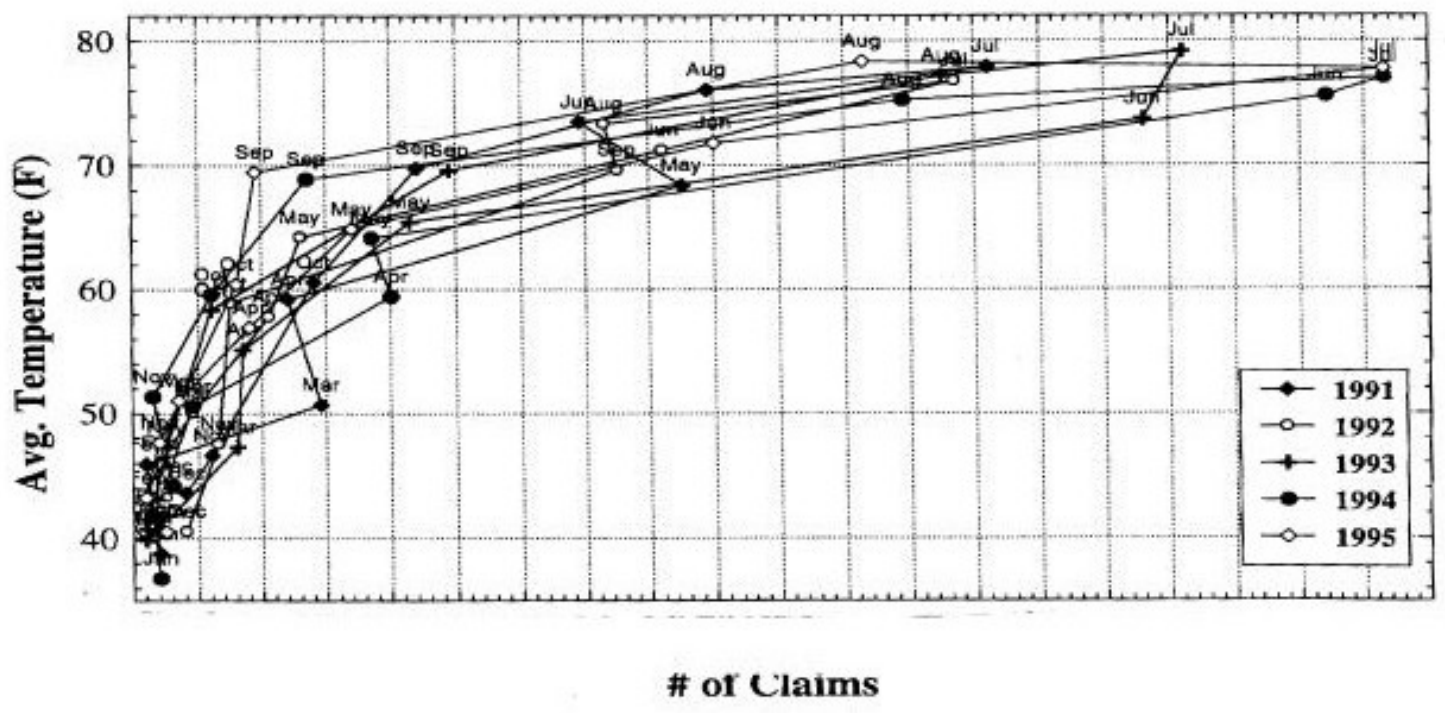

Figure 6-5. Lightning-Related Insurance Losses

Source: Hartford Steam Boiler Insurance and Inspection Company claims data

As a result of equipment breakdown and electricity service disruption, lightning-related insurance losses correlate strongly to temperature. An additional issue is that peak lightning periods occur in summer when electricity reliability problems are likely to cause other business interruption losses, as suggested by Figure 6-5. Climate change is expected to increase lightning events and associated insurance losses.

Federal and state government agencies do not disclose lighting-related loss statistics (Kithil 1995). As indicator of the effects on local governments, one Virginia city reported an average damage (malfunction) rate to street lights of more than \$100/lamp-year (Kithil 2000).

\footnotetext{
${ }^{22}$ See http://www.lightningsafety.com/nlsi_lhm.html
} 


\section{Box 1. The North American Ice Storm of 1998}

For seven days in January 1998, freezing rain fell on the Canadian provinces of eastern Ontario, southwestern Quebec, southern New Brunswick and Nova Scotia.* These areas were pelted with 80 millimeters or more of freezing rain, double the amount of precipitation experienced in any prior ice storm. The result was a catastrophe that produced the largest estimated insured loss in the history of Canada. The same storm affected northern New York and parts of Vermont, New Hampshire and Maine in the United States, resulting in approximately $\$ 200$ million in insured losses.

The combined Canadian and U.S. insured losses stood in excess of $\$ 1.2$ billion U.S. as of October 1, 1998. Total Canadian insured and uninsured economic losses were approximately $\$ 6.4$ billion (Cdn).

In Canada, 28 deaths were attributed to the storm; in the United States, 17 people lost their lives. According to Emergency Preparedness Canada, power outages in the affected areas of Canada deprived 16 percent of the Canadian population of electricity. In both countries, more than 5 million people were without heat and light (and in many instances water) in the cold of the mid-winter, which intensified the human suffering. The ice storm produced more than 835,000 insurance claims from policyholders in Canada and the U.S. This was 20 percent more claims than created by Hurricane Andrew, the largest natural disaster in the history of the United States.

The event served as a grim learning laboratory for the insurance and disaster-recovery communities. It evidenced the wide spectrum of insured and non-insured losses that can materialize from a single natural catastrophe, including:

- Property losses (e.g. roof damage and destruction of perishable goods due to loss of electric power).

- Business interruption losses (19 percent of the employed Canadian workforce was unable to get to work).

- Health/life losses (including losses incurred during recovery operations).

- Additional living expenses for people relocated to temporary housing.

- A host of agricultural losses ranging from livestock deaths to interrupted maple syrup and milk production.

- Disruption and damage to recreation and tourism infrastructure.

- Disaster-recovery costs, including personnel and overtime expenses, provision of back-up electric generators and fuel, debris clearing, temporary shelter for displaced citizens, and disaster assistance payments made to victims.

Total losses exceed the insured losses by a substantial margin. The event also threw into sharp focus the vulnerability of the electric power grid to natural catastrophes and raised questions about the connection between such events, the El Niño phenomenon, and global climate change. 


\begin{tabular}{|l|l|l|l|}
\hline Type of loss & Canada (Cdn \$) & United States (U.S.\$) & Total (U.S.\$) \\
\hline Insured losses & & & \\
\hline Insurance claims & $\$ 1.44$ billion & $\$ 0.2$ billion & $\$ 1.2$ billion \\
\hline Deaths & 28 & 139,650 & 835,240 \\
\hline $\begin{array}{l}\text { People (customers) } \\
\text { without power }\end{array}$ & $\begin{array}{l}4,700,000 \\
(1,673,000)\end{array}$ & 17 & 45 \\
\hline $\begin{array}{l}\text { Electricity transmission } \\
\text { towers / distribution } \\
\text { poles toppled }\end{array}$ & $130 / 30,000$ & 546,000 & $5,246,000$ \\
\hline $\begin{array}{l}\text { Electric transmission } \\
\text { system damage }\end{array}$ & $\$ 1$ billion & unknown & unknown \\
\hline $\begin{array}{l}\text { Manufacturing, } \\
\text { transportation, } \\
\text { communications, and } \\
\text { retail business losses }\end{array}$ & $\$ 1.6$ billion & unknown & unknown \\
\hline Forests damaged & unknown & unknown & unknown \\
\hline Loss of worker income & $\$ 1$ billion & 17.5 million acres & unknown \\
\hline $\begin{array}{l}\text { Dairy producers } \\
\text { experiencing business } \\
\text { disruption }\end{array}$ & 5,500 & unknown & unknown \\
\hline Loss of Milk & unknown & unknown \\
\hline $\begin{array}{l}\text { Agriculture sector } \\
\text { poultry, livestock, } \\
\text { maple syrup) }\end{array}$ & $\$ 25$ million & & \$10.5 million \\
\hline $\begin{array}{l}\text { Quebec \& Ontario } \\
\text { Governments }\end{array}$ & $\$ 1.1$ billion & $\$ 35.5$ million \\
\hline
\end{tabular}

* This discussion is based on an analysis conducted by two insurance industry organizations: the Canadian Institute for Catastrophic Loss Reduction and the U.S.-based Institute for Business and Home Safety (Lecomte et al. 1998). Losses as of 10-1-98. Mills et al. (2000).

\subsubsection{External Events: Other Natural Disasters}

Earthquakes typically result in widespread electricity disruptions, and, as noted above, can cause considerable BI and property insurance costs associated with power outages.

A modeling study estimated that it would take two weeks to fully restore power following a magnitude-7.5 earthquake in Memphis/Shelby County. The costs for repair, revenue loss, and direct economic losses was estimated at $\$ 450$ million, of which business interruption represented about $\$ 48$ million and lost revenues to the utility $\$ 1.7$ million (Chang et al. 1996).

The insurance industry has noted concern that cleanrooms (see Section 5), which represent substantial insurance loss risks, are typically located in earthquake-prone regions (Wassmer and Frey 1999). 


\subsubsection{External Events: "Space Weather"}

Insurers have also pointed to "space weather" (electromagnetic storms, solar wind, and solar cosmic rays) as a source of electricity interruptions. Limited loss data are available related to these phenomena. Events with major effects on utilities occurred in 1940, 1958, 1972, 1982, and 1989 (Spoiden 2000). According to a study by Swiss Re (Jansen and Pirjola 2000):

The first effects on a power transmission system occurred in North America in 1940, where a severe magnetic storm caused voltage fluctuations and transformer shutdowns. North America has experienced electrical power line shutdowns and blackouts during other storms. The best known event occurred during a major magnetic storm on 13 March 1989. Storms of geomagnetic origin saturated transformers in the Hydro Quebec power supply system, caused automatic shutdowns and produced voltage fluctuations and harmonic frequencies in the electricity. A domino effect ultimately caused the entire system to collapse. Quebec suffered a power cut lasting nine hours.

Insurance risks posed by geomagnetic storms range include electronic equipment failure, spacecraft and satellite damage, impacts on aviation and telecommunications, corrosion in oil and gas pipelines, disturbances in railway signaling systems, and damage to transformers in utility grids. Insurers have expressed concern about society's increasing vulnerability to geomagnetic storms because of the increased numbers and interconnectedness of these systems and the difficulty of anticipating and insuring the risks.

In 2000, an article in the insurance trade literature warned readers that we are entering an 11-year cycle of solar activity; the article notes that "power companies are preparing for major disruptions" and that "many portions of the North American power grid are vulnerable" (Spoiden 2000). The insurance trade literature has also pointed out that potential losses are higher than historic experience, because of the increasing dependence on electronics during the 11-year period since the last major incident. This source cites the potential for electricity interruptions as the single greatest concern in the industry (Sherman 2000).

\subsubsection{Trends towards Greater Incidence of Extreme Weather Events}

In a recent scientific article reviewing the current and projected dimensions of extreme weather events leading researchers in the field note that the frequency and intensity of many such events have been increasing and are expected to continue to do so in the future (Easterling et al. 2000). Events included are average summertime peak temperatures, extreme temperature episodes and heat waves, and extreme precipitation events, and 
more intense and frequent El Nino events. Notably, climatologists preqdict increasing temperatures and lightning strikes if average temperatures increase.

Some efforts have been made to evaluate the potential effect of changes in temperature regimes on peak power requirements. In an examination of nine sites across Canada, Columbo et al. (1998) found that for a $3^{\circ} \mathrm{C}$ increase in mean daily maximum temperatures, peak power demand would rise by 7 percent and the standard deviation of peak power would increase by 22 percent, potentially stressing the provincial power utilities.

Whether such weather trends are due to human-induced global climate changes or to natural variability in the climate system, the potential implications for electric system reliability are significant.

\subsection{Risk Management Strategies}

Insurers have a long tradition of "loss prevention" and a number of tools for managing risks. Given the exposures outlined above, it is natural to envision insurers as active supporters of enhanced electricity reliability. Risk-management techniques vary from financial instruments (e.g., insurance premium structure), to engineered management (e.g., back-up power systems), early-warning systems and to continuity planning to keep businesses running. All insurers engage in financial risk management, but customer-side loss control efforts vary widely throughout the industry. Customer-side loss control typically resides with risk managers who work for the insured although some insurers also offer risk-management services.

\subsubsection{Financial Risk Management}

Spreading risk is the essence of financial risk management in the insurance industry. Insurers construct a portfolio of insured parties that includes and represent a wide variety of customer types and risk types and spatially diversified loss potential.

Insurers reduce risk via deductibles. Particularly relevant to the question of business interruptions are "time deductibles," which are denoted in terms of a time period following a power disruption before losses will be insured. If outages are brief, few insured losses will be triggered, as was observed following June 1998 outages in the Midwest and New England (Szalai 1998). Figure 6-6 shows the service-restoration curves used in one study that estimated the potential losses of a large earthquake on Memphis/Shelby County, which lies within the New Madrid seismic zone. In this case, power outages are expected to persist for two weeks. Under normal circumstances,

${ }^{23}$ Reeve and Toumi (1999) have shown that a $1{ }^{\circ} \mathrm{C}$ increase in average wet-bulb temperature can be accompanied in mid latitudes by a 40 percent increase in lightning. Price and Rind (1993) found that in a $2 \mathrm{xCO} 2$ climate with a $4.2^{\circ} \mathrm{C}$ warming, global cloud-to-ground lightning strikes would increase by 72 percent relative to other continental regions. 
however, time deductibles mean that outages of just a few hours can trigger very few business interruption claims (Business Insurance 2001).

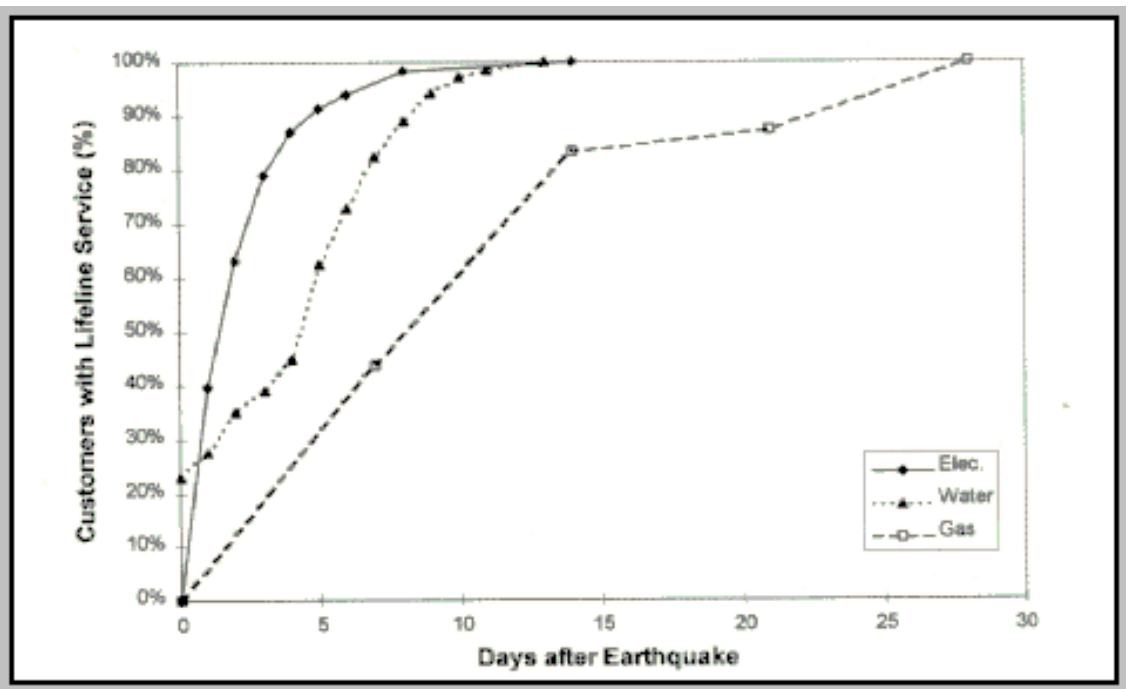

Figure 6-6. Restoration Curves for Lifeline Services Following a Hypothetical Magnitude-7.5 Earthquake in Memphis/Shelby County. Source: Chang et al. 1996.

A common risk-spreading system is referred to as Residual Market Mechanisms (RMMs), in which insurers (typically at the state level) contribute to a common pool that is used to pay claims. Business interruption losses are covered by RMMs in New York state.

Insurers also purchase reinsurance, which enables them to pass losses above a pre-agreed threshold to the reinsurer. Capital market alternatives to risk financing (e.g., catastrophe options or puts) are increasingly discussed although they remain in the early stages of application.

Following are three examples of insurance products designed to address power outages and manage the risk (exposure) assumed by the insurer (Bradford 2000):

- In 1999 Chubb introduced a bundled machinery breakdown and service interruption product (ESP Select) with limits up to $\$ 200$ million. Data loss is also included in the coverage.

- Great Bay Power Corp., a Portsmouth, New Hampshire-based energy company, bought a "double-trigger" insurance policy from the former Cigna Property Casualty (now part of ACE Ltd in Bermuda). The insurance kicks in when there is both an unscheduled outage at the Seabrook nuclear plant, causing it to shut down, and a hike in the spot price of electricity above a strike point.

- FirstEnergy Corp., an Akron, Ohio-based holding company, bought a double-trigger insurance policy from ACE USA Power Products. The insurance triggers when a

\footnotetext{
${ }^{24}$ See http://www.chubb.com/news/pr19990520.html.
} 
power outage results in more than $600 \mathrm{MWh}$ of lost power, and at the same time, a spot market electricity price exceeding $\$ 74$ per MWh occur in tandem. In the summer of 1999, both occured, but the loss fell below the company's $\$ 25$-million deductible.

\subsubsection{Engineered Risk Management}

Many technological risk-management tools are also available, and insurers have played varying roles in their deployment. Insurers also provide incentives for use of these practices by awarding premium credits. One report notes credits of up to 20 percent for firms that have good contingency plans and risk mitigation procedures for minimizing BI losses (Rodentis 1999).

Examples of risk-management tools include establishment of building codes that improve disaster resilience and promotion of back-up power capabilities and early-warning systems. In one example, Arkwright Mutual (now part of FM Global) established a computer system that notifies facility managers of impending severe weather or natural disaster (Coccia 1996) and provides extensive information on disaster preparedness. ${ }^{\text {[5] }}$ Similarly, Prudential Property and Casualty reimbursed residential policyholders who purchased back-up generators (up to \$600) following the great North American Ice Storm of 1998 (Gordes 2000). By doing so, Prudential could reduce its "additional living expense" reimbursements to customers who otherwise would have had to seek temporary shelter away from their homes.

Insurers can play a role in standardization of risk-management technologies, as exemplified by the Industrial Machinery Insurer's Association (IMIA) Risk Classification of Electrical Surge Protection Devices.

Insurers have also engaged in research and development and product labeling related to risk management. One example, although not directly related to electricity reliability, is the case of fire safety improvements in cleanrooms. Factory Mutual Research, a division of the insurer FM Global, began the move toward safer wet benches by establishing an index against which to measure cleanroom materials: Test Standard FM4910, Cleanroom Materials Flammability (1997) (Laurin and Tate 2000). Also involved were the insurer HSB and Underwriters Laboratory. FM provided testing services. Materials performance required under this standard exceeded that of materials typically used at the time. FM has promulgated the standard (and compliance inspections) among those it insures, and the new materials achieved a 50 percent market penetration (in new construction) within three years of the release of the voluntary standard.

In some cases, insurers have explored potential risk-reduction benefits associated with energy-efficient and distributed renewable energy technologies (Mills 1997 Mills et al. 1998, Mills 1999, Vine et al.1999 and 2000). There is an initial "inherent" benefit insofar as these technologies reduce loads and thus the need for back-up power. In addition, a

\footnotetext{
${ }^{25}$ See http://www.fmglobal.com/library/rmstrategies/disaster.html

${ }^{26} \mathrm{See}$ http://www.imia.com/computer_committee.htm
} 
subset of these technologies have specific benefits. These kinds of benefits are exemplified by the temperature-retaining capacity of high-efficiency refrigeration systems for valuable perishables such as pharmaceutical supplies. ${ }^{27}$ A prominent example of energy-efficient technologies is the trend toward super-clean mini-environments within standard cleanrooms, which yield dramatic energy savings and also reduced reliability risks given the vastly smaller load to be maintained by emergency back-up power systems. 28 The insurance trade press has even recognized the value of certain solar photovoltaic (PV) systems in averting business interruptions caused by power outages (Deering and Thornton 2000) although the potential insurance loss prevention benefits have not been quantified. PV backup power systems were used to power communications systems, street lights, and other loads in the aftermath of Hurricane Hugo (1989), Hurricane Andrew (1992), and the Northridge Earthquake (1994) (Stauffer 1995). The American Modern Insurance Group is testing a PV-powered mobile office for processing claims following disasters (Gordes 2000). More generalized arguments have been made for the risk-management benefits of distributed generation (Gordes 2000).

\subsubsection{Business Continuity Planning}

Maximizing disaster preparedness and post-event recovery are also critical, and many insurers provide products and services in this area. In the case of business interruption, business continuity is key (Rodentis 1999). Insurer organizations such as the Institute for Business and Home Safety have engaged in a discussion of business continuity, e.g., through their participation in EPRI's Disaster Recovery Business Alliance (DRBA) (Baruch and Carrido 1998) . EPRI's Disaster Planning and Mitigation Technologies (DPM\&T) effort has focused on prompt restoration of electrical power as part of the disaster recovery process (EPRI no date).

Insurers have encouraged utilities to also focus on continuity planning and pre-event preparedness. Writing in Power Engineering, a representative of FM Global (Tronsberg 1997) encouraged readers to:

...perform regularly scheduled inspections, equipment operator training programs, worker safety procedure training, electronic data back-up and off-site storage of critical information should be included. Preparation also ensures specific and well-trained individuals are assigned to cover critical roles and responsibilities, including: disaster team leader, operations supervisor, weather monitor, evacuation coordinator, security supervisor, firefighters, rescue and first-aid technicians, public relations contacts, and salvage team coordinator.

\footnotetext{
${ }^{27}$ As an example of the value of refrigerated perishables, the ConAgra Red Meat Company received \$1.7 million (\$1980) in insurance claims for spoilage following a power outage (Burcke 1994).

28 "Finger-style" configurations are also in use where smaller and cleaner spaces are placed adjacent to major corridors with less rigorous cleanliness standards (IMUA 2000).
} 
Some take a particularly proactive approach. Risk managers at Bell Atlantic will disconnect facilities from the grid in anticipation of brownouts or power surges (Kochaniec 1999).

\subsection{Innovative Partnerships between Insurers and the Energy Sector}

As society becomes more dependent on electricity and electronic communications systems, insurers perceive the growing importance of electric reliability issues. A recent article in the insurance trade literature noted that utilities' risk management offices are actively growing, spurred in part by utility deregulation. According to a representative of Swiss Re North America's New Markets division (Bradford 2000): "Energy deregulation has created a brand new playing field, compelling 'old shoe' companies into new areas of risk and the wide-scale trading of risks."

Although the increase in attention to risk management has to do mostly with diverse market and financial risks as regulated franchises disappear, it also reflects new risks associated with electricity reliability. Insurers will inevitably seek to cultivate new business opportunities based on providing appropriate loss-prevention services, perhaps in partnerships with the utility industry.

There is some precedent for insurance incentives for electricity reliability risk management measures. A fuel cell vendor (Sure Power) has bundled a high-reliability fuel cell system with BI insurance underwritten by American International Group (AIG), one of the world's largest insurers. The system was installed at data center of the First National Bank of Omaha, Nebraska, the country's largest independent bank and seventh largest credit card processor (Mannion 2000).

In another interesting development, the risk management unit of Enron has recently acquired Integrated Process Technologies, a subsidiary of Hartford Steam Boiler Insurance and Inspection Services. This brings a unique mix of talent in risk management and facility management to Enron.

There is considerable scope for collaborative efforts between insurers and the electricity industry. EPRI's DRBA has delved into this area in some depth and has cultivated partnerships with the insurance industry and others in the disaster-recovery community to facilitate business continuity following natural disasters (Carrido 2000). Webb et al. (2000) found that if a community has an effective plan in place for responding to disasters, businesses will benefit directly by being able to resume operations sooner. 


\subsection{Key Findings and Recommendations for Next Steps}

EPRI has already conducted a number of studies on specific technological options for addressing customer's reliability needs, such as back-up generation, uninterruptible power supply (UPS) systems, and other power-quality-enhancing technologies and approaches. We have complemented this work with new information on insurance as a financial option for addressing reliability costs.

Key Findings:

1. Power outages are a material issue for insurers. Insured loss data are, in turn, a valuable source of information on electricity reliability costs for the power sector and are more rigorous than many estimates promulgated by others.

2. Because of limited penetration of the relevant forms of insurance and role of deductibles, insurance loss data represent only part of the total cost. Some costs are covered by self-insurance, governments, and utilities who pay claims made by customers or municipalities.

3. Reliability-related insurance risks are perceived by insurers as being on the rise as customers become increasingly vulnerable to power outages. These losses can be triggered by natural or manmade catastrophes or localized interruptions in the utility system.

4. Power outages can precipitate various types of insurance claims from residential, commercial, or industrial customers (e.g., business interruption, property loss, machinery breakdown, additional living expense, and claims as well as claims by utilities for unserved energy). Insurance claims for "data losses" are a growing issue.

5. Risk management options for insurance companies fall into two broad categories. Financial techniques include limiting insurance exposure e.g., by means of deductibles or loss limits (for insurance providers). Engineering risk management techniques include a host of technology responses that may be promoted by insurers, ranging from specific technologies such as back-up generation to management strategies such as early warning systems and post-event business continuity planning.

6. Insurers are likely to increase their participation in risk management in the future (both to reduce their exposure and the loss potential on the customer side) and have begun to explore collaborations with electricity and equipment providers. Some innovative examples are already visible. In some instances, energy-efficient technologies offer ancillary loss-control benefits by making systems more resilient following power disruptions.

Recommendations for Next Steps:

1. Use insurance techniques to provide a new proxy for the value of electricity reliability nationally in order to seek additional insight on how insurers "value" electricity reliability. This could be approached by defining a series of representative customer types and having the appropriate insurances (e.g. business interruption with utility service interruption endorsements) priced by major insurers. These data could be generalized to the overall population, along with the magnitudes of deductibles stipulated by insurers. 
2. Obtain quantitative information from self insurers on reliability related losses, as well as on risk-management strategies. A weakness in our current assessment is that it does not capture information on self-insurance, which represents nearly half of today's insurance market (and is growing faster than commercial insurance). Data from self insurers (gathered via their trade association) may also be more comprehensive and more readily available than commercial insurance data, and would have special value in that it would include costs not captured by deductibles.

3. Conduct analysis for and pursue coordination among insurers and energy-focused firms to identify and value the risk-management characteristics of electricity reliability enhancing and energy efficiency technologies in the context of the insurance marketplace, both from technical and market standpoints. Part of the strategic value lies in the potential leverage provided by innovative partnerships between insurers and public and private entities already engaged in implementing energy efficiency. Insurers often serve as agents for new technologies. For example, certain energy end-use efficiency technologies can reduce the vulnerability of facilities to power outages, and the insurance community has begun to take note of this, although it has negligible knowledge of energy technologies. Meanwhile, energy-focused firms and organizations are in turn becoming increasingly sensitized to the so-called "non-energy benefits" of energy efficiency, although they have negligible knowledge of risk management.

4. Study and synthesize the growing scientific literature, particularly the soon-to-be released assessment of the Intergovernmental Panel on Climate Change, to provide energy planners and risk managers with a better sense of these changing risk factors. Most of today's power outages are caused or exacerbated by weather conditions and natural disasters. Anticipated changes in climate and weather systems could give rise to increased power outages. 


\section{Next Steps Toward a National Estimate of the Value of Reliable Electricity to the U.S. Economy}

In order to frame comprehensively the issue of trends in the economic value of reliability, this scoping study has offered partial answers to each of the following three key questions:

1. What is the cost to the U.S. economy of unreliable electricity?

2. How is the value of reliable electricity to the U.S. economy likely to change in the future?

3. How are customers addressing their reliability needs and risk management preferences?

An integral element of the project has been to develop recommendations for high-priority next steps that will lead to greater resolution of them. In this final section of the report, we integrate the recommendations developed in prior sections and prioritize them into a single list.

Our primary recommendation is to initiate development of a comprehensive framework and then estimate a range for the cost of unreliable electricity to the U.S. economy. We recommend a "bottom-up" approach in order to support sub-analyses for specific events, regions, or market sectors. First and most importantly, while an aggregate estimate is valuable for strategic reasons, estimates for specific events, regions, or market sectors are more useful for planning specific R\&D initiatives. Such estimates can only be developed through a bottom-up approach.

Second, a bottom-up approach is well-suited to future integration of information from different sources and perspectives. The organizing principle for future efforts should be triangulation. This scoping study has assembled information from a variety of sources and perspectives on the value of reliable electricity. Each source has added value to our understanding and should be an element of a comprehensive assessment. A bottom-up approach will facilitate piece-by-piece integration of new information as it becomes available.

Third, a bottom-up approach will permit a more structured approach to assessing uncertainty and prioritizing incremental data collection and analysis. That is, based on the information we have reviewed and our expectations regarding additional data and analysis that should be developed, a starting assumption for future work is that it will be incomplete to some degree. In order to be credible, therefore, it is critical that future analysis rigorously document key uncertainties. Credibility will be enhanced by clear statements regarding the limitations of future analyses. A bottom-up approach will provide a structure for making these qualifications.

In view of these considerations, we offer below a consolidated short-list of recommended priorities for next steps based on those developed in this scoping study. 
1. Collect, consolidate, and improve the quality of information on customer reliability costs. Priorities for pursuing this objective are reflected in the following recommended next steps from Section 2:

a) Extend the database on outage and power quality event costs to include older assessments, including work summarized in earlier surveys of the literature, and to include studies in the "gray" literature. By design, this study: 1) complemented the older body of work with information on newer estimates, and 2) focused on published estimates, which, for example do not include utility-sponsored studies that have not led to formal publications. A comprehensive database that includes all available estimates will facilitate meta-analysis and extrapolation.

b) Conduct meta-analysis to synthesize and better understand the limits of extrapolation of the database toward supporting development of a comprehensive national estimate and related sub-analyses. For any given event, location, or customer type, we are limited by available data. Meta-analysis can help to improve confidence in extrapolating from existing data.

c) Integrate information on costs of outages and power quality events with information on frequency of occurrence. Economic damage is a function of both the cost per event and the frequency of events; our work to date has focused only on costs per event.

d) Collect additional information on customer power quality costs. The paucity of data on power quality is a limitation of the current database for supporting the development of a national estimate or sub-analyses of the cost of reliable electricity. Case studies, such as those pursued to varying degrees in sections 3 and 5 of this report, should be considered (rather than limiting additional data collection to review of secondary data).

2. Systematically approach developing information on customer spending on capital and operations to address electricity reliability. Priorities for pursuing this objective draw from but also extend beyond recommendations in Sections 3, 4, and 5:

a) Work with vendors, manufacturers, trade associations (back-up generation, UPS, etc.) to gather aggregate information on spending and mitigation approaches. This scoping study has turned up anecdotal information on aspects of these trends. A more comprehensive approach working directly with the suppliers and vendors of reliability enhancing equipment and services is warranted. An important element of this work should be calculation of the implied cost of reliability as reflected in capital and operating expenditures for these activities. This is a "supply-side" approach to this issue.

b) Continue case studies to track high-reliability requirements customer market segments (cleanrooms, data centers, etc.) and/or equipment (PCs, ASDs, process controls). The analyses presented in Sections 3, 4, and especially 5 point to the value of case studies targeted to specific sectors, processes, or equipment types known to have high reliability requirements. Targeted analysis of these activities should be a priority for future studies. A high priority for these activities should be on-going 
review of trends in information technologies, including data on shipments, improvements in power management and tolerances for poor power quality, and insitu measurement of electricity use. This is a complementary "demand-side" approach to this issue.

3. Develop relationships with the insurance industry to develop information on customer spending on insurance. This scoping study has identified the insurance industry as key source of information on the cost of electricity reliability and as a potential partner for promoting technology solutions. For example, establishing an information sharing relationship with the insurance industry could lead to the availability of more disaggregate information on reliability-related premiums and claims. Several of the recommendations in Section 6 should be priorities for future work:

a) Use insurance techniques to provide a new proxy for the value of electricity reliability nationally in order to seek additional insight on how insurers "value" electricity reliability. This could be approached by defining a series of representative customer types and having the appropriate insurances (e.g. business interruption with utility service interruption endorsements) priced by major insurers. These data could be generalized to the overall population, along with the magnitudes of deductibles stipulated by insurers.

b) Obtain quantitative information from self insurers on reliability related losses, as well as on risk-management strategies. A weakness in our current assessment is that it does not capture information on self-insurance, which represents nearly half of today's insurance market (and is growing faster than commercial insurance). Data from self insurers (gathered via their trade association) may also be more comprehensive and more readily available than commercial insurance data, and would have special value in that it would include costs not captured by deductibles.

c) Conduct analysis for and pursue coordination among insurers and energy-focused firms to identify and value the risk-management characteristics of electricity reliability enhancing and energy efficiency technologies in the context of the insurance marketplace, both from technical and market standpoints. Part of the strategic value lies in the potential leverage provided by innovative partnerships between insurers and public and private entities already engaged in implementing energy efficiency. Insurers often serve as agents for new technologies. 


\section{References}

Aldred, C. 2000. "New Climate of Cooperation." Business Insurance (November 20) p. 29.

A.M. Best Co. 2000. Best's Aggregates \& Averages: Property-Casualty, United States. Oldwick, New Jersey. Information used in this report Copyright (C) by A.M. Best Company, Inc. All Rights Reserved. Reprinted with Permission.

Baruch, S.B. and M.L. Carrido. 1998. Disaster Recovery Business Alliance. http://www.acp-international.com/drba/

Beenstock, M., E. Goldin and Y. Haitovsky. 1997. "The Cost of Power Outages in the Business and Public Sectors in Israel: Revealed Preference vs. Subjective Valuation." The Energy Journal. 18(2):39-60.

Best's Review--Property-Casualty Insurance Edition. 1999. "Products Protect Computers from Interruptions in Power." P. 100 (August).

Billinton, R. and M. Pandey. 1999. "Reliability Worth Assessment in a Developing Country - Residential Survey Results." IEEE Transactions on Power Systems. 14(4):1226.

Billinton, R. and P. Wang. 1998. "Distribution System Reliability Cost/Worth Analysis Using Analytical and Sequential Simulation Techniques." IEEE Transactions on Power Systems. 13(4):1245 (6 pages).

Bollen, M. H. 1999. Understanding Power Quality Problems: Voltage Sags and Interruptions. New York: The Institute of Electrical and Electronics Engineers, Inc.

Bowers, B. 2000. "We Interrupt This Disaster...." Best's Review--Property-Casualty Insurance Edition. http://www.bestreview.com/pc/1998-08/pccover.html.

Bradford, S. 2000. "Powering Innovations." Risk Management (October) p. 18-24.

Brender, D. 1998. "Clean and Constant: The Basics of Power Quality." Energy User News. 23(11):49 (1 pages).

Brown, P. 1996. "Power Outages Spark a Drive for Back-Up Wafer Fabrication Facilities in Five Western States Hit by Massive Power Outage." Electronic News (1991). 42(2130):1 (2 pages).

Burcke, J.M. 1994. "Quick Action Averts Disaster at Plants - Mother Nature Tests Preparedness of Risk Managers.” Business Insurance, April 18. 
Business Insurance. 2001 "Utilities' Woes May Generate Financial Guarantee Claims." January 22, p.1.

Business Insurance. 1999a. "Con Ed Faces Suits in Blackout.” July 9.

Business Insurance. 1999b. "Deliberate Blackout in Chicago Might Spur Claims against Utility." (August 16):1.

Business Insurance. 1998a. "Bay Area Blackout Sparks Claims" (December 14), p. 1.

Business Insurance. 1998b. "Storms in Midwest, East to Cost Insurers Millions." (June 8), p. 1.

California Energy Commission (CEC). 1997. A Survey of the Implications to California of the August 10, 1996 Western States Power Outage. California Energy Commission.

Carrido, M.L. 2000. "An International Disaster Recovery Business Alliance." NaturalHazards Review, Vol. 1, No. 1, pp. 50-55.

Caves, D. W., J. A. Herriges and R. J. Windle. 1992. "The Cost of Electric Power Interruptions in the Industrial Sector: Estimates Derived from Interruptible Service Programs." Land Economics. 68(1):49-61.

Ceniceros, R. 2001a. "Utilities Facing New Risks." Business Insurance, January 15, p.1.

Ceniceros, R. 2001b. "Companies Cope with Outage Risk." Business Insurance, January 29, p.1.

Chang, S.E., H.A. Seligson, and R.T. Eguchi. 1996. "Estimation of the Economic Impact of Multiple Lifeline Disruption: Memphis Light, Gas and Water Division Case Study." NCEER Bulletin (April). Multidisciplinary Center for Earthquake Engineering Research. http://mceer.buffalo.edu/publications/bulletin/96/02/apr96nb.html

Chen, R.-L., K. Allen and R. Billinton. 1995. "Value-Based Distribution Reliability Assessment and Planning." IEEE Transactions on Power Delivery. 10(1):421 (9 pages).

Chen, S. 1999. "Taiwan's Power Outage Could Cost Chip Industry \$62m." Electronic Buyers' News. (August 2, 1999):8.

Clemmensen, J., J. Bates, and S. Kraft. 1999. "The Top 50 Equipment Suppliers and Service Providers," Power Quality Assurance Magazine, Vol. 10, No. 4 (July), pp. 13-25.

Clemmensen, J. M. 1993. "Estimating the Cost of Power Quality." IEEE Spectrum. 30(6):40 (2 pages). 
Coccia, R. 1996. "Insurer Topics: Insurers Jump in to Help Clients Prevent Losses." Business Insurance, November 18.

Colombo, A.F., D. Etkin and B.W. Karney. 1999. "Climate Variability and the Frequency of Extreme Temperature Events from Nine Sites across Canada: Implications for Power Usage." Journal of Climate, vol. 12. pp. 2490-2502.

D'Esopo, C.M.1997. “An Innovative Approach to Risk Evaluations and Risk-based Engineering.” Arkwright Mutual Insurance Company.

Deering, A. and J.P. Thornton. 2000. "Solar Solutions for Natural Disasters." Risk Management, pp. 28-33, Risk and Insurance Management Society: New York, NY (February).

Dlugolecki, A. 2001. CGU Insurance. Personal communication.

Donmoyer, R. J. 1998. "Darkness Down Under. Major Power Outage Enters Second Month in Auckland, New Zealand.” U.S. News \& World Report. 124(13):49 (1 pages).

Douglas, J. 2000. Personal communication.

Easterling, D.R., G.A. Meehl, C. Parmesan, S. Changnon, T.R. Karl, and L.O. Mearns. 2000. "Climate Extremes, Observations, Modelling and Impacts." Science, vol. 289, pp. 2068-2074.

Electronic News .1999. "Taiwan Blackout Watch." 1999. 45(31):4.

Electronic News. 1999. "No Interruption at Billion Dollar Mark." 45(13):35 (1 pages).

Emergency Preparedness Canada. 2000. EPC Disaster Database version 3.0. http://www.epc-pcc.gc.ca/research/epcdatab.html

EPRI. 2000. Electricity Technology Roadmap, Power Delivery. Palo Alto CA: EPRI.

EPRI Journal. 1993. "Superconducting May Keep Trains Running." 18(3):35 (1 pages).

EPRI. Nd. "About Disaster Planning and Mitigation Technologies." Electric Power Research Institute.

http://www.epri.com/targetDesc.asp?program $=207881 \&$ value $=00 \mathrm{~T} 022.0$

Fairfax, S. 2000. Personal communication.

Fitzgerald, P. 2000. Personal Communication. August 25 
Gastel, R. 2000. "Insolvencies/Guaranty Funds". Insurance Information Institute website, Washington, D.C., see http://www.iii.org

Gates, J., R. Billinton and G. Wacker. 1999. "Electric Service Reliability Worth Evaluation for Government, Institutions and Office Buildings." IEEE Transactions on Power Systems. 14(1):43 (8 pages).

Gilmer, R. W. and R. S. Mack. 1983. "The Cost of Residential Power Outages." The Energy Journal. 4:55-74.

Goel, L. 1998. "Power System Reliability Cost/Benefit Assessment and Application in Perspective." Computers \& Electrical Engineering. 24(5):315 (10 pages).

Goel, L. and R. Billinton. 1994. "Determination of Reliability Worth for Distribution System Planning." IEEE Transactions on Power Delivery. 9(3):1577 (7 pages).

Gordes, J. N. 2000. The Power to Insure: Reducing Insurance Claims with New Electricity Options. Northeast Sustainable Energy Association.

Gordon, P. and H.W. Richardson. 1992. Business Interruption Effects of a Major Earthquake in the Newport/Inglewood Fault Zone. Prepared for the National Committee on Property Insurance, Boston, MA, by the School of Urban and Regional Planning, University of Southern California, Los Angeles, CA.

Haney, C. 1999. "Power Loss Costs Taiwan Chip Vendors Up to US\$40M." International Data Group. August 3.

Hartford Steam Boiler Inspection \& Insurance Company. 2000. Presentation by Richard Jones at the Earth Technologies Forum, Washington, D.C.

Higgins, Y. 1998. "Report Faults Kiwi Utility in Outage. Power Failure in Auckland, New Zealand." Business Insurance. 32(33):41 (2 pages).

Hsu, G. J. Y., P.-1. Chang and T.-y. Chen. 1994. "Various Methods for Estimating Power Outage Costs: Some Implications and Results in Taiwan." Energy Policy. 22(1):69 (6 pages).

Industrial Machinery Insurance Association (IMIA). 1996. Failure of Large Oil Cooled Transformers. http://www.imia.com/documents/failure.htm\#8.

Inland Marine Underwriters Association (IMUA). 2000. Underwriting Semiconductor Manufacturing Exposures. New York, NY.

Institute for Business and Home Safety. 1999. Insured Losses from the Northridge Earthquake. Institute for Business \& Home Safety, Boston. 
Institute of Electrical and Electronics Engineers (IEEE). 1998. IEEE Recommended Practices for Design of Reliable Industrial and Commercial Power Systems, The Gold Book. IEEE Standard 493-1997. IEEE. Piscataway, NJ.

Insurance Information Institute. 1999. 29th Conference of the Insurance Information Institute. New York, NY.

Insurance Information Institute. 2000. The Insurance Fact Book: 2000. New York, NY.

Jansen, F. and R. Pirjola. 2000. Space Weather: Hazard to Earth? Swiss Reinsurance Company, Zurich. http://www.swissre.com/e/issues/spaceweather.html

Jonnavithula, A. and R. Billinton. 1997. "Features That Influence Composite Power System Reliability Worth Assessment." IEEE Transactions on Power Systems. 12(4):1536 (6 pages).

Kawamoto, K., J. Koomey, B. Nordman, R. Brown, M. Piette, and A. Meier. 2000. Electricity Used by Office Equipment and Network Equipment in the U.S. 2000 ACEEE Summer Study on Energy Efficiency in Buildings. Asilomar CA. August.

Keener, R. N., 1997: The estimated impact of weather on daily electric utility operations. In: Social and Economic Impacts of Weather [Pielke Jr., R., (Ed.)]. Proceedings of a workshop at the University Corporation for Atmospheric Research, Boulder, CO, USA. http://www.esig.ucar.edu/socasp/weather1/keener.html

Kithil, R. 2000. Results of Investigations into Annual USA Lightning Costs and Losses. National Lightning Safety Institute, Louisville Colorado USA. http://www.lightningsafety.com/nlsi lls/nlsi annual usa losses.htm

Kithil, R. 1995. "Lightning's Social and Economic Costs." Presented at the International Aerospace and Ground Conference on Lightning and Static Electricity, (28 September). Kochaniec, J.W. 1999. "Storm Surges can Plague Unprepared." Business Insurance, September 13.

Koomey, J., M. Cramer, M. Piette, and J. Eto. 1995. Efficiency Improvements in U.S. Office Equipment: Expected Policy Impacts and Uncertainties. Lawrence Berkeley Laboratory. LBL-37383. December.

Laurin, L. and M. Tate. 2000. "Wet Bench Fire Safety: Update." A2C2: The Journal of Advancing Applications in Contamination Control. http://www.a2c2.com/archive/02micro.htm.

Lecomte, E., A.W. Pang, and J.W. Russell. 1998. Ice Storm '98. Institute for Catastrophic Loss Reduction (Canada) and Institute for Business and Home Safety (U.S.). 
Lehtonen, M. and B. Lemström. 1995. Comparison of the Methods for Assessing the Customers' Outage Costs. VTT Energy.

Mannion, J. 2000. Sure Power Corporation. Presentation on "High 9s CHP in the Internet Age," at the EPA's $21^{\text {st }}$ Century Labs website.

Maclean's. 1996. "In the Dark." 109(29):37 (1 page).

McIlvane Co., 1996. World Cleanroom Markets 1996-2000. Illinois.

Mello, J. C. O., M. V. F. Pereira and A. M. L. da Silva. 1994. "Evaluation of Reliability Worth in Composite Systems Based on Pseudo-Sequential Monte Carlo Simulation." IEEE Transactions on Power Systems. 9(3):1318 (9 pages).

Mills, E., G. Lecomte, and A. Peara. 2000. Perspectives of U.S. Insurers on Global Climate Change. LBNL-45185. Lawrence Berkeley National Laboratory, Berkeley, CA.

Mills, E. 1999. "The Insurance and Risk Management Industries: New Players in the Delivery of Energy-Efficient Products and Services." Proceedings of the ECEEE 1999 Summer Study, European Council for an Energy-Efficient Economy, May 31-June 4, 1999, Mandelieu, France, and for the United Nations Environment Programme's $4^{\text {th }}$ International Conference of the Insurance Industry Initiative, Natural Capital at Risk: Sharing Practical Experiences from the Insurance and Investment Industries, (July 1011), Oslo, Norway.

Mills, E. 1997. "Going Green Reduces Losses." Reinsurance, London (March), p. 24.

Mills, E., A. Deering, E. Vine. 1998. "Energy Efficiency: Proactive Strategies for Risk Managers. " Risk Management, pp.12-16, (March), and as Lawrence Berkeley National Laboratory Report 41751.

Mills, E., G. Bell, D. Sartor, A. Chen, D. Avery, M. Siminovitch, S. Greenberg, G. Marton, A. de Almeida, and L.E. Lock. 1996. Energy Efficiency in California

Laboratory-Type Facilities. Lawrence Berkeley National Laboratory Report No 39061.

MSS Clean Technology, 2000. Personal Communication.

Mulligan, T.S. 2000. “Tech Companies a Drain on Power Grid.” Los Angeles Times, Tuesday, December 12.

Munasinghe, M. 1980. "Costs Incurred by Residential Electricity Consumers Due to Power Failures." Journal of Consumer Research. 6:361-369.

National Underwriter. 2000. 'New Cyber-Risk Cover Offered." (October 23) p. 48. 
Neudorf, E. G., D. L. Kiguel, G. A. Hamoud, B. Porretta, W. M. Stephenson, R. W. Sparks, D. M. Logan, M. P. Bhavaraju, R. Billinton and D. L. Garrison. 1995. "CostBenefit Analysis of Power System Reliability: Two Utility Case Studies." IEEE Transactions on Power Systems. 10(3):1667.

Odam, G. 2000. Effects of Lightning on Assets, Facilities and Structures. Lightning Safety Institute. http://www.lightningsafety.com/nlsi lhm/effect.html

O’Dwyer, G. 1998. "Scandinavian Utilities Turning to Captives." Business Insurance, April 6.

Oil and Gas Journal. 1997. "Frmosa Plastics and Other Petrochemical Producers in Taiwan Face Losses in Excess of \$11 Million from a 2-Min. Power Outage May 29, 1997" 95(23):28 (1 pages).

Price, C. and Rind, D. 1993. "Lightning Fires in a 2xCO2 World." Proceedings of the 12th Conference on Fire and Forest Meteorology, Oct. 26-28, Jekyll Island, Georgia, pp. 77-84.

Price, K. 1993. "Practices for Solving End-User Power Quality Problems." IEEE Transactions on Industry Applications. 29(6):1164.

Property Claim Services. 2000. Catastrophe Loss Database. PCS, A unit of the Insurance Service Office, Inc.

Reed, P. and P. I. Thomas. 1969. Adjustment of Property Losses. McGraw Hill. $3^{\text {rd }}$ Ed.

Reeve, N. and R. Toumi. 1999. "Lightning Activity As An Indicator of Climate Change." Quarterly Journal of the Royal Meteorological Society, vol 124, pp. 893-903.

Reuters. 1999. "Chevron Corp. Got An Initial Insurance Payment of \$15 Million." (March 16).

Robertson, C. 2000. Personal Communication.

Rodentis, S. 1999. "Can Your Business Survive the Unexpected?" Journal of Accountancy. (February). 187(2). American Institute of Certified Public Accountants. http://www.aicpa.org/pubs/jofa/feb1999/rodetis.htm.

Rutkin, A.S. 2000. "Policies Must Be Specific." Best's Review--Property-Casualty Insurance Edition (October) p. 122.

Sanghvi, A. P. 1990. Cost-Benefit Analysis of Power System Reliability: Determination of Interruption Costs. Volume 1: Measurement Methods and Potential Applications in Reliability Cost-Benefit Analysis. Palo Alto: Electric Power Research Institute. EL-6791, 
Volume 1.

Sankarakrishnan, A. and R. Billinton. 1996. "Effective Techniques for Reliability Worth Assessment in Composite Power System Networks Using Monte Carlo Simulation.” IEEE Transactions on Power Systems. 11(3):1255.

Schmerken, I. 1990. "Wall Street Stretches to Stem the Tide." Wall Street Computer Review. 8(2).

Semiconductor Industry Association (SIA), 2000. http://www.semichips.org/

Sherman, R.E. 2000. “Ask a Casualty Actuary.” Business Insurance. February 14.

Spoiden, J-F. 2000. "Sun Burned." Best's Review--Property-Casualty Insurance Edition (July) p. 72-76.

Stauffer, R.F. 1995. Nature's Power on Demand: Renewable Energy Systems as Emergency Power Sources. U.S. Department of Energy, Office of Energy Efficiency and Renewable Energy. http://www.sustainable.doe.gov/freshstart/articles/enrgsyst.htm.

Streetskamp, I. and A. Van Wijk. Stroomloos: Kwetsbaarheid Van De Smenleving; Gevolgen Van Verstoringen Van De Elektriciteitsvoorziening. Rathenau: Rathenau Instituut.

Sullivan, M. J., B. N. Suddeth, T. Vardell and A. Vojdani. 1996. "Interruption Costs, Customer Satisfaction and Expectations for Service Reliability." IEEE Transactions on Power Systems. 11(2):989.

Sullivan, M. J., T. Vardell and M. Johnson. 1997. "Power Interruption Costs to Industrial and Commercial Consumers of Electricity." IEEE Transactions on Industry Applications. 33(6):1448-1458.

Swaminathan, S. and R. Sen. 1998. Review of Power Quality Applications of Energy Storage Systems. SAND98-1513. Sandia National Laboratories, Albuquerque NM and Livermore CA.

Swiss Re. 2000. Twister! The Professional Reinsurer's Perspective. Sigma Report No. 1/2000. Swiss Re, Zurich.

Szalai, G. 1998. "Businesses in the Dark: Outages Don't Switch On Insurance Coverage." Business Insurance, July 6.

Time International. 1998. "Blackout Problems Continue in New Zealand.” 150(32):10 (1 pages).

"To Attract High-Tech Tenants, Give Them High-Quality Power.” 1996. Electrical 
World. 210(10):53 (3 pages).

Tollefson, G., R. Billinton and G. Wacker. 1991. "Comprehensive Bibliography on Reliability Worth and Electrical Service Consumer Interruption Costs: 1980-1990." IEEE Transactions of Power Systems. 6(4):1508-1514.

Tollefson, G., R. Billinton, G. Wacker, E. Chan and J. Aweya. 1994. "A Canadian Customer Survey to Assess Power System Reliability Worth." IEEE Transactions on Power Systems. 9(1):443 (8 pages).

Tronsberg, C. 1997. "Disaster Planning Remains Critical as Deregulation Drives Ahead." Power Engineering (July), PennWell Publishing Company.

http://www.fmglobal.com/news/media/bl199707.html

U.S. Department of Commerce, Bureau of the Census. 2000. Annual Survey of Manufactures. Washington, D.C.

U.S. Department of Commerce, Bureau of the Census, 1998. Annual Survey of Manufacturers. Washington, D. C.

U.S. Department of Commerce, Bureau of the Census, 1995. Annual Survey of Manufacturers. Washington, D. C.

University of Surrey and IIASA. 2000. The Uninsured Elements of Natural Catastrophic Losses: Northridge Earthquake.

Vine, E., E. Mills, and A. Chen. 1999. "Tapping Into Energy: New Technologies and Procedures that Use Energy More Efficiently or Supply Renewable Energy Offer a Largely Untapped Path to Achieving Risk Management Objectives," Best's Review-Property-Casualty Insurance Edition, (May), pp. 83-85.

Vine, E., E. Mills, and A. Chen. 2000. "Energy-Efficient and Renewable Energy Options for Risk Management \& Insurance Loss Reduction." Energy 25 131-147.

Wall Street Journal. 1990. "New York's Con Edison Hit with Lawsuits Arising from Monday's Blackout." (August 16), p. B4.

Wang, P. and R. Billinton. 1999. "Time Sequential Distribution System Reliability Worth Analysis Considering Time Varying Load and Cost Models." IEEE Transactions on Power Delivery. 14(3):1046 (6 pages).

Wassmer, L. and M. Frey. 1999. "Insurance for Semiconductor Plants During Construction and Operation." Industrial Machinery Insurers' Association (IMIA) meeting 1999. Prepared by Swiss Re; presented by Munich Re.

http://www.imia.com/documents/semiconductor.htm 
Webb, G.R., K.J. Tuierney, and J.M. Dahlhamer. 2000. "Business and Disasters: Empirical Patterns and Unanswered Questions." Natural Hazards Review, Vol 1, No. 2. p. 83-90.

Wintrob, S. 1995. "Trouble on the Exchange: Vsf Survives One-Day Scare." Computing Canada. 21(12):1-2.

Wojcik, J. 1998. “Bay Area Blackout Sparks Claims.” Business Insurance, December 14.

Option in Residential Electricity Pricing.” The Energy Journal. 7(3):123-135.

Worrell, E., Martin, N., and Price, L. 1999. Energy Efficiency and Carbon Emissions Reduction Opportunities in the U.S. Iron and Steel Sector. Berkeley CA: Lawrence Berkeley National Laboratory (LBNL-41724).

Xenergy, Inc. 1998. "United States Industrial Motor Systems Market Opportunities Assessment," prepared for U.S. DOE-OIT and ORNL, Burlington MA: Xenergy, Inc.

Zolkos, R. 1998. “1998 RIMS Report: Contingent Coverage Poses Challenges.” Business Insurance, May 11.

Zolkos, R. 1997. 'Property Loss Control: 'Just-in-Time' Approach Exacerbates Risk of Contingent Business Interruption.” Business Insurance. August 18. 


\section{Appendix A. Electricity Outage Cost Literature Review - References and Abstracts}

Adams, R. A., S. W. Middlekauf, E. H. Camm and J. A. McGee. 1998. "Solving Customer Power Quality Problems Due to Voltage Magnification." IEEE Transactions on Power Delivery. 13(4):1515 (6 pages).

Reports by a Duke Power customer concerning equipment malfunctioning coincident with the switching of a $100 \mathrm{kV}$ shunt capacitor bank led to field measurements and EMTP simulations to identify the possible sources of the problems and to find an economical solution. Measurements and simulation revealed the occurrence of voltage magnification at the customer's site due to the effects of three different distribution capacitor banks on the feeder supplying the customer. A comparative evaluation of commercially-available capacitor-switching transient mitigation switching devices suggested the use of lowresistance pre-insertion inductors applied with circuit switchers to energize the $100 \mathrm{kV}$ capacitor bank. Field measurements of capacitor-switching events after installation of pre-insertion inductors verified the elimination of voltage magnification and customer power quality problems.

Aniba, M. A., K. M. Bradley, S. A. Hurff and F. J. Mercede. 1992. "Industry-Sponsored Student Projects to Promote Power Quality Education." IEEE Transactions on Power Systems. 7(4):1550 (9 pages).

At Widener University, undergraduate power engineering students are exposed to the practical issues of power quality through the Senior Design Project Program. The purpose of this paper is to present the results of two industry-sponsored senior design projects on power quality: "Effect of Harmonic Current Distortion on Power Transformer Capability," sponsored by the Philadelphia Electric Company (PECO), and "Power Quality Survey of a Commercial System," sponsored by BCM Engineers. The success of these student projects has promoted interest in power engineering as a career for many of the group members and generated enrollment in the senior-level power program.

"Blackout Problems Continue in New Zealand." 1998. Time International. 150(32):10 (1 pages).

Beenstock, M., E. Goldin and Y. Haitovsky. 1997. "The Cost of Power Outages in the Business and Public Sectors in Israel: Revealed Preference vs. Subjective Valuation." The Energy Journal. 18(2):39-60.

Cross-section data on investment in back-up generators and uninterruptable power supplies (UPS) are used to infer the implied cost of electricity outages in the business and public sectors in Israel. Two-limit to bit models of the demand for back-up are estimated and used to simulate the mitigated and unmitigated cost of power outages. These "revealed preference" estimates of outage costs are then compared with estimates based on the method of subjective evaluation.

Billinton, R. and R. Ghajar. 1994. "Evaluation of the Marginal Outage Costs of Generating Systems for the Purposes of Spot Pricing." IEEE Transactions on Power 
Systems. 9(1):68 (8 pages).

This paper describes a methodology based on quantitative power system reliability evaluation for calculating the marginal outage costs of generating systems. The proposed method involves the calculation of the incremental expected unserved energy at a given operating reserve level and lead time and the multiplication of this value by the interrupted energy assessment rate of the system. The method is illustrated in this paper by calculating the marginal outage cost profile of the IEEE-Reliability Test System and by examining the effect of various modeling assumptions on that profile.

Billinton, R. and M. Pandey. 1999. "Reliability Worth Assessment in a Developing Country - Residential Survey Results." IEEE Transactions on Power Systems. 14(4):1226.

This paper presents the results of a residential customer survey conducted in service areas of the Nepal Integrated Electric Power System (NPS). The objective was to determine the power interruption costs incurred by the residential customers of a developing country, and extend the customer survey approach to reliability worth evaluation in a developing environment. Interruption cost estimates were obtained using in-person interviews with 944 sample customers. The results indicate the implications of service reliability to residential customers of Nepal, and show that reliability worth evaluation in a developing country is both possible and practical.

Billinton, R. and P. Wang. 1998. "Distribution System Reliability Cost/Worth Analysis Using Analytical and Sequential Simulation Techniques." IEEE Transactions on Power Systems. 13(4):1245 (6 pages).

The requirements for extensive justification of new facilities and emphasis on the optimization of system cost and reliability are steadily increasing. Customer interruption cost analysis provides valuable input to electric power supply reliability worth assessment. This paper presents both a generalized analytical approach and a time sequential Monte Carlo simulation technique for evaluating the customer interruption cost in complex radial distribution systems. Studies are conducted on two practical distribution systems. The results obtained using the analytical technique incorporating average restoration times are compared with those obtained using the time sequential simulation method and random restoration times. The effects on customer interruption cost indices associated with alternate supply and protection devices are also considered.

Bollen, M. H. 1999. Understanding Power Quality Problems: Voltage Sags and Interruptions. New York: The Institute of Electrical and Electronics Engineers, Inc.

Brender, D. 1998. "Clean and Constant: The Basics of Power Quality." Energy User News. 23(11):49 (1 pages).

Brown, P. 1996. "Power Outages Spark a Drive for Back-Up Wafer Fabrication Facilities in Five Western States Hit by Massive Power Outage." Electronic News (1991). 42(2130):1 (2 pages).

A massive five-state power outage in the western U.S. has focused emphasis on the 
need for uninterruptible power supplies (UPS) for semiconductor facilities. The Western Systems Coordinating Council (WSCC) states that it is impossible to prevent future power outages, but the organization is taking steps to make the system as reliable as possible. American Power Conversion's (APC) UPSs are already protecting some major semiconductor facilities, including National Semiconductor, LSI Logic and Applied Materials. Intel and Motorola suffered wafer losses and equipment damage because neither company has formulated contingency plans or purchased backup power generators. Fujitsu's of Portland, OR suffered minor losses, but the company feels that the possibility of more blackouts in that state are so minimal they do not warrant preventive measures.

Caves, D. W., J. A. Herriges, P. Hanser and R. J. Windle. 1988. "Load Impact of Interruptible and Curtailable Rate Programs: Evidence from Ten Utilities." IEEE Transactions on Power Systems. 3(4):1757-1763.

Caves, D. W., J. A. Herriges and R. J. Windle. 1992. "The Cost of Electric Power Interruptions in the Industrial Secotr: Estimates Derived from Interruptible Service Programs." Land Economics. 68(1):49-61.

The electric power industry has become increasingly interested in the value customers place upon service reliability, with the demand for reliability couched in terms of outage or shortage costs. The survey-based method of eliciting these costs dominates the literature. This paper explores and demonstrates a method for estimating outage and shortage costs based on behavioral data. A discrete choice model is developed for estimating shortage costs using observed decisions of industrial customers regarding participation in interruptible service programs. The resulting shortage cost estimates of $\$ 4$ per $\mathrm{kWh}$ unserved for a one-hour interruption are consistent with previous surveybased estimates.

CEC (California Energy Commission). 1997. A Survey of the Implications to California of the August 10, 1996 Western States Power Outage. California Energy Commission.

On December 13, 1996, the California Energy Commission contracted for a telephone survey sample of California's residential, commercial and industrial electricity consumers to assess the effects of the Saturday, August 10, 1996, western states power outage. Results include information on experiences with interruptions and outages, financial losses, use of back-up power supplies, satisfaction with electric power service, and the importance of reliable service.

Findings show that most consumers experience very few outages. Outages are more disruptive for residential consumers on weekends, and more disruptive for most commercial and industrial consumers on weekdays.

Approximately 44 percent of California consumers experienced the August 10, 1996, outage, and most did not incur financial losses. However, a few commercial and industrial consumers experienced losses of $\$ 50,000$ to $\$ 5,000,000$. More in-depth research regarding losses from outages is needed. Some commercial and industrial 
consumers have back-up power supplies and used them during the August 1, 1996, outage.

Most consumers are either very or somewhat satisfied with their present electric service. A total of 85.5 percent of residential, 89.5 percent of commercial, and 95.0 percent of industrial consumers said reliable, uninterrupted service is important. Some would be willing to pay higher rates for greater reliability. However, more research is needed to determine amounts and levels of reliability expected.

Chang, S. E., H. A. Seligson and R. T. Eguchi. 1996. "Estimation of the Economic Impact of Multiple Lifeline Disruption: Memphis Light, Gas and Water Division Case Study.” NCEER Bulletin. (April 1996)

Chao, H.-p. and R. Wilson. 1987. "Priority Service: Pricing, Investment, and Market Organization." The American Economic Review. 77(5):899-916.

Chen, R.-L., K. Allen and R. Billinton. 1995. "Value-Based Distribution Reliability Assessment and Planning." IEEE Transactions on Power Delivery. 10(1):421 (9 pages).

This paper presents a reliability assessment method for radial distribution systems. It combines the radial network reliability and the customer interruption costs to form the Value-Based Distribution Reliability Assessment (VBDRA) methodology, which is a valuable tool for distribution system planning incorporating customer interruption costs. The proposed method is implemented in a Lotus 1-2-3 macro program with a specially designed data structure for the radial network. The analysis of the proposed computational method shows that the method is valid and fast in practical applications. Various applications of VBDRA planning at the Scarborough Public Utilities are reported in the paper.

Chen, S. 1999. "Taiwan's Power Outage Could Cost Chip Industry \$62m.” Electronic Buyers' News. (August 2, 1999):8.

Chowdhury, A. A. and D. O. Koval. 1999. "Value-Based Power System Reliability Planning." IEEE Transactions on Industry Applications. 35(2):305 (7 pages).

In a competitive energy market in which power supply reliability can influence customer purchasing decisions, electric utilities throughout the world are rapidly recognizing that they cannot ignore customer preferences. Today's energy market is characterized by intense price competition, and electric utilities are faced with new challenges of large debts, budget constraints, safety, environment and economic issues, lower load growth than in the past, need for more involvement of public at large in the planning and design process, and more competitive nonconventional suppliers of electricity. In addition, in a deregulated competitive energy market, electric utilities are under conflicting pressures of providing even higher standards of service reliability and holding the line on rates. Value-based system facility planning offers a rational response to these conflicting customer demands. This paper presents two case studies to illustrate the basic concepts and applications of value-based power system planning. The paper also 
presents a methodology for determining the unique composite customer cost of interruptions (i.e., damage functions) for changing area system network configurations. These techniques are presently being used in the decision-making processes at Alberta Power Limited, Edmonton, Alta., Canada.

Clemmensen, J. M. 1993. "Estimating the Cost of Power Quality." IEEE Spectrum. 30(6):40 (2 pages).

Estimating the cost of power interruption can demonstrate the advantage of backup power supplies. Equations to calculate costs appear in the IEEE 466-1987 standard Orange Book for power-interruption costs. Estimators first figure the costs of power interruption per incident, including loss of productivity and scrap. Estimators should include employees' rate of pay and overhead, cleanup costs, equipment damage and restart time. Estimators should also consider loss of opportunity such as interest payments. Companies can then compare the estimates with the costs of improvements. Groups of companies could use their estimates to figure the loss caused by power interruptions to their industry. Costs to service and commercial sectors should be figured instead by estimating the probability of power interruption, the number of commercial facilities in the US and the average energy used per year.

Coursey, D. L., J. L. Hovis and W. D. Schultz. 1987. "The Disparity between Willingness to Accept and Willingness to Pay Measures of Value.." Quarterly Journal of Economics. August 1987:679-690.

Crew, M. A. and P. R. Kleindorfer. 1978. "Reliability and Public Utility Pricing." The American Economic Review. 68(1):31-40.

Daish, M. and J. L. Fetters. 1999. "The Key to Knowing the Quality of Your Purchased Power." Energy User News. 24(1):40.

Dalton, J. G., III, D. L. Garrison and C. M. Fallon. 1996. "Value-Based Reliability Transmission Planning." IEEE Transactions on Power Systems. 11(3):1400 (9 pages).

This paper presents a new value-based reliability planning (VBRP) process proposed for planning Duke Power Company's (DPC) regional transmission system. All transmission served customers are fed from DPC's regional transmission system which consists of a $44-\mathrm{kV}$ predominantly radial system and a $100-\mathrm{kV}$ predominantly non-radial system. In the past, any single contingency that could occur during system peak conditions and cause a thermal overload required the overloaded facility to be upgraded, regardless of the costs or the likelihood of the overload occurring.

The VBRP process is based on transmission system reliability evaluation and includes the following important elements: 1) a ten-year historical data base describing the probabilities of forced outages for lines and transformers; 2) a five-year average load duration curve describing the probability of an overload should a contingency occur; 3) a customer outage cost data base; 4) and probabilistic techniques. The new process attempts to balance the costs of improving service reliability with the benefits or value 
that these improvements bring to these customers. The objective is to provide our customers their required level of reliability while minimizing the Total Cost of their electric service.

"Deliberate Blackout in Chicago Might Spur Claims against Utility." 1999. Business Insurance. (August 16):1.

Domijan, A., G. T. Heydt, A. P. S. Meliopoulos, S. S. Venkata and S. West. 1993. "Directions of Research on Electric Power Quality." IEEE Transactions on Power Delivery. 8(1):429 (8 pages).

In this paper, several important research areas in electric power quality are described. Aspects of electric power quality have been categorized: fundamental concepts; modeling and analysis; measurement and instrumentation; sources; solutions; effects; and educational issues. The goal of the paper is to identify the high priority research areas in electric power quality, and to stimulate interest in this topic. COPYRIGHT Institute of Electrical and Electronics Engineers Inc. 1993

Donmoyer, R. J. 1998. "Darkness Down Under. Major Power Outage Enters Second Month in Auckland, New Zealand." U.S. News \& World Report. 124(13):49 (1 pages).

Dorr, D. S. 1995. "Point of Utilization Power Quality Study Results." IEEE Transactions on Industry Applications. 31(4):658 (9 pages).

A wide variety of electromagnetic phenomena occurring on ac power lines has been held responsible for literally billions of dollars per year in lost revenue. Information related to actual probability of occurrence of these power line deviations is presently limited. This paper describes the results of four years of point of utilization power quality monitoring at 112 North American locations. A quantity of 1,057 site months of data collected between 1990 and 1994 was used in this assessment. The data indicate that the numbers of events occurring at typical locations may range from almost none, to thousands per month. The analysis results characterize several aspects of power quality related to the occurrence of low RMs events, high RMs events, transient events, and power interruptions (outages).

Dorr, D. S., M. B. Hughes, T. M. Gruzs, R. E. Jurewicz and J. L. McClaine. 1997. "Interpreting Recent Power Quality Surveys to Define the Electrical Environment." IEEE Transactions on Industry Applications. 33(6):1480 (8 pages).

Recent ac power-line monitoring projects have enabled a better understanding of the typical electrical environment within which sensitive electronic equipment must be able to operate. Voltage variations caused by utility protective regulation devices, as well as variations caused by load equipment, contribute to the total power quality picture. Regardless of the origin of these variations, the load equipment must be able to operate with some degree of immunity. The paper presents a combined assessment of data from three of the most recent power quality surveys. Results of this assessment suggest that load equipment with reasonable voltage regulation and interruption ride-through will withstand the majority of recorded power-line variations. A detailed analysis of monitor capabilities and limitations is presented, along with a discussion of the interpretation of 
power-line variations recorded at different monitoring locations.

Douglas, J. 1993. "Solving Problems of Power Quality." EPRI Journal. 18(8):6 (10 pages).

Power quality problems are a troublesome and costly concern for industries and personal users. The Electric Power Research Institute (EPRI) is currently undertaking research to develop new equipment and techniques for eliminating or minimizing power quality problems. In addition, the EPRI has also developed several thyristor-based controllers which allow users to eliminate power quality problems originating from the distribution system.

Eisenberg, B. 1997. "Ups Keeps Outages under Tight Control. Long-Term Backup with Upses. Special Report on Power Technologies; Part I: Power Protection." Electronic Engineering Times. (942):104 (1 pages).

Providing power backup over the long term with UPSs makes sense because they can be more convenient and more cost-effective compared to using generators. A UPS does not require flammable fuel and a permit to operate, and a UPS can be installed at the locale where it is needed rather than in a basement or on a roof. An optimal solution would be to use a UPS and a generator; during an outage, the UPS would provide a bridge of power while a generator is getting started. The more simple UPS is the off-line UPS, which provides power backup solely during power outages. Another option is the line-interactive UPS, which provides power backup during blackouts but offers added features compared to off-line UPSs, such as a tap-switching transformer. A third option is online UPSs, which provide better usage of input utility power.

Faber, J. 1988. "Upgraded Control Systems Need High-Quality Power." Electrical World. 202(5):73 (4 pages).

"Formosa Plastics and Other Petrochemical Producers in Taiwan Face Losses in Excess of \$11 Million from a 2-Min. Power Outage May 29, 1997" 1997. Oil and Gas Journal. 95(23):28 (1 pages).

Garber, L. 1996. "AOL Blackout Indicates Need for Reliable on-Line Systems." Computer. 29(9):16 (2 pages).

The power outage suffered by America Online's (AOL) computer network in August 1997 could compel online service providers to implement measures needed to make their systems stronger and more reliable. Industry analysts agree that the blackout resulted from AOL's failure to integrate adequate redundancy into its network. They advise online service providers to have full backup systems in place to avoid similar incidents in the future.

Gates, J., R. Billinton and G. Wacker. 1999. "Electric Service Reliability Worth Evaluation for Government, Institutions and Office Buildings." IEEE Transactions on Power Systems. 14(1):43 (8 pages).

This paper presents the results of an investigation conducted by the Power Systems 
Research Group at the University of Saskatchewan to determine the costs of electric service interruptions in the government, institution and office building sector. The methodology used to obtain customer interruption cost information in this sector and to analyze the results is also presented.

Geier, J. 1996. "Upss to the Rescue.” LAN Magazine. 11(11):97 (5 pages).

Ghajar, R. and R. Billinton. 1993. "Comparison of Alternative Techniques for Evaluating the Marginal Outage Costs of Generating Systems." IEEE Transactions on Power Systems. 8(4):1550 (7 pages).

Quantitative evaluation of the marginal outage costs associated with generating systems involves, among other things, the construction of a model of the system capacity outages. This model is inherently discrete and application of the well-known and basic recursive technique requires lengthy computations when applied to large power systems. Alternatively, continuous distributions and Fast Fourier Transforms can be used to approximate the generating system capacity model. These techniques can in some cases introduce inaccuracies in the results, which depend on the system under consideration. Several authors have used these approximate techniques in the calculation of capacity outage probabilities, the study of parameter uncertainty in generating capacity reliability evaluation, the calculation of the expected energy production costs and the maintenance scheduling of generating facilities. This paper discusses the potential application of the approximate techniques in the evaluation of the marginal outage costs of a power system. The results of the approximate techniques are illustrated by comparison with those produced by the exact recursive technique for the IEEE-Reliability Test System.

Ghajar, R. and R. Billinton. 1995. "Evaluation of the Marginal Outage Costs in Interconnected and Composite Power Systems." IEEE Transactions on Power Systems. 10(2):753 (7 pages).

The structure of electric utilities is undergoing dramatic changes as new and expanded service options are added. The concepts of unbundling the electric service and offering customers a range of new services that more closely track actual costs are expanding the options open to customers. Spot pricing provides the economic structure for many of these new service options. An important component of spot prices is the marginal outage cost incurred by customers due to an incremental change in load. This paper presents a formalized approach of calculating the marginal outage cost incurred by customers due to an incremental change in load. This paper presents a formalized approach of calculating the marginal outage cost in interconnected generating systems and composite generation and transmission systems using quantitative reliability techniques. The effects of selected pertinent factors on the marginal outage cost in composite systems are also presented. The proposed methods are illustrated by application to the IEEE-Reliability Test System (IEEE-RTS).

Ghajar, R., R. Billinton and E. Chan. 1996. "Distributed Nature of Residential Customer Outage Costs." IEEE Transactions on Power Systems. 11(3):1236-1244.

Reliability worth assessment is an important factor in power system planning and 
operation. An equally important issue is how to use customer costs of electric supply interruptions as surrogates to appropriately quantify reliable worth. Postal or in-person surveys of electric customers are often used to determine interruption costs. The results obtained from the surveys are transformed into customer damage functions which are applicable to individual customer classes and sectors. Standard customer damage functions use aggregate or average customer costs for selected outage durations. This paper develops a practical alternative to the customer damage function method of describing the interruption cost data. The alternate technique, which is designated as the probability distribution approach, is capable of recognizing the dispersed nature of the data. The proposed probability distribution method is illustrated in this paper using the interruption cost data collected in a 1991 survey of the Canadian residential sector.

Gilmer, R. W. and R. S. Mack. 1983. "The Cost of Residential Power Outages." The Energy Journal. 4:55-74.

This paper assesses the cost of electrical outages to households, using customers of the Tennessee Valley Authority as an example. Unlike the industrial or commercial sectors where a loss of electric service disrupts a flow of goods and services, the residential sector has no measure of its output that is routinely valued by the market. This necessitates indirect methods to measure losses due to power outages. In this paper, two basic approaches are employed to assess outage costs. The first is based upon the loss of consumer's surplus. Estimates are made by using the overall demand curve for residential electricity in the Tennessee Valley and also by aggregating the demand curves for electricity use by individual electric appliances. A second approach estimates the value of the work performed within the home that is interrupted by an electric power loss.

Gilmer, R. W. and R. S. Mack. 1986. "Long-Run Adjustment to Alternative Levels of Reliability in Electricity Supply." The Energy Journal. 7(4):89-94.

We show that the treatment of long-run adjustments by electricity customers to a change in the reliability of electricity supplies is straightforward and analytically tractable. The presentation is deliberately simplified to highlight the long-run adjustment. An example for apparel manufacturers illustrates the ease with which long-run adjustments are incorporated, as well as the overvaluation of outages that can result if these long-run adjustments are ignored.

Goel, L. 1998. "Power System Reliability Cost/Benefit Assessment and Application in Perspective." Computers \& Electrical Engineering. 24(5):315 (10 pages).

The basic concepts associated with quantitative reliability assessment of electric power systems are reasonably well established and well accepted by the power industry. The evaluation of the costs and benefits of competing investments is now becoming a standard practice in power system planning. The justification of new facilities and system modifications now normally includes specific reference to reliability and one approach that is receiving considerable attention is the evaluation of the societal worth (benefit) of system reliability, or conversely the costs incurred by consumers due to power supply interruptions. In order to make a consistent appraisal of economics and reliability, it is imperative to compare the investment cost needed to attain a specified level of reliability 
with the reliability worth or benefits derived by the society at that level of system reliability. This paper discusses the developments made in existing techniques in the area of power system reliability cost/benefit evaluation and application. Reliability worth data presently used in cost/worth evaluation are presented, and their applications in conjunction with the system reliability indices are also presented in this paper.

Goel, L. and R. Billinton. 1993. "Utilization of Interrupted Energy Assessment Rates to Evaluate Reliability Worth in Electric Power Systems." IEEE Transactions on Power Systems. 8(3):929 (8 pages).

Power system planning is concerned both with the level of predicted reliability and the investment/operation alternatives associated with satisfying the desired level. The total societal cost consist of costs associated with required investments and operation of the system and the customer unsupplied energy costs due to electric supply interruptions. The predicted system reliability in quantitative terms and the consumer costs associated with supply interruptions can be used to compute the customer unserved energy costs. This association is formed by the development of a reliability-worth factor designated as the interrupted energy assessment rate (IEAR). This paper shows how IEAR can be utilized in a generating capacity adequacy study, composite system adequacy study and at each individual customer load point and/or sectors within the overall electric power system in an assessment of the monetary worth of reinforcements.

Goel, L. and R. Billinton. 1994. "Determination of Reliability Worth for Distribution System Planning." IEEE Transactions on Power Delivery. 9(3):1577 (7 pages).

There is an ever-growing demand to justify reliability projects on a more quantifiable basis, i.e. investments related to the provision of service reliability needs to be carefully evaluated in regard to their cost and benefit implications. In addition, utilities are recognizing the significant customer and community costs that are incurred when electric supply is abruptly curtailed. Consequently, the utility industry is under pressure to assess their reliability evaluation tools and formulate methods for incorporating the economics of reliability in the decision-making process. This paper is concerned with the evaluation of a reliability-worth index that can be used to make decisions in distribution system planning and design. The reliability worth index is termed the interrupted energy assessment rate (IEAR) and is obtained by relating the reliability indices to the customer cost of interruption data. Three fundamentally different approaches for evaluation distribution system reliability worth indices are presented and compared using a small but comprehensive test system. The impact on the worth indices of distribution system operating policies and configurations is also illustrated using the three methods. The worth indices developed can be used to determine the monetary implications of customer supply interruptions thereby incorporating economics in the reliability cost-benefit equation.

Gordes, J. N. 2000. The Power to Insure: Reducing Insurance Claims with New Electricity Options. Northeast Sustainable Energy Association.

In recent years, the insurance industry has seen property-casualty losses increase significantly, in great part because of the proliferation of high-value property in coastal 
areas and other locations prone to disasters. Significant portions of these financial losses were caused by business interruptions tied to the loss of electricity. Distributed generation offers a potential loss mitigation strategy.

Gray, J. W. and F. J. Haydock. 1996. "Industrial Power Quality Considerations When Installing Adjustable Speed Drive Systems.” IEEE Transactions on Industry Applications. 32(3):646 (7 pages).

Developments in digital electronics and power semi-conductors have led to a rapid increase in the use of nonlinear devices including adjustable speed drives. For this reason harmonics have become a common problem in many industrial electrical systems. The importance of a complete power system analysis prior to the installation of new equipment will be discussed in this paper. Methods of harmonic mitigation and the effect of the IEEE 519 Guideline-1992 on industry will also be discussed.

Higgins, Y. 1998. "Report Faults Kiwi Utility in Outage. Power Failure in Auckland, New Zealand.” Business Insurance. 32(33):41 (2 pages).

The two-month power failure in Auckland, New Zealand's central business district is being blamed by the government to the faulty risk management, contingency planning, operations and maintenance practices of power provider Mercury Energy. A government inquiry regarding the power outage revealed that the power company's operations and power line maintenance are below industry standards. This is believed to be the main cause of the Auckland blackout.

Higgins, Y. 1998. "Power Company Generates Relief. Mercury Energy Ltd.” Business Insurance. 32(12):21 (2 pages).

Mercury Energy Ltd. has developed a compensation package for customers affected by the power outage in Auckland, New Zealand which began on Feb. 20, 1998. Under the deal, customers will be given either six months free electricity or up to $\$ 5,596$ in exchange for not suing the company for additional compensation. Customers incurring bigger losses than covered by the package were also told to seek compensation from their own insurers.

Higgins, Y. 1998. "Power Outage Disrupts Kiwi Business District. Auckland, New Zealand." Business Insurance. 32(9):35 (1 pages).

Financial losses stemming from the power outage that hit the central business district of Auckland, New Zealand, during late Feb. 1998 could run into tens of millions of dollars. The power interruption started on Feb. 20, when four power lines failed leaving the district without electricity and phone service. Power was not restored for about a week and also delayed the opening of Auckland University. Insurance Council of New Zealand CEO David Sargent said that most businesses have inadequate business interruption policies to recover their losses.

Hoffman, S. 1996. "Enhancing Power Grid Reliability.” EPRI Journal. 21(6):6 (10 pages).

The electric power outage that affected 14 American states and 2 Canadian provinces 
in 1996 illustrates the need to reexamine the power grid of the U.S. Some sectors have started to question the reliability of the existing North American system due to the increasing frequency of outages. Some of the solutions offered include the deployment of innovative devices and the use of upgraded data communications systems.

Hoffmann, M. A. and M. Prince. 1998. "Ice Losses to Grow: Business Interruption Claims to Boost U.S. Storm Toll.” Business Insurance. 32(3):1 (2 pages).

Business interruption insurance claims resulting from losses due to ice storms that affected New England, New York and parts of Canada, can only be determined several weeks after the calamity has happened. This is due to the delays in the reports filed by the affected entities. Also, the specific type of damage must be classified in the reporting of the business losses. The estimated claim costs are pegged between $\$ 5$ million to $\$ 7$ million. The most affected entities are the service utilities, particularly in the power generation sector.

Holtz, J., W. Lotzkat and S. Stadtfeld. 1994. "Controlled Ac Drives with Ride-through Capability at Power Interruption." IEEE Transactions on Industry Applications. 30(5):1275 (9 pages).

General purpose PWM inverter drives are equipped with an undervoltage protection mechanism, causing the system to shut down within a few milliseconds after a power interruption in the mains. This may entail loss or damage of material in such critical applications as the production of textile fibers, paper, or with extruder drives. The proposed solution to this problem is to recover some of the mechanical energy stored in the rotating masses. When a power interruption occurs, a sequence of fast-feed forward commands is applied to force an immediate transition into the regeneration mode. During the interrupt interval, the drive system continues to operate at almost zero torque, just regenerating a minor amount of power to cover the electrical losses in the inverter. The method is implemented in an additional software package to be used with generalpurpose inverter drives of limited dynamic performance. Experimental results are presented.

Hsu, G. J. Y., P.-1. Chang and T.-y. Chen. 1994. "Various Methods for Estimating Power Outage Costs: Some Implictions and Results in Taiwan.” Energy Policy. 22(1):69 (6 pages).

The effectiveness of the consumer surplus method, the back up power method and the subscription load method for the estimation of power outage costs are comparatively evaluated in terms of total and partial outage costs to both average and marginal customers. It is suggested that the selection of an appropriate technique for the estimation of a specific outage cost type is extremely important.

Hughes, B. M., J. S. Chan and D. O. Koval. 1993. "Distribution Customer Power Quality Experience." IEEE Transactions on Industry Applications. 29(6):1204 (8 pages).

In recent years there has been a significant increase in the number of disturbance producing loads and "sensitive" loads being utilized by society resulting in increased customer complaints being directed at utilities. B.C. hydro is taking a proactive approach 
in determining its own power quality by monitoring voltage disturbances and harmonic levels dictated by a power quality survey program. This paper will present and discuss in detail some of the key objectives of the power quality program. A methodology for quantifying power quality as experienced by customers in a graphical form will be presented. Several detailed case studies will be presented to illustrate the methodology. Estimating algorithms for the duration and magnitude of the various types of power supply disturbances will be developed and illustrated.

IMIA. 1996. Failure of Large Oil Cooled Transformers. 29th Conference of the International Machinery Insurers' Association. Major losses due to failures of large oil cooled transformers appeared to be occurring with increasing frequency in the years leading up to 1995. An IMIA Working Group was established to examine and report on the topic at the IMIA Conference in 1996.

A request was sent to all national delegations seeking information on losses involving transformers rated at 100 MVA and above from 1989 onwards. In all, information was obtained in 75 cases of failures of large oil cooled transformers, and these formed the basis of further study.

The losses were examine by marshalling the information for successive years into the following categories:

Numbers and amounts of losses.

Ages of transformers.

Causes of failures.

Types of industry using the transformers.

Ratio of Business Interruption loss amounts to Physical Damage loss amounts.

The study revealed a fairly even pattern of losses over the years reviewed. This demonstrated that failures of large oil cooled transformers are predominantly associated with the generation, transmission and distribution of power. Losses are more likely to arise from internal failure rather than external failure. In particular during the early years in service, and a major failure could cost insurers between $\$ 1$ million and $\$ 3$ million for Physical Damage and for Business Interruption in the same order of magnitude, although an exceptional Business Interruption loss may escalate to tens of millions of U.S. dollars.

"In the Dark. 1996. Maclean's. 109(29):37 (1 pages).

Jayasankaran, S. 1996. "Lights Out: Power Failure Embarrasses Malaysian Government." Far Eastern Economic Review. 159(34):61 (1 pages).

A nine-hour blackout in Malaysia has resulted in calls for the reorganization of Tenaga Nasional, the national power utility that is 70 percent owned by the government. Foreign investors already committed to Malaysia will not be deterred in all likelihood, but the government believes the power outage threatens its claims that Malaysia is technologically advanced. Tenaga has faced declining profits since 1992 when another 
blackout, lasting 48 hours, caused the government to license five private power generators.

Jonnavithula, A. and R. Billinton. 1997. "Features That Influence Composite Power System Reliability Worth Assessment." IEEE Transactions on Power Systems. 12(4):1536 (6 pages).

Reliability worth assessment using customer interruption costs is an important element in electric power system planning and operation. This paper deals with two features that affect the composite generation-transmission system reliability worth assessment. One feature is the incorporation of temporal variations in the cost of interruption. This paper illustrates the effect on the expected annual system outage cost of temporal variation in the interruption costs for the residential, agricultural, industrial, commercial and large user sectors. The other aspect considered in this paper is using a probability distribution approach to represent the cost of interruption model. The conventional customer damage function approach utilizes average customer costs while the probability distribution approach recognizes the dispersed nature of the customer outage data. These two methods of cost evaluation are applied to reliability worth assessment in this paper. A sequential Monte Carlo approach incorporating time varying loads is used to conduct all the studies. Case studies performed on two composite test systems show that incorporating time varying costs of interruption for the industrial sector resulted in a significant reduction in the expected outage cost. A comparison of the reliability worth obtained using the customer damage function method (CDF) with the probability distribution approach suggests that using the CDF method may significantly undervalue the reliability worth by a factor of three to four.

Koch, B. 1999. "Power Quality: Things That Go Bump in the Lights." Electrical World. 213(6):24 (5 pages).

Customer pressure and technological improvements are enabling utilities to provide power which is more reliable and constant, by the use of networked power-quality metering and monitoring systems provided by Power Measurements Ltd. and Power Quality Systems Inc.

Koch, W. 1997. "Customers, Utilities Work Together on Power Quality." Electrical World. 211(6):42 (4 pages).

A number of utilities are working with customers in solving power quality problems, both as a customer service improvement strategy and as a pro-active means of avoiding costly transmission equipment repair. A number of products and technologies are available to ease power quality monitoring and repair.

Koval, D. O., R. A. Bocancea, K. Yao and M. B. Hughes. 1998. "Canadian National Power Quality Survey: Frequency and Duration of Voltage Sags and Surges at Industrial Sites." IEEE Transactions on Industry Applications. 34(5):904 (7 pages).

The occurrence of voltage sags and surges originating on the primary and secondary sides of industrial facilities can disrupt continuous and noncontinuous industrial computer processes, a costly issue for society. This paper will attempt to answer several questions 
concerning the frequency and duration of voltage sags and surges posed by industrial customers. The answers to these questions will be based on the national survey results [1], [2] of the frequency and duration of voltage sags and surges at industrial sites monitored at their utilization voltage levels (e.g., 120, $347 \mathrm{~V}$ ) and on the utility primary side of their facilities. The survey results provide a knowledge base for monitoring, designing, and utilizing voltage sag and surge mitigating technologies.

Koval, D. O. and C. Carter. 1997. "Power Quality Characteristics of Computer Loads." IEEE Transactions on Industry Applications. 33(3):613 (9 pages).

Computer loads and systems can be found in all of society's industrial, commercial, and residential sectors. The nature of these loads is such that they distort the line-current waveforms and, in some cases, can significantly distort the supply-voltage waveforms causing disruption in computer system performance. The voltage (i.e., line-to-line, lineto-neutral and neutral-to-ground) and the phase current waveform characteristics of many computer loads are similar and reported in the literature [1]-[6]. Some waveform patterns remain fairly stable during loading cycles, while others vary significantly and randomly. This paper will present several case studies to reveal the unique power quality characteristics of several commonly used computer systems (e.g., workstations, heating plant process computers, and electron microscopes). The dominant even- and oddharmonic components of the waveforms will be presented and discussed in some detail. This paper will also discuss the impact of the computer loads on the supply voltage waveforms.

Koval, D. O., J. C. Chang and J. Leonard. 1992. "Rural Power Quality.” IEEE Transactions on Industry Applications. 28(4):761 (6 pages).

Very little published literature is available on the quality of power being delivered to rural industries. This paper will present the results of a detailed power quality monitoring survey of 17 out of the 23 small rural industries surveyed (i.e., poultry broiler, poultry layer, beef feedlot, and pig (farrow to finish) rural industrial sites) and sponsored by the Canadian Electrical Association; the survey will provide a knowledge base on rural power quality and the possible origins of power supply anomalies. This paper will summarize the major power quality problems experienced at the various industrial sites and present some of the significant results of an across Canada questionnaire survey on "On-farm Electrical Power Disturbances." The results of these surveys will provide a basis for mitigating actions by the utilities and their rural industrial customers by enhancing their ability to identify the possible origins of power supply disturbances affecting the performance of electronic and electrical equipment at the various farm industrial sites.

Koval, D. O., W. Xu and J. Salmon. 1999. "Power Quality Characteristics of Rural Electric Secondary Power Systems." IEEE Transactions on Industry Applications. 35(2):332 (7 pages).

The occurrence of power supply anomalies (e.g., voltage sags, surges and swells, sustained under and overvoltages, etc.) originating on the secondary side of rural facilities and high utilization voltage levels can often damage and/or disrupt rural computerized processes, electric equipment, and interrupt loads, a costly issue for rural society. This 
paper will attempt to answer several questions concerning the frequency and duration of voltage sags, swells, and surges posed by rural customers and reveal the statistical characteristics of the utilization voltage levels at rural sites. The answers to these questions will be based on the national survey results of the frequency and duration of voltage sags and surges at rural sites monitored at their utilization voltage levels. The survey results provide a knowledge base for monitoring, operating electric equipment, and designing and utilizing power quality mitigating technologies in rural electric environments. COPYRIGHT 1999 Institute of Electrical and Electronics Engineers Inc Index Terms - Power quality, rural electric, sags, secondary, surges, swells.

Lamoree, J. 1992. "How Utility Faults Impact Sensitive Customer Loads." Electrical World. 206(4):60 (3 pages).

Interruption of power transmission is caused by faults on the power system, brought on by lightning, falling limbs or other accidents. Voltage sags usually cause equipment interruptions in commercial plants. Information is provided for reducing transmission problems.

Lehtonen, M. and B. Lemström. 1995. Comparison of the Methods for Assessing the Customers' Outage Costs. VTT Energy.

This paper gives a comparative study of various methods for assessing the customers' outage costs. The methods considered are: the willingness to pay in order to avoid an outage, the willingness to accept compensation for having had an outage, the customer survey where the costs are estimated directly by the customers themselves and an econometric model based on price elasticity. In the case of industrial customers, also the correlation between outage costs and the value added by the production is examined. The use of different methods is illustrated by the main results of a large Nordic study, carried out in 1992 and 1993.

Long, M. H. 1997. "Business Interruption Risk Assessment: A Multi-Disciplinary Approach.” Disaster Recovery Journal.:

McIntyre, K. J. 1998. "By Holding Back, Power Company Pays. Mercury Energy Ltd." Business Insurance. 32(13):29 (1 pages).

Power outage in the central business district of Auckland, New Zealand, has resulted in business losses. Compensation for the losses incurred should be handled by the utility, Mercury Energy Ltd. and its insurance provider as they should be held liable for the power interruption beyond the premises of the firms in the central business district. The overall cost to the economy of the month-long power interruption is estimated at $\$ 56$ million. The cost to Mercury Energy's reputation has been far more because it stalled in delivering its obligation to its customers.

\section{Marin Power Blackout: Marin's Vulnerability to a Failure of the PG\&E Ignacio Substation. 1998. Marin County Civil Grand Jury.}

Mehling, H. 1998. "Small Businesses Tackle Unreliable Power Quality.” Computer 
Reseller News. (806):86 (1 pages).

Mello, J. C. O., M. V. F. Pereira and A. M. L. da Silva. 1994. "Evaluation of Reliability Worth in Composite Systems Based on Pseudo-Sequential Monte Carlo Simulation." IEEE Transactions on Power Systems. 9(3):1318 (9 pages).

This work describes a new methodology for calculating total system interruption costs in composite generation and transmission systems. The proposed approach, called pseudo-sequential simulation, is based on the non-sequential Monte Carlo sampling of system states and on the chronological simulation of only the sub-sequences associated with failed states. Case studies with the IEEE Modified Reliability Test System (MRTS) and a 415-bus system derived from the Brazilian Southeastern region are presented and discussed.

Michaels, K. M. 1997. "Sensible Approaches to Diagnosing Power Quality Problems." IEEE Transactions on Industry Applications. 33(4):1124 (7 pages).

Power quality site surveys are electrical system investigations that attempt to locate and solve power quality problems affecting electrical and electronic equipment. Site surveys combine state-of-the-art diagnostic instrumentation with the intuitive nature of the individuals who endeavor to utilize them. Successfully performing a power site survey requires the management of issues and resources on many levels. Some of the minutiae to consider are: 1) coordinating the involved parties; 2) procuring and safely utilizing necessary test equipment; 3 ) implementing proper diagnostic techniques to the perceived problem; 4) suitable interpretation of the results; and 5) providing costeffective recommendations to eliminate or mitigate the cause of the disturbance. A problem-solving checklist and its components can be introduced as a guide for participants who may have a concern with the uniformity of their trouble-shooting techniques. This paper will review these and other aspects of a power site survey based upon the recent changes to the recommended practices set forth by Chapter 6 of IEEE Std. 1100 (Recommended Practice for Power and Grounding Electronic EquipmentEmerald Book.)

Munasinghe, M. 1980. "Costs Incurred by Residential Electricity Consumers Due to Power Failures." Journal of Consumer Research. 6:361-369.

In this paper, an explicit theoretical framework for measuring residential outage costs is presented and empirically tested using the results of a survey of household electricity consumers in the city of Cascavel, Brazil. Although the model or variations thereof are relevant to most countries, simplicity of application has been emphasized because of the data constraints in developing countries. In brief it is argued that:

(1) The principal outage cost imposed on a household is the loss of leisure during the evening hours when electricity is essential, and (2) The marginal monetary value of this lost leisure is equal to the effective net income earning rate on the basis of the consumer's labor-leisure choice.

"New York's Con Ed Self-Insured for \$3 Million in Blackout Claims." 1999. Business Insurance. (July 12):1. 
NEW YORK-The Consolidated Edison Co. of New York Inc. has insurance above a \$3 million self-insured retention for losses and potential lawsuits from a blackout last week that affected nearly 200,000 Manhattan residents. One proposed suit by the City of New York still is in the planning stages, a spokeswoman for the Office of Corporation Counsel said. The suit will seek reimbursement for city property destroyed by the blackout, such as spoiled food from city schools and damaged computers. The suit, however, will not seek reimbursement for the costs of extra city services, such as police overtime, resulting from the blackout. No dollar amount has yet been calculated for the city's losses, she said.

Neudorf, E. G., D. L. Kiguel, G. A. Hamoud, B. Porretta, W. M. Stephenson, R. W. Sparks, D. M. Logan, M. P. Bhavaraju, R. Billinton and D. L. Garrison. 1995. "CostBenefit Analysis of Power System Reliability: Two Utility Case Studies." IEEE Transactions on Power Systems. 10(3):1667 (9 pages).

There is an emerging recognition that utility investment and other decisions that affect electric service reliability should be explicitly evaluated on the basis of their cost and benefit implications. A cost-benefit approach that quantifies the reliability benefits of alternatives in terms of the reduction in costs resulting from unserved energy enables the evaluation of generation and transmission capacity additions on a consistent, economic basis. This approach has been applied to two utility case studies. In a case study for Pacific Gas \& Electric Company, it was used to evaluate three options for maintaining reliability in a major load center--two involving local generation, and the third, a new $230-\mathrm{kV}$ transmission connection. In a case study for Duke Power Company, the approach was used to evaluate alternative designs for proposed additions to a transmission station. This paper describes the methodology and presents the two utility studies.

"No Interruption at Billion Dollar Mark. 1999. Electronic News (1991). 45(13):35 (1 pages).

Nolan, G. J., V. J. Puccio and C. W. Calhoun. 1997. "Standby Power Generation under Utility Curtailment Contract Agreements." IEEE Transactions on Industry Applications. 33(6):1432-1438.

Penton, H. S. 1993. "Outage Monitoring Boosts Power Quality." Electrical World. 207(3):62 (3 pages).

Idaho Power Co implemented a program in 1992 designed to reduce the number of momentary power outages experienced by customers and to monitor outages in real time. Results and evaluation of the program, in addition to its guidelines, are presented.

Petreley, N. 1998. "Rightside-up Wisdom Comes from Upside-Down Land of New Zealand." InfoWorld. 20(17):132.

"Power Quality Brochure Helps Educate Textile Customers.” 1997. EPRI Journal. 22(5):35 (1 pages).

Power quality is an integral part of highly automated textile plants. The increasing 
demand for an innovative power distribution system has prompted Duke Power Co to designate a special staff section who would help customers solve productivity problems related to power quality issues. A brochure entitled "Power Quality Considerations for the Textile Industry" was launched. Such brochure has provided textile customer several tips on how to reduce downtime, increase production and productivity and improve product quality.

Price, K. 1993. "Practices for Solving End-User Power Quality Problems.” IEEE Transactions on Industry Applications. 29(6):1164 (6 pages).

One of the primary tasks of utility personnel responsible for customer's Power Quality concerns is to identify whether disturbances are generated within the customer's facility or on the transmission and distribution system. Advances in both instrumentation and troubleshooting methodology have made it possible to make these determinations with greater accuracy and less investment of time. Techniques will be discussed which have proven useful in conducting power quality investigations. Case study examples will illustrate how these techniques have been put into practice and become successful by utility power quality groups.

Reason, J. 1988. "End-Use Power Quality: New Demand on Utilities." Electrical World. 202(11):43 (6 pages).

Reid, W. E. 1996. "Power Quality Issues - Standards and Guidelines." IEEE Transactions on Industry Applications. 32(3):625 (8 pages).

As a result of the wide-ranging addition of electronically controlled equipment within the last five to ten years, the lack of industry standards and application criteria in the area of power quality has become very evident. This paper outlines the significant factors associated with power quality by summarizing the key considerations, the relevant standards, the areas where standards are being developed, and useful application guidelines. Power quality is discussed here in terms of three major categories--system disturbances, harmonic distortion, and grounding.

Rodentis, S. 1999. "Can Your Business Survive the Unexpected." Journal of Accountancy. 187(2)

Sandia National Laboratories. 1998. Estimating Costs of Electricity Outages: Report of FY 98 Activity. Sandia National Laboratories.

This report presents results form the phase I effort of the Modeling and Analysis of Infrastructure Interdependencies project. The object of this project is to develop methods to better estimate the cost effects of infrastructure interdependencies during power outages. The work has focused on the San Francisco area infrastructure system because of its place as a modern, international financial center and because of the opportunities to obtain data from recent power failure incidents. This report includes a review of approaches that have been used in the past to estimate the costs of power outages and presents a path forward for developing a dynamic simulation model in phase II of this project. The prototype model developed in phase II will be a tool for estimating the 
economic consequences of power outages including the second order effects caused by infrastructure interdependencies. The model will also provide a means to better calibrate the multi-agent infrastructure models that are being developed at Sandia National Laboratories.

Sanghvi, A. P. 1990. Cost-Benefit Analysis of Power System Reliability: Determination of Interruption Costs. Volume 1: Measurement Methods and Potential Applications in Reliability Cost-Benefit Analysis. Palo Alto: Electric Power Research Institute. EL-6791, Volume 1.

This study examines and characterizes the impacts and costs of service interruptions to customers. Alternative methods to measure interruption costs are reviewed, and the major steps involved in conducting and interruption cost measurement study are described. The applications of interruption cost data in reliability planning are discussed, and the results of a survey of U.S. and Canadian utilities on reliability planning practices are evaluated.

The study also documents two case studies, one for the Bonneville Power Administrations and one for a major utility in the southeast U.S. For these studies, surveys of households and commercial and industrial firms were conducted using a survey instrument tailored to each segment. The survey data were statistically analyzed to develop estimates of customer interruption costs that are representative of the "customer mix" at typical delivery points in the network. This study also documents the survey methodology, and presents summary statistics that describe the survey respondents' experience with service reliability and power quality. Finally, the results of econometric analyses of the survey data are described. These analyses identify the subset of variables that best explain the variation in interruption costs across different customer types.

Sankarakrishnan, A. and R. Billinton. 1996. "Effective Techniques for Reliability Worth Assessment in Composite Power System Networks Using Monte Carlo Simulation." IEEE Transactions on Power Systems. 11(3):1255 (7 pages).

Reliability cost / reliability worth assessment plays an important role in electric power system planning and operation. The paper proposes a technique for evaluating the costs of interruption and hence, the reliability worth in a composite power system network with time varying loads at load buses using sequential Monte Carlo simulation. A generalized methodology of determining the interruption costs, without considering the time varying aspect of the loads is discussed and the results are compared with those obtained by utilizing a load duration curve to represent the time dependent loads. Case studies conducted on the IEEE Reliability Test System (IEEE - RTS) are presented and discussed.

Schmerken, I. 1990. "Wall Street Stretches to Stem the Tide." Wall Street Computer Review. 8(2):20 (8 pages).

Semilof, M. 1999. "Power Glitch Slams Isp -- All the High Tech Preparation in the World Is Useless in a Power Outage." Computer Reseller News. (May 24):3. 
Shipp, D. D. and W. S. Vilcheck. 1996. "Power Quality and Line Considerations for Variable Speed AC Drives." IEEE Transactions on Industry Applications. 32(2):403 (8 pages).

Variable speed ac drives are finding their way into all types of industrial and commercial power applications. Their application to the load (motor) generally is reasonably well selected--at least within heavy industry. However, there are many line (source) design parameters learned in the 1950's and 1960's, which are now being frequently overlooked. This paper represents many years of experience doing power quality investigations. The authors combined this experience with recent technology and discuss some the areas of concern which frequently result in serious performance or power quality problems. Finally, basic design guidelines are given to greatly minimize system problems--especially as newer technologies are intermixed with old.

Siddiqui, S. N. and M. L. Baughman. 1993. "Reliability Differentiated Real-Time Pricing of Electricity." IEEE Transactions on Power Systems. 8(2):548 (6 pages).

Optimal resource planning and power dispatch models (from a societal welfare point of view) imply an optimal pricing policy, which is referred to here as reliability differentiated real-time pricing or, in short, reliability differentiated pricing. This pricing scheme combines real-time pricing and priority pricing with reliability differentiation based on consumer outage costs. An analysis is made of this reliability differentiated pricing policy of electrical energy. The model used in the analysis is developed with particular emphasis on consumer behavior and welfare effects. The implications of the model to the pricing of spinning reserve and firm capacity, as well as to the issue of revenue reconciliation are examined. It is concluded that such a pricing scheme, will in general, result in greater attainable welfare than use of either the real-time pricing or priority pricing paradigms. Moreover, it results in the maximum attainable welfare for the system with revenue reconciliation, provides an optimal pricing scheme for spinning reserve and firm capacity, and is thus an efficient pricing mechanism.

Sikes, D. L. 2000. "Comparison between Power Quality Monitoring Results and Predicted Stochastic Assessment of Voltage Sags -- "Real" Reliability for the Customer." IEEE Transactions on Industry Applications. 36(2):677.

By utilizing probabilistic methods to predict and characterize events on the power system in terms of frequency, engineering methods and calculations can then be applied to assess the impact of these predicted events. This leads to a complete appraisal of how often various types of consequences will affect an individual customer's load point. Matching this predictive system performance with the expectations of the customer and the requirements of the customer's equipment yields not only where deficiencies exist, but also how to apply proper and cost-effective solutions for each load point.

Souter, G. and A. Sullivan. 1998. "Power Outages, Property Damage to Generate Canadian Claims." Business Insurance. 32(3):1 (2 pages).

The extent of the ice storms that affected Canada in 1998 may have a direct impact on both the business and property insurance sectors. Insurance rates are expected to increase with the filing of claims weeks after the calamity. Types of claims filed are mostly for 
commercial vehicles and structural damages. Closure of business establishments is mainly due to power failure, but these businesses cannot file for business interruption claims because of the limited coverage of the insurance programs or policies.

Streetskamp, I. and A. Van Wijk. Stroomloos: Kwetsbaarheid Van De Smenleving; Gevolgen Van Verstoringen Van De Elektriciteitsvoorziening. Rathenau: Rathenau Instituut.

Strickler, G. F. and S. K. Noell. 1988. "Residential Air Conditioning Cycling: A Case Study." IEEE Transactions on Power Systems. 3(1):207-212.

Subramaniam, R. K., R. Billinton and G. Wacker. 1993. "Understanding Industrial Losses Resulting from Electric Service Interruptions." IEEE Transactions on Industry Applications. 29(1):238 (7 pages).

Reliability worth assessment is a relatively immature and imprecise technique in comparison with reliability cost assessment. The most obvious means of assessing the worth of reliability is to evaluate the societal and user costs attributed to interruptions in the electrical supply. An approach that is considered to yield relatively definitive results is the customer survey approach. This paper presents the results of a comprehensive study conducted to identify the customer- and interruption-related variables that affect the small industrial customer losses.

Subramaniam, R. K., G. Wacker and R. Billinton. 1993. "Understanding Commercial Losses Resulting from Electric Service Interruptions." IEEE Transactions on Industry Applications. 29(1):233 (5 pages).

This paper presents the results of an investigation of the direct short-term impacts and costs incurred by commercial customers resulting from local random supply interruptions. A description of the customer- and interruption-related variables affecting the customer losses is presented.

Sullivan, M. J., B. N. Suddeth, T. Vardell and A. Vojdani. 1996. "Interruption Costs, Customer Satisfaction and Expectations for Service Reliability." IEEE Transactions on Power Systems. 11(2):989 (7 pages).

This paper summarizes results of a comprehensive study of the economic value of electric service carried out by Duke Power Company in cooperation with the Electric Power Research Institute. In the study, customer interruption costs were estimated for generation, transmission and distribution outages of differing lengths occurring under varying circumstances. Interruption costs for momentary outages and voltage disturbances are also reported. In addition to these economic indicators of customer value of service, customer expectations for service reliability and power quality and their satisfaction with the service currently offered are reported. Statistical methods and procedures used in estimating interruption costs are described.

Sullivan, M. J., T. Vardell and M. Johnson. 1997. "Power Interruption Costs to Industrial and Commercial Consumers of Electricity." IEEE Transactions on Industry Applications. 33(6):1448-1458. 
This paper summarizes the results of a survey of 210 large commercial and industrial customers to obtain detailed descriptions of the components of interruption costs they would experience under varying outage conditions. In addition, the survey observed plant-operating schedules, products and services, and equipment designed to ensure power quality. The paper describes a statistical approach for obtaining inexpensive outage cost estimates for individual customers by combining information from on-site interviews with less costly information obtained from utility representatives. Results from regression models estimated from the information obtained in the on-site survey are described in detail.

"Superconducting Storage May Keep Bart Trains Running." 1993. EPRI Journal. 18(3):35 (1 pages).

Researchers are studying the feasibility of using superconducting magnetic energy storage (SMES) device to compensate for the voltage sag being experienced by Bay Area Rapid Transit (BART) trains during heavy power use in the San Francisco Bay Area. The SMES device could provide 3.2 megawatts of power for about three seconds and can be easily fitted into a section of the BART tunnel. It also has a higher efficiency than conventional lead-acid, battery energy storage systems.

"Taiwan Blackout Watch." 1999. Electronic News (1991). 45(31):4.

Tishler, A. 1993."Optimal Production with Uncertain Interruptions in the Supply of Electricity: Estimation of Electricity Outage Costs." European Economic Review. 37:1259-1274.

In this paper we develop a model to measure expected electricity outage costs in the industrial and commercial sectors. Four sources contribute to the costs of outage in these sectors: foregone profits (output), possible reduction in productivity due to the outage, damage to materials, and payments to labor during the outage. The beginning and duration of the electricity outage are random variables with known distribution functions. Thus, the business customer maximizes his expected profits, taking into account his ability, or lack of ability, to respond to the random electricity outage. The model is applied, assuming a quadratic production function, to eleven industrial branches in Israel. The estimates indicate a large variation in customer preferences for reliability.

"To Attract High-Tech Tenants, Give Them High-Quality Power." 1996. Electrical World. 210(10):53 (3 pages).

Consolidated Edison Co. of New York Inc. has provided high quality power for the Information Technology Center office building in Manhattan to attract high technology tenants. The power is supplied by motor/generator sets, which provide a steady voltage and frequency.

Tollefson, G., R. Billinton and G. Wacker. 1991. "Comprehensive Bibliography on Reliability Worth and Electrical Service Consumer Interruption Costs: 1980-1990." IEEE Transactions of Power Systems. 6(4):1508-1514.

This paper has been prepared to provide a comprehensive bibliography that relates to 
the development, results and continuing research into the theory of the worth of electrical service reliability. It covers the material that has been published from 1980 to 1990 . The primary emphases are on the theories and methods used in determining the interruption costs experienced by the consumers. Application of interruption cost data in planning of electrical systems is also included.

Tollefson, G., R. Billinton, G. Wacker, E. Chan and J. Aweya. 1994. "A Canadian Customer Survey to Assess Power System Reliability Worth." IEEE Transactions on Power Systems. 9(1):443 (8 pages).

A common approach used in quantifying the worth or benefit of electric service reliability is to estimate the customer costs (monetary losses) associated with power interruptions. Customer surveys are often used to determine interruption costs. The Power Systems Research Group has recently conducted surveys of Canadian electric utility customers in the residential, commercial and industrial sectors. These surveys were sponsored by the Natural Sciences and Engineering Research Council and seven participating utilities. This paper presents the overall results of these surveys with emphasis on the cost results.

Tsuruoka, D. 1992. "National Gridlock. (Controversial Blackout in Malaysia and Singapore)." Far Eastern Economic Review. 155(41):59 (1 pages).

A nationwide blackout that struck Malaysia on Sep 29, 1992 has exposed flaws in the power-generation policies and operations of Tenaga Nasional Berhad, the country's semiprivatized national power utility, and has damaged Malaysia's attractiveness to foreign manufacturers. Businesses are still recovering from the resulting loss in production and the public is now scrutinizing the utility more closely. The incident was preceded by another blackout in Singapore only hours before and Malaysia reports importing power to its neighbor before it occurred.

Vojdani, A. F., R. D. Williams, W. Gambel, W. Li, L. Eng and B. N. Suddeth. 1996. "Experience with Application of Reliability and Value of Service Analysis in System Planning." IEEE Transactions on Power Systems. 11(3):1489 (8 pages).

This paper documents the material presented at the IEEE 1994 Summer Power Meeting Panel on Application of Reliability in Least Cost System Planning, sponsored by the Application of Probability Methods (APM) Subcommittee of the Power System Engineering Committee of IEEE. The paper contains Short Notes by five panelists, representing five electric utilities in North America, on application of reliability and value of service analysis in planning.

Wagner, J. 1998. "Power Quality and Info. Technology Equipment." Energy User News. 23(5):24 (1 pages).

Wang, P. and R. Billinton. 1999. "Time Sequential Distribution System Reliability Worth Analysis Considering Time Varying Load and Cost Models." IEEE Transactions on Power Delivery. 14(3):1046 (6 pages).

This paper presents a time sequential Monte Carlo simulation technique for 
evaluating customer unreliability costs in distribution systems. Annual chronological load models for different individual customer sectors are developed and used in the analysis. Random load fluctuations are combined with the time varying load models to recognize the residual uncertainty associated with system load. The concept of time varying cost weight factors is introduced. The customer damage function (CDF) is combined with the time varying cost weight factors to create a time varying cost model (TVCM) for each individual customer. The TVCM for seven customer sectors are developed and used in the evaluation. The results show that different load and cost models result in different interruption costs, which can lead to different planning and operating decisions.

Warren, C. A., T. A. Short, J. J. Burke, H. Morosini and C. W. Burns. 1999. "Power Quality at Champion Paper - the Myth and the Reality." IEEE Transactions on Power Delivery. 14(2):636 (4 pages).

Reliability and power quality are two of the most discussed topics in the utility industry today. Many groups have performed power quality studies with varying results. One large industrial customer in northern New York State, which experienced numerous process interruptions, due to power system disturbances was the focus of this study. Monitoring methods, results, inadequacies of standards, and unique mitigation techniques used to conquer their problems are discussed in this paper.

Weller, G. H. 1988. "Managing the Instantaneous Load Shape Impacts Caused by the Operation of a Large-Scale Direct Load Control System." IEEE Transactions on Power Systems. 3(1):197-199.

Willis, K. G. and G. D. Garrod. 1997. "Electricity Supply Reliability: Estimating the Value of Lost Load." Energy Policy. 25(1):97 (7 pages).

The study evaluates the performance of electricity distribution companies based on reliability of supply, emphasizing the monetary value placed by customers on the number of power outages and minutes of electricity lost per year. A review of a technique that appraises monetary worth of outages from a consumer point of view is made, employing a ranking method from a survey of industrial companies of different types. Results showed the value consumers placed on avoided outages was higher than present estimates.

Wintrob, S. 1995. "Trouble on the Exchange: Vsf Survives One-Day Scare." Computing Canada. 21(12):1-2.

Woo, C.-K. and R. L. Pupp. 1992. "Costs of Service Disruptions to Electricity Consumers." Energy. 17(2):109-126.

After reviewing 16 recent studies, (i) we identify the general approaches used to estimate customer outage costs, (ii) ascertain the relative merits of each approach, and (iii) determine the extent to which existing studies can provide accurate and meaningful estimates. We present cost estimates on a common denominator, explain variations in the results, and suggest areas for future research.

Woo, C.-K., R. L. Pupp, T. Flaim and R. Mango. 1991. "How Much Do Electric 
Customers Want to Pay for Reliability? New Evidence on an Old Controversy." Energy Systems and Policy. 15:145-159.

Electric utilities are facing competitive challenges from independent power producers, cogenerators, qualifying facilities, and customer bypass, in addition to increasing resistance to building new capacity whether it be conventional or nuclear. Utilities are meeting these challenges by offering an array of demand-side management programs and differentiated tariffs that better match utility rates and customer preferences for service reliability. Customer preferences for service reliability may be gathered by market survey, however, survey estimates are subject to various common criticisms--a fact that has retarded the adoption of this approach. By using proper survey design techniques and statistical methods, we show how accurate customer value of service reliability data may be collected with a market survey.

Woo, C.-K. and N. Toyama. 1986. "Service Reliability and the Optimal Interruptible Rate Option in Residential Electricity Pricing." The Energy Journal. 7(3):123-135.

Wyckoff, B. 1997. "Power Management: More Than a Plug." Communications News. 34(9):68 (2 pages). 


\section{Appendix B: Insurance Implications for Electric Utility Operations}

Events that result in power interruptions and costs to electricity end users also tend to have impacts on utilities. Losses can manifest in the form of physical damages to the utility infrastructure, lost sales, and claims for damages from customers and local municipalities. In many cases the resulting losses are commercially insured, in other cases self-insured.

There are numerous cases in which insurers or end-use customers have sought recourse from utilities for business-interruption claims paid to insureds. A newspaper company opted to file a claim with their utility rather than with their business insurer, because the insurer had a 24-hour time deductible (Wojcik 1998). As illustrated in the case of a \$3million BI claim paid to Boeing by National Union Insurance Company, insurers have pursued remedies from utilities for power disruptions based on arguments that the utility did not adequately prepare for outages. The loss occurred on January 20, 1993, when the "Inauguration Day Storm" interrupted electric service to over 500,000 utility customers in the Puget Sound area, including Boeing's Renton plant (Washington Utilities and Transportation Commission 1999). Similar suits were brought against Con Edison after outages (Wall Street Journal 1990); the utility noted that it carried insurance for such suits. ${ }^{2}$ Con Edison was also the subject of suits from the City of New York after a major outage in Summer 1999 (Business Insurance 1999a). Commonwealth Edison experienced similar suits from the City of Chicago following outages in Summer 1999 (Business Insurance 1999b).

Following are some examples of power outages that impacted utilities:

- 1968 and 1999 - Losses experienced by public utilities in Canada totaled 14\% of total losses nationally (Emergency Preparedness Canada 2000).

- 1989 - 1994 -- Losses involving 75 large oil-cooled transformers resulted in $\$ 55$ million in insured losses, of which property losses were $\$ 20$ million and BI losses $\$ 35$ million (IMIA 1996). ${ }^{30}$ This includes a single event resulting in a 3.5-month outage experienced by a $230 \mathrm{MW}$ power station and $\$ 21.3$ million of corresponding lost sales versus less than $\$ 1$ million in physical damage to the transformer.

-1989-1996 -- Duke Power has published the costs associated with distribution system damages caused by major storms (Table B-1) (Keener 1997). Typical-year outages reflect costs of approximately $\$ 750 \mathrm{k}$. These values run as high as $\$ 65,000 \mathrm{k}$ (nearly 100 -times

\footnotetext{
${ }^{29}$ An extreme example is evidenced by $\$ 1$ billion of lawsuits against a Spanish utility following outages in early 1999 (Kielmas 1999).

${ }^{30}$ Although not clear from the source document, it appears that "business interruption" losses in this case refer to lost sales in the cases where the transformers were operated by electric utilities (and not the BI losses to the utility customers).
} 
the "normal" level) for years with severe storms. Between 88,000 and 660,000 customers were impacted and costs per customer ranged from $\$ 10$ to $\$ 114$ for these events.

- March 13, 1989 -- A Geomagnetic storm resulted in a 9-hour blackout affecting 6 million Hydro Quebec customers (Spoiden 2000). The same storm affected power systems in Sweden and England.

- August 24, 1992 -- Hurricane Andrew left 3 million homes and businesses without power, downing 21,100 utility poles (Stauffer 1995).

- July 11, 1993 -- Des Moines Water Works was flooded by Rancoon River. After substations were flooded, over 35,000 households and the entire downtown business district were without power (Stauffer 1995).

- January 17, 1994 -- After the Northridge earthquake, the entire LADWP system went down leaving 1.3 million customers without power, while in SCE service territory, 1.1 million customers (approximately one in four) were without power. California utilities spent well over $\$ 100$ million to pay for repair costs and lost revenues following the Northridge Earthquake (Stauffer 1995). Repair costs incurred by electric utilities amounted to $\$ 137$ million (Chang et al. 1996).

- 1998 -- The North American Ice Storm of 1998 provides a recent and dramatic example of the impacts of ice storms on utilities (Lecomte et al. 1998); see Box 1. According to Emergency Preparedness Canada, electric outages in the affected areas of Canada deprived $16 \%$ of the Canadian population of power, and $19 \%$ of the workforce was unable to get to work. In Canada, 130 transmission towers and 30,000 distribution poles were toppled, and damage to the transmission system was $\$ 1$ billion. In the U.S. 546,000 people were without power. A majority of the claims in Canada were made for perished foods in home refrigerators and freezers.

- December 8, 1998 -- Pacific Gas \& Electric Company took responsibility for claims resulting from an 8-hour electricity failure in San Francisco and San Mateo County. The largest claimant was the City of San Francisco. Total claims were projected to be approximately equal to PG\&E's \$10-million liability insurance deductible (Business Insurance 1998a; Wojcik 1998).

- July 1999 -- Following the New York City power outage, the city filed a suit against the utility for $\$ 3$ million and some claimed that the outage was caused by a failure to upgrade the distribution system (Gordes 2000). Con Ed's self-insurance was approximately $\$ 3$ million at the time (Business Insurance 1999).

\footnotetext{
${ }^{31}$ Paul Kovacs, Insurance Bureau of Canada, Personal Communication.
} 
An estimate attributed to EPRI (Keener 1997) ascribes lightning-related outage costs (materials and labor) to U.S. utilities at over $\$ 100$ million/year, and states that $90 \%$ of Duke Power's summertime power outages are caused by lightning.

Table B-1. Costs of Power Outages at Duke Power

\begin{tabular}{llrrc} 
Date & Storm Type & $\begin{array}{l}\text { Customer } \\
\text { Outages }\end{array}$ & Cost (\$k) & $\begin{array}{l}\text { Cost/Customer } \\
(\mathbf{\$})\end{array}$ \\
\hline Typical Year* & & & 754 & \\
May-89 & Tornadoes & 228,341 & 15,190 & 67 \\
Sep-89 & Hurricane Hugo & 568,445 & 64,671 & 114 \\
Mar-93 & Wind, Ice, and Snow & 146,436 & 9,176 & 63 \\
Oct-95 & Hurricane Opal & 116,271 & 1,655 & 14 \\
Jan-96 & Western NC Snow & 88,076 & 873 & 10 \\
Feb-96 & Ice Storm & 660,000 & 22,906 & 35 \\
Sep-96 & Hurricane Fran & 409,935 & 176,472 & 43 \\
\hline
\end{tabular}

*1990 taken as a proxy of typical year.

Source: Keener 1997. 